\title{
Educating the Developing Mind: Towards an Overarching Paradigm
}

\author{
Andreas Demetriou • George Spanoudis • \\ Antigoni Mouyi
}

Published online: 13 September 2011

(C) The Author(s) 2011. This article is published with open access at Springerlink.com

\begin{abstract}
This essay first summarizes an overarching theory of cognitive organization and development. This theory claims that the human mind involves (1) several specialized structural systems dealing with different domains of relations in the environment, (2) a central representational capacity system, (3) general inferential processes, and (4) consciousness. These systems interact dynamically during development so that changes in each are related to changes in others. The changes in all systems and the change mechanisms are described. This theory integrates research and theorizing from cognitive, developmental, and differential psychology. Based on this theory, a model for education is proposed that specifies, first, educational priorities for different phases of development according to the cognitive developmental milestones associated with each phase. The theory also specifies how education can educate students to (1) construct mental models for the sake of conceptual change, (2) use their central representational capacity efficiently, (3) advance analogical and deductive reasoning, (4) learn how to learn, and (5) become critical and creative thinkers. The theory is offered as an overarching paradigm for the architecture, the development, and the education of the human mind.
\end{abstract}

Keywords Assessment - Cognitive development - Conceptual change · Consciousness · Critical thinking $\cdot$ Education $\cdot$ Intelligence $\cdot$ Learning to learn $\cdot$ Mental models . Metarepresentation $\cdot$ Reasoning $\cdot$ Working memory

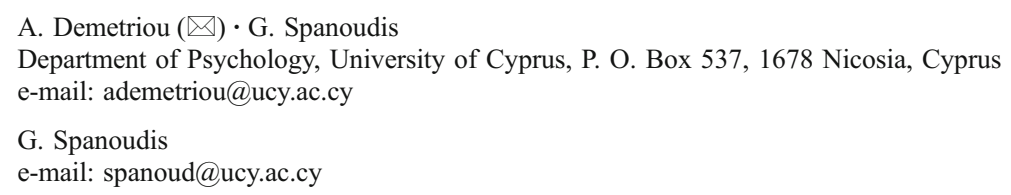

A. Mouyi

Center for Educational Research and Evaluation, Nicosia, Cyprus

e-mail: mougi@ucy.ac.cy 
In the second half of the twentieth century, developmental and cognitive sciences were solid enough to start systematically informing educational policy and practice (e.g., Anderson et al. 2001; Linn and Eylon 2011; Olson 2003; Stearns 2006). However, we still have a long way to go in the direction of integrating educational science with psychological science in the way modern engineering is integrated with the natural sciences. For this to be possible, a comprehensive theory of the developing mind is needed. This is the aim of the theory proposed here. This theory integrates findings and concepts from the psychology of intelligence, the psychology of cognitive development, and cognitive psychology. If properly integrated, these traditions can lead to a unified theory of learning, understanding, and development.

The integration attempted here initiates from our earlier empirical (Demetriou 2002; Demetriou et al. 1993, 2008; Demetriou and Kazi 2001, 2006) and theoretical work on cognitive development (Demetriou 1998, 2004, Demetriou et al. 2010a, b; Kargopoulos and Demetriou 1998; Demetriou and Raftopoulos 1999) and is expanded to include current research and theorizing in all three fields mentioned above. The integration of the theory with research and theory on educational implications and applications is new and is first presented here. This theory specifies the following:

1. The architecture of the mind. That is, the general cognitive structures and processes underlying understanding, problem solving, and learning across different domains and also the processes underlying the operation of specialized domains of thought. Thus, the theory goes beyond theories which emphasize the importance of different domains but underestimate the role of central processes and constrains, such as Gardner's theory (1983), and theories which stress the importance of central processes but minimize the role of domain-specific processes, such as Jensen's (1998) or Piaget's (1970) theory.

2. The development of the mind. That is, the condition of the various general and domainspecific structures and processes during development, their dynamic relations, and the mechanisms which are responsible for change and learning in different phases of development. The theory integrates research and theory on developmental changes in representational and information processing capacity (e.g., Case 1985; Halford 1993; Kail 1991; Pascal-Leone 1988) with research and theory on the development of thought and consciousness (Demetriou 2000; Demetriou et al. 1993, 2002; Demetriou and Kazi 2001, 2006) to provide an integrated model explicating the development of self-aware individuals that have a strong sense of unity, a personal style of functioning, and a differentiated profile of competence and modus operanti.

3. Guidelines as to how educators can use this understanding of mind and its development to organize instructional content across diverse subject matter and to create teaching methods that are appropriate for different individuals at different phases of learning. Obviously, social understanding and interaction are extremely important for education both as a frame where cognitive processes operate and as a major goal which aspires to educate citizens well adapted in their cultural and social environment. Moreover, emotion and motivation are also important dimensions of cognitive functioning and education. Although this essay focuses on cognitive processes, for the sake of completeness, we also briefly integrate into the theory considerations about motivational and emotional processes.

This essay is addressed to three groups of scholars: cognitive and developmental scientists who would be interested to see how the cognitive, the differential, and the developmental traditions are integrated into a unified theory of the developing mind and 
explore the implications of this theory for education; education policy makers and planners who need to tune important aspects of educational policy, such as setting major priorities for the successive phases of education and curriculum development, with current thought and knowledge in the cognitive and the learning sciences; and, finally, this essay is addressed to classroom teachers who would like to inform their teaching practices and decisions in relation to the actual possibilities and weaknesses of their students.

Thus, this essay includes two parts. The first part presents the psychological theory. Specifically, it outlines the architecture of the human mind, its development, and the dynamic relations between the various structures and processes in real and developmental time. The second part presents the implications of the theory for education.

\section{The Architecture and Development of the Mind}

Research and theory in psychometric (Carroll 1993; Demetriou 2002; Gustafsson and Undheim 1996; Hunt 2011; Jensen 1998), cognitive (Hunt 2002), and developmental psychology (Case 1992; Demetriou 1998; Demetriou et al. 1993, 2002, 2008, 2010a, b) converge on the assumption that the human mind is a universe of processes that are organized into systems which carry out different tasks during real-time problem solving. The systems are: (1) specialized structural systems (SSS). These constitute a set of mental processes that interface with several environmental domains. (2) The representational capacity system. This system is responsible for meeting representational and information processing needs activated by the environment-oriented SSS or the systems to be discussed below. (3) The inference system is responsible for connecting and integrating information and operations vis-à-vis the goal of the moment. (4) The consciousness system is responsible for monitoring, controlling, and regulating the processes activated at a given moment. Figure 1 highlights this architecture. Below, we first outline the architecture and development of each of the systems. Then we discuss the interrelations between the various systems in real and developmental time and present relevant evidence.

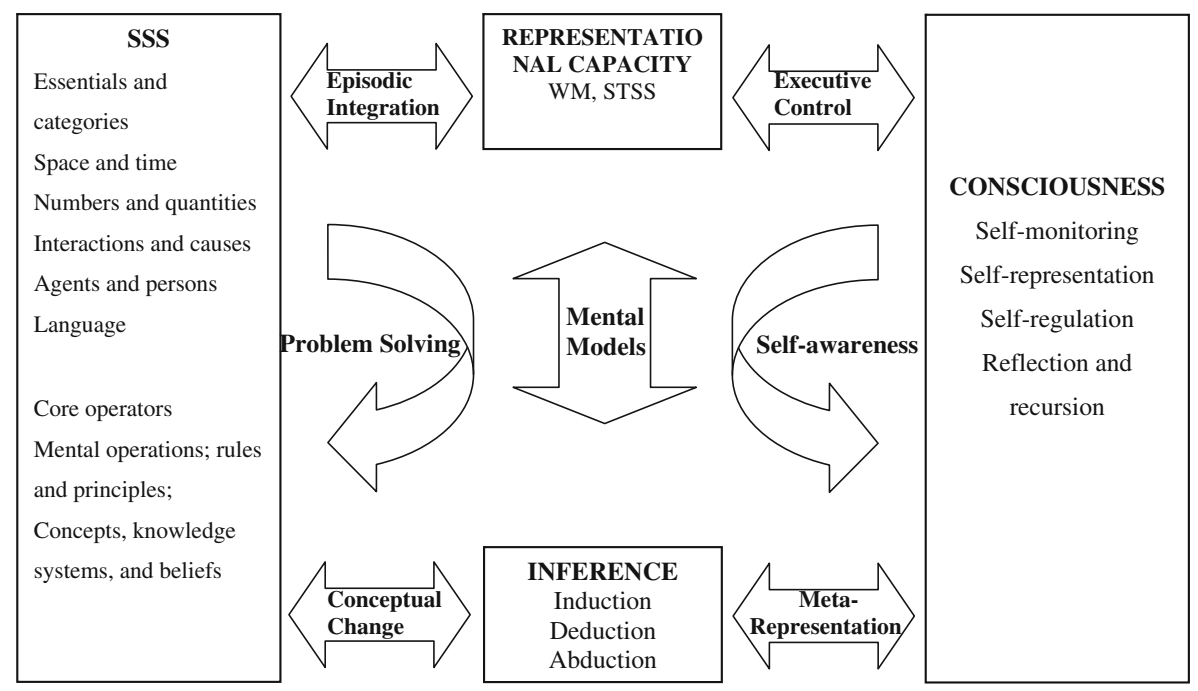

Fig. 1 General architecture of the human mind 
The architecture of the specialized structural systems

Each SSS includes processes that specialize in processing information coming from different domains of the environment. Five SSS were specified by research: (1) Categorical thought deals with similarity-difference relations. Forming hierarchies of interrelated concepts about class relationships is an example of the domain of this system. (2) Quantitative thought deals with quantitative variations and relations in the environment. Mathematical concepts and operations are examples of the domain of this system. (3) Causal thought deals with cause-effect relations. Representations about causal relations between objects and persons and operations related to causality, such as trial-and-error or isolation of variables, that enable one to decipher causal relations belong to this system. (4) Spatial thought deals with orientation in space and the imaginal-iconic representation of the environment. Mental maps of places or mental images of familiar persons and objects and operations on them, such as mental rotation, belong to this system. (5) Social thought deals with social relationships and interactions. The mechanisms for monitoring non-verbal communication or skills for dealing with social interactions belong to this system. These SSS were identified by a number of studies involving participants from preschool age to adulthood. Specifically, in factorial studies, all five SSS emerge as separate factors (Case et al. 2001; Demetriou and Bakracevic 2009; Demetriou and Efklides 1989; Demetriou et al. 1993, 2002; Demetriou and Kazi 2001, 2006; Shayer et al. 1988). Moreover, together with common inferential processes, each of the SSS involves SSS-specific logical process for problem solving (Kargopoulos and Demetriou 1998).

SSS involve (1) core processes, (2) mental operations, and (3) knowledge and beliefs. Table 1 summarizes the main features of the SSS. Core processes are pre-adapted and foundational inferential traps that impose their ready-made meaning on the aspect of the environment concerned. For example, categorical perception on the basis of shape, perception of the numerocity of small sets, depth perception in space, perception of causality, and human face preference in the social domain are examples of core process in each SSS. Core processes are fundamental because they ground each domain into its respective environmental realm and they form the background for the development of the other levels of the SSS, namely, mental operations and knowledge and beliefs (Carey 2009; Cosmides and Tooby 1994; Gelman and Brenneman 1994). Mental operations arise as a result of the dynamic interactions between domain-specific core processes and the informational structures of the environment. The systems of operations within each domain emerge by differentiation of the core processes when these do not satisfy the understanding and problem-solving needs of the moment. Examples of mental operations are sorting in the categorical SSS, numerical operations in the quantitative SSS, hypothesis testing in the causal SSS, mental rotation in the spatial SSS, or emotion regulation in the social SSS. Knowledge and beliefs accumulate over the years as a result of the interactions of each SSS with the respective domain, such as time reading, money values, and rules underlying everyday transactions in the quantitative system, mental images and mental maps in the spatial system, social attributions in the social domain, etc. (Carey 1985, 2009; Demetriou et al. 1992, 1993, 2002).

\section{The development of the SSS}

Table 2 summarizes the development of the SSS. With development, each of the domains moves along three dimensions: complexity, abstraction, and flexibility. As children grow older, they become able to deal with increasingly more representations simultaneously. This 
Table 1 Three levels of organization of each specialized system of thought and reasoning

\begin{tabular}{|c|c|c|c|}
\hline Domain & Core processes & Mental operations & Knowledge and beliefs \\
\hline Categorical & $\begin{array}{l}\text { Perception according to } \\
\text { perceptual similarity; } \\
\text { inductive inferences } \\
\text { based on similarity- } \\
\text { difference relations }\end{array}$ & $\begin{array}{l}\text { Specification of the semantic } \\
\text { and logical relations between } \\
\text { properties, classification; } \\
\text { transformation of properties } \\
\text { into mental objects; construction } \\
\text { of conceptual systems }\end{array}$ & $\begin{array}{l}\text { Conceptions and } \\
\text { misconceptions } \\
\text { about the world }\end{array}$ \\
\hline Quantitative & $\begin{array}{l}\text { Subitization; counting, } \\
\text { pointing, bringing in, } \\
\text { removing, sharing }\end{array}$ & $\begin{array}{l}\text { Monitoring, reconstruction, } \\
\text { execution and control of } \\
\text { quantitative transformations, } \\
\text { the four arithmetic operations }\end{array}$ & $\begin{array}{l}\text { Factual knowledge about } \\
\text { the quantitative aspects of } \\
\text { the world, algebraic and } \\
\text { statistical inference rules }\end{array}$ \\
\hline Spatial & $\begin{array}{l}\text { Perception of size, depth, } \\
\text { and orientation; } \\
\text { formation of } \\
\text { mental images }\end{array}$ & $\begin{array}{l}\text { Mental rotation, image } \\
\text { integration, image } \\
\text { reconstruction, location } \\
\text { and direction tracking } \\
\text { and reckoning }\end{array}$ & $\begin{array}{l}\text { Stored mental images, mental } \\
\text { maps, and scripts about } \\
\text { objects, locations, scenes, } \\
\text { or layouts maintained } \\
\text { in the mind }\end{array}$ \\
\hline Causal & $\begin{array}{l}\text { Perception of overt } \\
\text { and covert causal } \\
\text { relations }\end{array}$ & $\begin{array}{l}\text { Trial-and-error; combinatorial } \\
\text { operations; hypothesis } \\
\text { formation; } \\
\text { systematic experimentation } \\
\text { (isolation of variables); } \\
\text { model construction }\end{array}$ & $\begin{array}{l}\text { Knowledge, attributions and } \\
\text { understanding of the } \\
\text { reasons underlying physical } \\
\text { and social events and the } \\
\text { dynamic aspects of the world }\end{array}$ \\
\hline Social & $\begin{array}{l}\text { Recognition of } \\
\text { conspecifics, } \\
\text { recognition of } \\
\text { emotionally laden } \\
\text { facial expressions }\end{array}$ & $\begin{array}{l}\text { Deciphering the mental } \\
\text { and emotional states } \\
\text { and intentions of others; } \\
\text { organization of actions } \\
\text { accordingly; imitation; } \\
\text { decentering and taking } \\
\text { the other's perspective }\end{array}$ & $\begin{array}{l}\text { System of social attributions } \\
\text { about other persons, their } \\
\text { culture and their society }\end{array}$ \\
\hline Reasoning & $\begin{array}{l}\text { Use of the grammatical } \\
\text { and syntactical } \\
\text { structures of language }\end{array}$ & $\begin{array}{l}\text { Identifying truth in information; } \\
\text { abstraction of information } \\
\text { in goal-relevant ways; } \\
\text { differentiation of the } \\
\text { contextual from the formal } \\
\text { elements; elimination of } \\
\text { biases from inferential process; } \\
\text { securing validity of inference }\end{array}$ & $\begin{array}{l}\text { Knowledge about grammar, } \\
\text { syntax and logical } \\
\text { reasoning; metalogical } \\
\text { knowledge about nature } \\
\text { and justifiability of logical } \\
\text { inferences; metacognitive } \\
\text { awareness, knowledge, } \\
\text { and control of inferential } \\
\text { processes }\end{array}$ \\
\hline
\end{tabular}

permits them to consider alternative representations of a situation or alternative actions upon these representations or the situation itself. Increasing complexity necessitates the elaboration of relations between representations, which results into abstractions which are subsequently encoded and processed as representations, thereby leading to increasingly abstract systems of representations. Envisaging representations from the point of each other and focusing on their relations gradually frees thought from the specifics of particular representations, rendering it increasingly fluid and flexible (Table 3).

Thus, development of the SSS is a continuous process of emergence, differentiation, and integration of new representations. However, this is one aspect of development. Some changes at some periods alter how the world is viewed by the developing person. These changes may be taken as milestones that are important both from the point of view of the person's own subjective experience and for his or her relations with the world. 


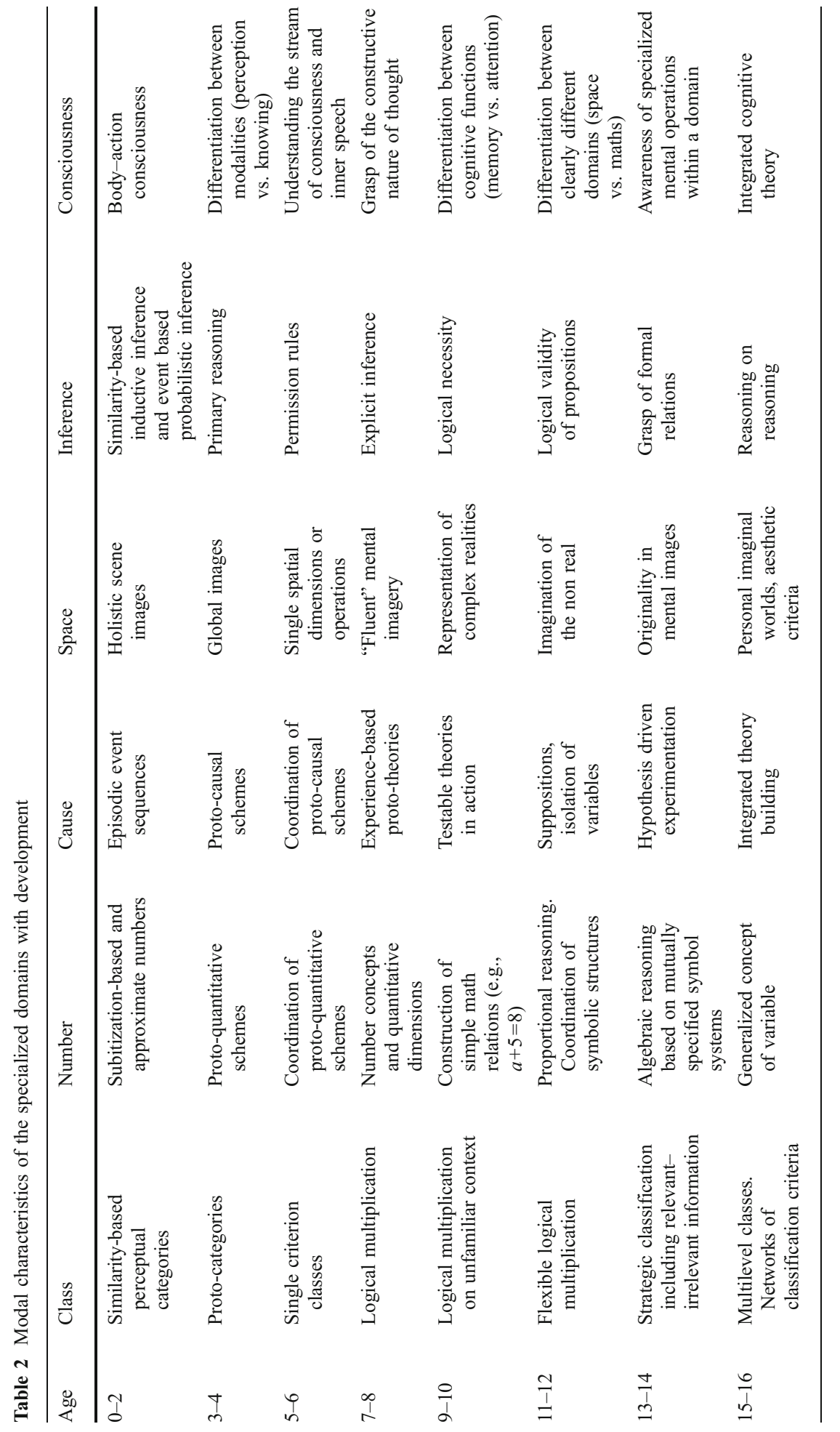




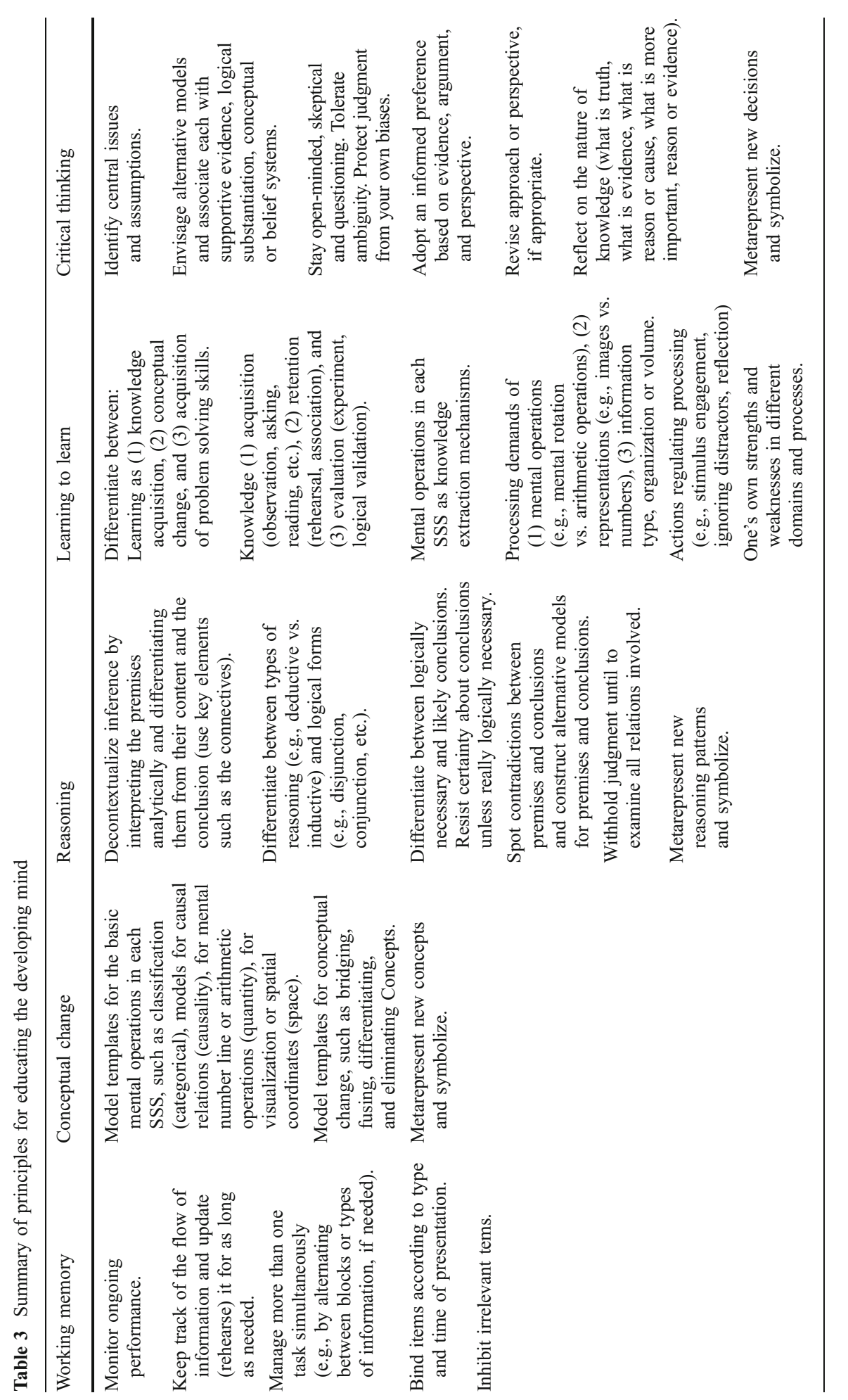




\section{Emergence of representations}

All systems are present at birth. There is strong evidence that the core processes of categorical (Butterworth 1998; Carey 2009), quantitative (Dehaene 1997; Piazza 2010; Sloutsky and Fisher 2011), causal (Haun et al. 2010; Keil 2011), spatial (Haun et al. 2010), and social (Molenbergs et al. 2009; Rizzolatti and Craighero 2004) thought are present in the first weeks of life. The engagement of core operators with their respective aspects of the environment generates representations that provide the behavioral or mental analogues of the basic laws of physics, biology, and psychology. These enable the infant to interact with increasing efficiency with physical objects, animals, and other humans. Therefore, the development in the first 2 years of life suggests, contrary to Piaget, that this period of life, far from being simply sensorimotor, is richly conceptual (Carey 2009; Gelman 2003; Mandler 2004). According to Carey (2009), the major domains of infant cognitive development are objects (the physical world), agency (the psychological world), and number. These are envelop categories which include concepts and categories about the identity, the spatial, and the causal relations of objects; the active self which acts as a causal agent for objects and other persons generating self-knowledge and knowledge about others (agency); and the quantitative relations between objects and beings.

However, thought at this period is constrained by limited concentration and floating attention that is easily attracted by sensory variation in the environment. These limitations, together with the lack of language, hinder drastically the integration of experience. As a result, the infant's conceptual world is incoherent and content- and context-bound. It needs to be stressed, however, that what appears as a limitation from one point of view is an advantage from another. Specifically, floating attention and ensuing superficial processing of information about the world enables the infant to generate a rich pool of experience and knowledge about the world at a period of universal inexperience and ignorance that will be pruned, elaborated, differentiated, and integrated in the following phases.

\section{Differentiation of representations}

The gradual emergence of language during the second year of life brings representations as such into focus so that they can be reflected upon and elaborated. The explosion of the "why" questions at this phase (Brown 1968; McCune 2008) is indicative of a reorientation of the infants' knowing priorities from the world itself to their own representations about the world. In a sense, the infants appear to realize, though not explicitly, that it is time to work on the representations already constructed.

Two-year-olds represent, but they cannot metarepresent. DeLoache and Burns (1994) showed a dramatic developmental change between 24 and 30 months of age in this regard. Specifically, 24-month-olds could not use a picture to retrieve an object whereas 30-month-olds could. Therefore, in the middle of the third year of life, children start to be able to view pictures as representations of current reality. In line with these findings, Dalke (1998) showed that 3-year-olds have some ability to make and use maps as a guide for their actions (e.g., where to look for an object). Huttenlocher et al. (2008) showed that this ability develops gradually from less (e.g., placing an object in actual place following a map at the age of 3 years) to more complex tasks (e.g., retrieving an object following a map at the age of 4 years).

Thus, at about the age of 3-4 years, children start to differentiate representations from each other and from the objects they represent. For example, they can see a toy car as a representation of real cars and as an object in itself. DeLoache $(1995,2000)$ called this 
emerging differentiation of representations dual representation. Dual representations enable children to reflect on and operate explicitly on representations as tokens of reality. Thus, they represent a major milestone in development because they open the way for the intentional use of symbols and symbol systems, such as writing.

As a result, preschoolers start to build concepts in the various environment-oriented domains. There must be at least two representations to conceive of a class (e.g., "fruit"), a quantity (e.g., more or less), a cause-effect relation, or a spatial relation (e.g., "above"; Case 1985; Demetriou 1998; Fischer 1980). Moreover, they start to understand the multifaceted nature of the world, as indicated by their understanding of the appearance-reality distinction, because they can represent an object in its present and in an earlier condition (Flavell et al. 1995), and their acquisition of a theory of mind, because they can understand that the same thing can be represented differently by two persons (Wellman 1990).

\section{Integration of representations}

Another important milestone comes at about the age of 7-8 years. With practice and increasing awareness about representations (Demetriou and Kazi 2006; Flavell et al. 1995), children begin to realize that representations constrain each other. For example, words in a sentence constrain how other words will be used and sentences constrain the meaning of the sentences to follow (Brown 1968; McCune 2008). This is the beginning of the grasp of logical necessity (Miller et al. 2000; Moshman 1990, 1994). With logical necessity as a reference criterion for the validity of the relations between representations, children can start to systematically build alternative mental models for concepts and relations (Ricco 2010) and to represent the underlying relations between concepts or mental operations. For example, in the domain of categorical thought, systematic classification starts to be possible because a criterion may be preselected and applied in order to specify the identity of objects and their similarity relations (e.g., color, shape, etc.). This criterion may be used to classify things on the basis of having or not having the attributes specified by the criterion. Thus, the logical relation of class inclusion can be grasped, indicating that semantic networks are bound by obligatory relations.

\section{Conditional representations}

A third milestone comes at the beginning of adolescence, when adolescents become able to construct conditional representations. Conditional representations enable the thinker to view systems of representations from the point of view of each other. Technically speaking, they can integrate at least two dimensions with at least two levels each (e.g., they grasp proportionality and they formulate alternative hypotheses which they can test with especially designed experiments).

The meaning of each component representation in conditional representations emerges from the relations of this representation with all other representations in the system. Consistency and coherence in these representations gears on the relations between the relations involved rather than in the relations between representations and the objects represented (e.g., in the proportional relation 2/4:3/x, $x$ is derived from the relations rather than from the numbers themselves). Logical necessity is fully established at this phase and acquires its full use as a gauge of the fit of each representation or variation in the system. In the previous phase, logical necessity is a tool for evaluating consistency within concepts. Now it is a tool for guiding the exploration of the relations across concepts. Therefore, empirically invalid or counterintuitive representations are acceptable if they can be derived 
from the logical relations involved. As a result, each representation in a system of conditional representations is a point of variation, given the relations involved. Thus, new representations can be introduced and the implications examined from the point of view of all other representations, given the relations that bind them. This results in the transformation of thought from being descriptive and organizational to suppositional and foresighted (Demetriou et al. 1993; Demetriou and Kyriakides 2006).

\section{Differentiation of thought from knowledge}

The next milestone comes at about the end of secondary school or in the early 20 s. Young adults differentiate (1) between thought processes vis-à-vis their use for different aspects of knowledge acquisition and problem solving and (2) between thought, as a system of processing, and knowledge, as information about the world. That is, they understand that different knowledge or belief systems governing the operation of social and cultural groups are constrained by rules related to the values of these groups rather than from cognitive or inferential processes as such. It is understood that conclusions or interpretations may vary across systems even when the same inferential or thought processes are used. Therefore, knowledge or belief systems may be compared, integrated, or used separately according to goals or needs (Demetriou and Bakracevic 2009; Demetriou and Kazi 2001, 2006; Reynolds et al. 2005; Schaie 1996).

These changes interweave with the social life of the adult which requires the flexibility that is necessary to consider and negotiate the multiple perspectives that are usually associated with different individuals, groups, or institutions adults normally interact with. Thus, on the one hand, relativistic and dialectical thinking (Basseches 1984; King and Kitchener 1994; Riegel 1973) emerges from the flexibility that is associated with the multiplicity of perspectives that the social environment forces onto the adult. On the other hand, the handling of this very reality is conducive to the elaboration of a principled approach to problems and situations that would give coherence to meaning making, life choices, and orientations. That is, despite the recognition of the relativity of perspectives or belief systems, and the respect that may be accorded to each, persons have to choose one of them and structure and justify their actions or choices accordingly. Eventually, judgment and decision making may be elevated to wisdom. Wisdom generates integrative and balanced judgments and decisions that are rational rather than logical, oriented to the future rather than the present, and to the best interests of many rather than one or few persons (Baltes and Staudinger 2000; Demetriou and Bakracevic 2009; Stanovich 2009).

The architecture of the representational capacity system

Mental functioning at any moment occurs under the constraints of the available representational capacity. Representational capacity is the maximum amount of information chunks or units (e.g., mental images, words, and numbers) and mental operations (e.g., mental rotation, grammatical rules, and arithmetic operations) that the mind can efficiently activate simultaneously. Representational capacity is the work space of the mind. That is, it is the mental field where information is operated upon, analyzed, connected, combined, and transformed for the sake of interpretation, inference drawing, reaching conclusions, formation of action plans, and problem solving (Baddeley 1990; Cowan 2010; Engel de Abreu et al. 2010). In psychometric studies, representational capacity always emerges as a separate block of factors (Demetriou et al. 1993, 2002, 2005, 2008; Engel de Abreu et al. 2010; Hornung et al. 2011; Unsworth and Spillers 2010). The content of this field is 
transparent to awareness and thus amenable to interaction with the processes of control and consciousness, to be described below.

There is general agreement that representational capacity involves (1) modality-specific components that hold information for a very short period of time, (2) a short-term storage that holds a part of information that is available in modality-specific components for further processing according to a goal, and (3) an executive component that involves processes applied on the information represented in short-term storage for the sake of the goal (Baddeley 1990; Hornung et al. 2011; Tillman et al. 2008). Wood (2011) showed that there are storage systems for spatiotemporal information related to the movement of objects in space, for object identity information related to the retention of the characteristics of objects, and for snapshot information related to the location of objects. It is highly interesting that these storage systems relate closely to the core processes in the SSS. The first system is related to spatiotemporal processes for tracking objects in the spatial SSS, and it may also be related to the core processes for representing causal relations. The second is clearly related to the construction of concepts in the categorical SSS. The third system is an important component of the spatial SSS, and it may be related to subitization processes in the quantitative system.

Therefore, the architecture of specialized storage capacity reflects the strong domainspecific origin of mental processing. The integrative role of this space that can put together information coming either from the same or from different specialized domains is reflected in Baddeley's (2000) episodic buffer; it emanates from the interaction between representational capacity and both inferential and control processes, to be discussed below.

The development of representational capacity

The developmental profile of working memory varies in different research paradigms depending upon the combination of components measured. However, there is general agreement on the following:

First, iconic memory capacity approaches adult levels very early in life. Specifically, Blaser and Kaldy (2010) showed that iconic memory has a capacity of five objects by the age of 6 months, which is very close to the six-object capacity of adults. Moreover, Zosh et al. (2011) showed that 9-month-old infants, like adults, can represent in working memory up to three ensembles of information, each of which contains summary information for many more than three objects at a time. The processing of information within the ensembles is possible after the age of 2-3 years according to the development patterns summarized below. This finding is important in suggesting that infants do posses the visual memory space that is required for the operation of the core processes discussed above. Thus, representations seem to emerge from the contents of sensory memory and held as undifferentiated blocks. Their differentiation begins during the third year of life, and it opens the way for the elaboration of their relations as discussed above.

Second, until the end of the second year of life, children can focus on and represent in short-term storage only one unit of the information held in iconic storage. This implies that some control of attention becomes possible around the age of 2 years that enables infants to focus processing on a small part of the content of their sensory storage. From the age of 2 years onwards, when executive operations are held to a minimum, short-term storage capacity is two, three, and four units at the age of 3-4, 5-6, and 10-11 years, respectively (Case 1985; Cowan 2010; Halford 1993; Demetriou et al. 1993, 2002). Pascual-Leone (1970) maintained that it continues to increase until it reaches the limit of seven units at the age of $15-17$ years. 
Third, at any age, the exact capacity of working memory varies considerably depending upon the volume of executive processes needed. Overall, Barouillet et al. (2011) showed that the short-term memory span for a given type of information is a function of the total storage possible for this type of information and the cognitive load induced by processing, which is itself related to the time devoted to them: With increasing load, the storage decreases. However, executive processes do not only have a cost for storage capacity. They are also beneficial to it. Camos and Barrouillet (2011) showed that 7-year-old children were able to shift attention from processing in one set of information to rehearse the information in another set that they would have to recall later and come back again. Six-year-olds did not demonstrate this flexibility. This is due to the fact that between the ages 7 and 9 years, children acquire the cognitive flexibility needed to switch attention between different cognitive processes, such as rehearsal needed for the maintenance of information in shortterm storage and the processing of information. Davidson et al. (2006) showed that flexibility in switching between goals during processing develops throughout adolescence and that adults are more adept than adolescents to regulate their rate of processing to ensure accuracy. Therefore, with development, accurate self-monitoring and flexible executive control processes compensate for the mental space required to represent them.

Fourth, the type of information and related experience are also important. For example, in the spatial domain, the capacity varies from three units at the age of 6 years to five units at the age of 12 years. In the domain of mathematical thought, it varies from about two to about four units in the same age period. Demetriou et al. (2005) showed that extensive training in a particular modality, such as the massive training that is required to learn the Chinese logographic system of reading and writing, may have a highly beneficial effect on visuospatial working memory that does not generalize to phonological storage or to the representation of executive operations. This study showed that the capacity of visuospatial short-term storage of Chinese children exceeded the corresponding capacity of Greek children by about three units of information throughout the period from 8 to 14 years of age, whereas their working memory for words and numbers was the same.

In conclusion, these variations reflect the fact that different types of information, related to the various SSS, put different demands on the available mental resources. The executive operations required for control and processing compete with SSS-specific information for available resources. Training and familiarity facilitate short-term storage because they diminish the demands of executive processes due to the utilization of the accumulated experience to novel situations and to the automatization of procedures through practice. These findings are consistent with the findings of Ericsson and Kintsch (1995) which suggest that the effective use of working memory depends upon the coding schemes available in long-term memory. For instance, the inclusive concept "energy," once in working memory, alerts a large number of component concepts in long-term memory if the person has these schemas. Working memory is largely a holding system for pointers to schemas in long-term memory. Therefore, developmental differences between adult experts and younger persons may be explained, partly, by the fact that adults posses more efficient and informationally richer schemas than younger persons do. Moreover, the differences in developmental rates across domains may, in part, be explained by the relative differences in the experience in different domains. Education is of course crucial in this regard.

The architecture of the inference system

Inference involves processes enabling the transfer of meaning from one representation to another. Transfer normally occurs on the basis of properties which are present in both the 
initial (or source) representation and the target representation. In inference, these common properties are used as an intermediary between the two representations such that properties characterizing the initial representation (apart from their common properties) are also ascribed to the target representation.

There are several types of reasoning. Inductive, analogical, (Holland et al. (1986), and deductive reasoning (Moshman 1994; Ricco 2010; Rips 1994) are the three types that have been studied extensively in both logic and psychology. Several studies have shown that these types of reasoning are based on different inferential mechanisms (Heit and Rotello 2010), and they emerge as separate constructs in structural models of reasoning. Moreover, they are related to each other by common inferential processes which emerge as a separate level in hierarchical models of cognition that involves several of the SSS summarized above (Demetriou and Efklides 1994; Demetriou et al. 2008, 2010a, b; Mouyi 2008).

The development of inference

\section{Induction and analogy}

Students of infancy converge on the assumption that the core systems allow generalizations that enable infants to interpret new encounters on the basis of their similarity with available concepts (Carey 2009; Gelman 2003; Mandler 2004). Thus, inductive inference is part of the very organization and functioning of the mental architecture of the mind probably from birth.

Initially, inference is based on perceptual similarity, which is the most readily apparent form of similarity. In fact, the very methods used to study infants' cognitive abilities, such as the habituation method (decline of interest in a sequence of stimuli, such as a particular shape or image of an object, when they are similar to each other; see Butterworth 1998), assume that infants are sensitive to "same" and "different" relations (Tyrrel et al. 1991). This ability enables infants to construct categories by extracting general characteristics from overlapping perceptual features that appear across objects and by selectively attending to relevant features while ignoring irrelevant ones based on available core concepts that direct feature search and interpretation (Sloutsky and Fisher 2011).

In a similar vein, analogical reasoning transfers meaning on the basis of relations between objects or concepts rather than individual objects or representations. Wagner et al. (1981) showed that infants as young as 9 months of age preferred to look at an arrow pointing up when hearing an assenting tone and at an arrow pointing down when hearing a descending tone. In line with this evidence, recent studies of intuitive statistics showed that 8-month-olds make first-order generalizations about the composition of a population on the basis of exemplars of this population (Xu and Garcia 2008). Impressive as it may sound, 9-month-old infants seem able for second-order generalizations or metageneralizations. Dewar and $\mathrm{Xu}$ (2010) showed that 9-month-olds were able to abstract a first-order relation and thus capture the pattern underlying the characteristics of objects in different boxes (i.e., all round or all square or all triangular) and generalize to a second-order relation that generates expectations about new objects (i.e., all objects in a box are similar in shape, so if there is a starlike object in a new box all objects in this box must be starlike). Gelman and Coley (1990) showed that 30-month-old children use perceptual similarity as a basis for drawing inductive inferences. Interestingly, Williamson et al. (2010) have recently shown that 3-year-olds can abstract and imitate rules underlying behavior, in addition to imitating the behaviors they observe as such.

Mouyi (2008) (Demetriou et al. 2010a, b) showed, in a very detailed study of reasoning, that inductive reasoning develops in three main levels from the age of 6 to the age of 12 years. At the first level, children can identify patterns and formulate generalizations on the basis of a 
single dimension or relation. However, at this level, the child's experiences and knowledge may bias inference to conclusions inconsistent with the generalizations suggested by patterns. Therefore, control processes are not yet powerful enough to protect inference from privileged knowledge and experiences. At the second level, inductive reasoning can handle hidden or implied relations that require from the thinker to combine information present to the senses with knowledge stored in long-term memory. Mapping out the implied relation requires that non-relevant information in the premises or in long-term memory are inhibited. Moreover, inductive inferences based on the syntactical components of verbal premises can be drawn. Negative premises may be manipulated at this level. Thus, it is suggested that control processes at this level are powerful enough to direct the inferential process on target and protect representational capacity from overloading with irrelevant information. Finally, at the third level, inductive reasoning is based on theoretical supposition. That is, possibilities can be specified in advance and information in the premises is analyzed in reference to them. As a result, multiple parameters and relations can be simultaneously considered and manipulated. Generalizations can therefore be extracted from the relations and elevated to mental models.

Later on, analogical reasoning can structure third- or higher-order relationships involving abstract relations such as "parents are to family what teachers are to education," which require a rich culturally relevant knowledge (Demetriou and Kyriakides 2006).

\section{From probabilistic to deductive reasoning}

There are signs of pure reasoning that is based on probabilistic inference very early in life. Téglás et al. (2011) showed that infants can make correct predictions about the future state of an event (e.g., which of several objects will exit an opening) based on several parameters (such as each objects' frequency in the set, distance from the opening, and time available). According to Téglás et al. (2011), 1-year-old infants have "the ability to generate physically plausible candidates for future world states, consistent with the observed present" (p. 1058).

However impressive this finding is, there is nowadays general agreement that deductive reasoning as such does not appear before representations are differentiated from each other and expressed into natural language. Moreover, in all models of reasoning, the development of deductive reasoning is associated with awareness of cognitive processes and cognitive control. These enable the thinker to search systematically for and envisage the relations suggested by the premises of an argument and their relations; resist belief biases, if the content of the premises and their relations do not converge to the same conclusion; and gear on the reasoning process so that the logical conclusion overrides the conclusion suggested by knowledge and belief biases.

This interpretation is consistent with the dual-process theory of reasoning and reasoning development. "Dual-process accounts postulate the operation of a central domain general system (often termed "System 2"), characterized as "analytic" and relatively content free in nature, and a peripheral domain-specific system (often termed "System 1"), which is more "heuristic, modular and highly context dependent" (Ricco and Overton 2011), and hence drawing upon the SSS-specific core processes. In terms of the theory proposed here, system 2 reasoning emerges from the operation of system 1 reasoning through awareness of similarities and differences between heuristic processes and the construction of representations that unify and represent these heuristic processes. That is, the key components of reasoning are gradually decoupled from their context, fused with each other, and metarepresented as logically necessary reasoning schemes which are gradually interconnected with each other as reasoning rules. This is the system 2 algorithmic reasoning (Ricco 2010; Overton 2010). In line with this model, Heit and Rotello (2010) showed that inductive reasoning is based on a more automatic mechanism that uses 
similarity as a basis for inferring a relation and deductive reasoning is based on analytical processes that draw on validity. Moreover, they showed that even deductive reasoning may shift to similarity for inference drawing, if forced to operate under time constraints that do not allow the activation of the analytical processes required for the evaluation of validity.

Moshman's (1990, 1994) and Mouyi's (2008) levels of deductive reasoning development explicate the gradual emergence of system 2 reasoning from system 1 reasoning. During the preschool years, children reason logically using inferences, but they do not think about inference. Children correctly use most of the connectives and conditionals involved in inference schemas, but they have no understanding of the inferential process and are not aware that the premises constrain the conclusion (e.g., "there is a cat; there is an apple; so, there is a cat and an apple).

This awareness appears for the first time by about the age of 5 or 6 years, when inference becomes explicit but logic is implicit. Children at this stage are explicitly aware of the inferential process that connects premises and conclusions into coherent arguments and are sensitive to logical necessity. Thus, they can grasp modus ponens arguments (e.g., "if there is a either a cow or a goat then there is a pear; there is a cow; therefore there is a pear"). However, logic as such is still implicit in their reasoning and does not function as a frame to explicitly guide reasoning. Thus, they fail on problems in which the logical form of the argument must be explicitly differentiated from its content (e.g., birds fly; elephants are birds; therefore, elephants fly). At the end of this phase, at the age of about 9-10 years, children can deal with modus tollens inferences (e.g., "if there is a cow there is an apple; there is no cow; therefore, there is no apple"). In comparison to modus ponens, modus tollens requires a model construction process which takes the modus ponens argument as a basis and then constructs alternative models which are compared with each other. Overall, reasoning at this level involves more steps and more operations (Johnson-Laird 2001).

At 11-12 years of age, logic becomes explicit, but metalogic is still implicit. Preadolescents understand that "an argument is valid if, regardless of the empirical truth of its premises and conclusions, has a logical form such that, if the premises were true, the conclusion would have to be true as well" (Moshman 1990, p. 212). Thus, at this phase, they can deal with simple denying the antecedent and affirming the consequent fallacies (e.g., "if there is a cow there is a pear; there is a pear; we cannot be sure if there is a cow"). Fallacies place high demands on the system. Many alternatives must be retrieved from memory and processed (Barrouillet et al. 2000). Moreover, the very nature of the outcome of processing is peculiar because the conclusion is that no conclusion can be reached. Therefore, the thinker at this level must accept that not all arguments are determinate and thus uncertainty may be part of the reasoning process itself. Finally, at the stage of explicit metalogic, adolescents can function as theorists of reasoning. As a result, they can specify all implications of an argument, determinate or indeterminate, based on all possible logical forms involved.

The architecture of the consciousness system

Humans usually operate under conditions of uncertainty caused by novel, conflicting, or incongruent information relative to a specific goal. Thus, to meet their goals, humans must be able to focus attention and process goal-relevant information efficiently, filtering out goal-irrelevant information, and assemble action. The core mechanisms of consciousness involve monitoring processes ensuring (1) awareness of the current goal, (2) an evaluative function which regularly compares the present state with the goal, and (3) a control function which registers discrepancies between the present state and the goal and suggests corrective actions (Demetriou 2000). The core mechanisms of self-regulation and executive control 
involve a process of (1) selection by inhibition (Leslie et al. 2004) and (2) a regulatory process that enables the individual to adjust mental or overt action to goals (Gibson and Pick 2003; Zelazo et al. 2003, 2005). It needs to be noted, however, that not all cognitive functioning ever reaches consciousness. In fact, consciousness is needed when no ready-made or automated schemes of action are available.

Thus, the input to consciousness is information arising from the functioning of all other systems. It operates as one of the main mechanisms for the integration of otherwise separate and independent mental constructs or brain networks (Baars 2002) and, eventually, for cognitive and behavioral control and flexibility (Cleeremans 2008). In its integrative role, consciousness is the seat of subjectivity and self because it unites one's own known past, present, and intended future in a single line of experience. Thus, at one and the same time, it is a causal factor for one's own action and a source of attributions and explanations for the action of other persons (Printz 2003).

Metarepresentation is the generative aspect of consciousness. That is, metarepresentation is an ideoplastic process that looks for, encodes, and typifies similarities between mental experiences (past or present) and between representations to enhance understanding and problem-solving efficiency. As a result of this process, new mental operations, new higherorder rules integrating different operations, and new representations to stand for these new operations and rules are created. We will explicate this process below in reference to the development of reasoning.

Also, metarepresentation gradually builds maps of mental functions which are continuously updated. These maps are generally accurate representations of the actual organization of cognitive processes in the domains mentioned above. Research suggests that the SSS, the components of working memory, and inference emerge from selfevaluations of performance on tasks as they emerge when we analyze actual performance on the same tasks. This finding indicates that working on the tasks generates experiences that reflect performance on them and that these experiences are recorded and recovered as such (Demetriou and Efklides 1989; Demetriou et al. 1993; Demetriou and Kazi 2001, 2006). Thus, when needed, these maps may be called upon to guide problem solving and understanding (Demetriou and Bakracevic 2009). Admittedly, there are large individual differences in the accuracy of these maps (Demetriou and Kazi 2001). Metarepresentation reminds one of Piaget's (2001) reflective abstraction and Karmiloff-Smith's (1992) representational redescription. Like reflective abstraction, it abstracts general patterns from different mental functions or activities. Like representational redescription, it reorganizes them at a higher, more efficient representational level.

It is important to note that consciousness is also the link between mind and personality (Demetriou et al. 2003). On the one hand, it integrates self-representations and selfevaluations of cognitive processes with personality dispositions underlying attitudes to learning and problem solving, such as being organized and systematic or adventurous and open to experience. On the other hand, it brings personality and emotional influences into cognitive functioning through the moderating effects that the emotional outcomes of cognitive processing, such as failure-based avoidance, may have. This integrative role is expressed through a personal constant that moderates mental, emotional, and personality experiences and dispositions. "That is, the individual adopts a particular attitude to his or her performance and ability which is consistently applied across different domains. This constant is used to adjust any signals regarding his or her functioning to a level which is personally characteristic" (Demetriou and Kazi 2001, p. 117). This mechanism explains why individuals are consistently accurate, lenient, or strict in their self-evaluations. Interestingly, this mechanism is recognizable by others, such as parents and teachers, and it 
moderates even interpersonal interactions. We will see below that this mechanism must be of concern to education because it influences the students' choices and attitudes to learning.

The development of consciousness

All aspects of consciousness develop systematically from birth to maturity (Demetriou and Kazi 2001, 2006; Demetriou and Bakracevic 2009; Zelazo 2004), improving the quality of subjective experience, the resolution and refinement of mental processing, and executive control (Baars and Franklin 2003). In the first year of life, there is body-action consciousness that involves implicit awareness of one's own actions and bodily sensations (Kopp 2011). This is minimal consciousness that is intertwined with the emergence of representations from the core operators of infancy. In the second year of life, body-action consciousness is embedded into self-consciousness that involves self-recognition in the mirror and self-reference through language or pointing. This enables infants to consider their capabilities vis-à-vis a situation and to execute means-end actions. Using the dimensional change card sort task, Zelazo et al. (2003) showed that 2-year-old children can operate with only a single rule (e.g., "If it is red, it goes here"). In the third year of life, infants become capable of reflective consciousness. As a result, by the age of 3 , children can operate with a contrastive relation (e.g., "If it is red, it goes here; if it is blue, it goes here"), which indicates reflective planning of action. At the age of 5 years, children can shift from one rule to another rule. According to Zelazo and Frye (1998), to be able to shift from the one rule to the other, the child must be able to integrate the rules into a higherorder rule that specifies when each of the two lower-order rules is to be used and be aware of them. For instance, in the example of dimensional change card sort described above, this rule might be as follows: "If we were playing color, then if it is red it goes here and if it is blue it goes here, but if we were playing shape, then if it is a red car it goes here and if it is a blue flower it goes here").

The development of awareness of cognitive processes is more complicated and lags behind awareness of action and executive control. Preschoolers understand that thinking is an internal mental activity referring to objects or events (Flavell et al. 1995, 1997). Moreover, they are aware of their own actions and can intentionally modify them as they evolve (Demetriou 2000). One of our studies (Demetriou and Kazi 2006, study 1) examined whether 3- to 7-year-old children are aware of the cognitive processes involved in tasks addressed to three domains of reasoning - that is, spatial, quantitative, and categorical reasoning. Specifically, children were asked to judge whether pairs of persons doing various tasks with various objects (e.g., both classifying or both counting or the one classifying and the other counting) were thinking of the same thing. We found that at the age of 3-5 years, the majority of children based their judgements on the perceptual similarity of the objects involved rather than on what the persons were required to do with them. At the age of 6 years, children were able to recognize that pairs of tasks belonging to a different domain require different mental processes. However, it was only at the age of 7 years that the majority of children were able to recognize the mental operation of pairs of tasks where the same operation, such as classification or counting, was applied on different objects.

In another study, 11- to 17-year-old adolescents were examined by tasks addressed to four domains: quantitative reasoning, causal reasoning, social reasoning, and drawing. In addition to solving the various tasks addressed to each of these domains, participants were asked to evaluate their performance on the tasks and to answer a general self-representation inventory probing their general self-concept related to each of the domains (e.g., "I can easily derive the mathematical rules behind many specific examples", "To find out which of 
my guesses is correct, I proceed to methodically consider each time only the things my guess proposes", "I understand easily the intentions of others before they express them"). It was found that the relation of self-evaluation with reasoning was very weak at the age of 11 years and then steadily and systematically increased until it became very strong (0.97) at the age of 15-16 years. Interestingly, the relation of self-representation and reasoning did follow the same trend, but with a considerable age lag. It was very low until the age of 13, it rose to moderate at the age of $14(0.34)$, and to high $(0.55)$ at the age of $15-16$ years. In a similar fashion, the relation of self-representation and self-evaluation was very low until the age of 13 years, rose to moderate at the age of $14(-0.30)$, and to very high at the age of $15-$ 16 years $(-0.80)$. The negative relation here implies that with increasing accuracy in selfevaluations, adolescents become more conservative and strict in their self-representation (Demetriou and Kazi 2001, 2006, study 2).

The findings above suggest that self-awareness and self-evaluation of cognitive processes develop in a recycling fashion, which involves four major cycles: $0-2,3-7,8-12$, and 13-18 years of age. Within each phase of development, self-evaluation and self-awareness concerning the representations and relevant mental operations are very low and inaccurate at the beginning, and they tend to increase and to become more accurate with development until the end of the phase. Entering the next phase resets both of them to an initial low level, from where they gradually take off again with the development of the new phase-specific problem-solving operations and skills. This pattern of change indicates that increasing self-awareness of cognitive processes becomes part of the very functioning of the processes concerned. We will try to show below that this intertwining of cognitive functioning with awareness about the cognitive processes enables the explicit representation of cognitive processes and their restructuring into new, more inclusive, and flexible representations. This is metarepresentation. There is accruing evidence that self-awareness and executive control are part of the learning process and that the efficiency of learning changes in development because of changes in these processes (Kuhn and Pease 2006).

\section{Structural, Functional, and Developmental Relations Between Systems and Processes}

In this section, we will review research that substantiates the architecture of mind proposed by this theory and reveals the dynamic relations between the various structures and processes during development. The emphasis of presentation is to highlight the relative importance of domain-general and domain-specific processes in intellectual development.

\section{Relations among structures and functions}

Figure 2 shows an idealized model that translates the architecture of mind proposed here into the conventions of structural equations modeling of cognitive abilities. It can be seen that this model includes four blocks of factors that correspond to the four major systems of processes involved in the proposed architecture of mind. The relations between systems are also represented. Specifically, the model involves factors that stand for (1) different mental operations within each of the five SSS, one factor for each SSS, and a higher-order factor that stands for general problem-solving ability; (2) different components of working memory and executive control and a higher-order factor that stands for representational capacity; (3) self-evaluations and self-representations of different mental operations within each of the five SSS, one factor for general self-concept in concern to each SSS, one factor for metarepresentation, and a higher-order factor that stands for general self-awareness and 


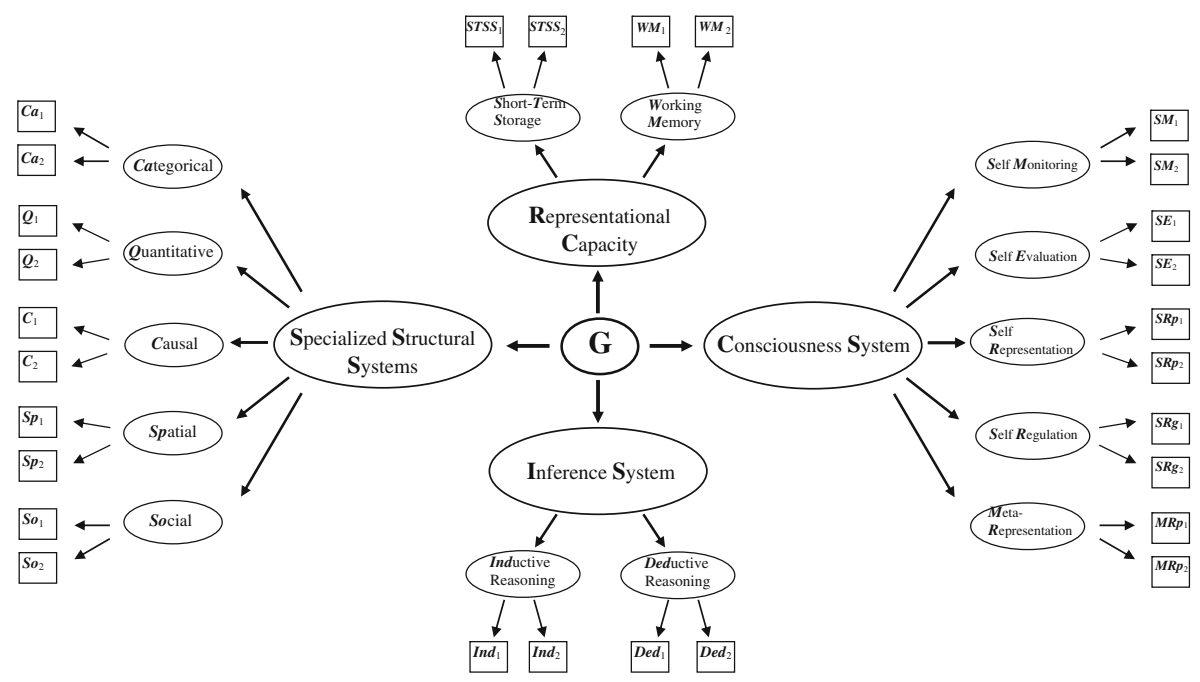

Fig. 2 Idealized structural model for the architecture of mind proposed by the theory

self-representation; and (4) factors that stand for different processes within inductive and deductive reasoning and a general factor that stands for general inferential processes. No study has examined this model in its entirety. However, several studies substantiated models which are close approximations to this model (Demetriou and Efklides 1989; Demetriou et al. 1993, 2008; Demetriou and Kazi 2001, 2006).

This is an all-encompassing model that incorporates several local architectures suggested by psychometric research. A broad and generally accepted architecture in psychometric psychology stipulates that cognitive abilities are hierarchically organized, including narrow domain-specific abilities at a first level of organization; several broad abilities at a second level, which frame and coordinate the functioning of the narrow abilities; and, finally, general intelligence (called psychometric $g$ in psychometric literature), underlying everything, at a third level (Carroll 1993; Deary 2000; Gustafsson and Undheim 1996; Hunt 2011; Jensen 1998; Johnson et al. 2008).

There is wide variation between studies concerning the number and identity of the narrow abilities, depending upon the particular focus of different studies. In terms of the present architecture, core processes and mental operations within each of the various domains reside at this level of narrow abilities. However, there is wide agreement as to the number and identity of systems at the second level. All studies speak about six to eight abilities. There is complete agreement about the domains of spatial, quantitative, verbal, and social thought. These are recognized in all traditions of research. The domains of categorical and causal thought are not directly mentioned in psychometric research, but they are both associated with inferential processes residing at higher levels, that is, either with fluid intelligence or $g$ itself. Case et al. (2001) showed that all domains of thought noted above can be abstracted from performance on developmental tasks and tasks drawn from the WISC-R intelligence test.

General intelligence has been variably defined. For Spearman (1904) and Carroll (1993), $g$ is mainly defined by inferential processes underlying reasoning and problem solving activated by the tasks. In fact, content-free tests of $g$, such as the Raven's Progressive Matrices, are considered to tap these processes. Thus, these scholars believe that $g$ is mainly 
located in the inference panel and the domain-inference arrow in Fig. 1. Cattell (1963) differentiated between fluid $(\mathrm{G} f)$ and crystallized intelligence $(\mathrm{Gc})$ and suggested that fluid intelligence refers to general reasoning processes used to solve unfamiliar problems and that crystallized intelligence refers to skills and knowledge acquired as a result of the operation of fluid intelligence and have been crystallized for future use. Gustafsson (1984) showed that $g$ and $\mathrm{G} f$ are psychometrically identical.

With the years, $\mathrm{G} f$ was gradually identified with working memory and executive control. Kyllonen and Christal (1990) showed, in a highly cited study, that working memory determines the condition of psychometric $g$ almost completely. Several authors, following this line of research, showed that working memory and executive control largely determine the condition of $\mathrm{G} f$ and psychometric $g$ (Blair 2006; Colom et al. 2004; Conway et al. 2002; Kyllonen and Christal 1990; Miller and Vernon 1992). In fact, Engel de Abreu et al. (2010) showed that cognitive control mechanisms, rather than storage as such, are the source of the link between working memory and fluid intelligence.

In terms of the present theory, psychometric $g$ may be seen from two different but interdependent perspectives. On the one hand, $g$ is based on the two main mediatory constructs which serve the representation (representational capacity) and the integration (inference) of domain-specific representations. On the other hand, it depends on the quality of communication between all of the systems and functions involved at a given moment: how efficiently and accurately the SSS activated deliver their content for representation to the representational system, how precise and flexible is executive control until attaining a goal, how relevant are the models constructed and considered in the process, how timely and efficient was inference when making decisions, and how accurately and stably are new mental units metarepresented for future use (Demetriou and Kazi 2001, 2006; Demetriou et al. 2008). Therefore, $g$ also resides in the arrows standing for the flow of interactions between constructs, in addition to the constructs themselves.

Interestingly, van der Maas et al. (2006) have shown that the correlations between abilities underlying $g$ can be accounted for by the dynamic reciprocal relations between cognitive processes rather than by an underlying common cognitive or biological process or capacity. The present architecture lends support to this dynamical conception of $g$ and shows how the various processes are interrelated. Also, it is consistent with Jensen's (1998) conception of $g$. Jensen suggested that $g$ is a biological rather than a psychological or behavioral construct, which reflects the ability of the brain itself to process information. In agreement with this conception of $g$, there is extensive research showing that speed of processing is a background factor that is related to psychometric $g$ and that the strength of relation increases with the complexity of the tasks used to measure it (Demetriou et al. 2002, 2008, 2010a, b; Salthouse 2000; Sheppard and Vernon 2008) or with the effort required to learn a new task (Hunt 2011).

The present theory seems to resolve the long-standing debate over the nature of intelligence as either general or domain-specific (Carroll 1993; Jensen 1998; Gardner, 1983; Hirschfeld and Gelman 1994). The theory suggests that it is both. On the one hand, there are systems and processes which participate in every directed mental action, although their combination and effect may vary with task-related experience and development. On the other hand, there are domain-specific processes whose domain specificity varies according to the level of organization of mind concerned. Core processes in each of the SSS are strictly domain-specific because each is activated by a specific pattern of perceptual information which has the affordance to activate it. Mental operations within the SSS are by and large domain-specific. However, they are subject to development and training, and coordination between SSS. Knowledge and beliefs are object- or theme-oriented and 
therefore span over different SSS by definition (Demetriou et al. 1992, 1993; Efklides et al. 1992; Kargopoulos and Demetriou 1998). For example, a theory about motion in physics involves a causal component about the factors that can cause motion, a quantitative component that shows how causes and effects are associated with each other, and a visualspatial model that represents these relations. Obviously, knowledge and beliefs in our theory correspond with $\mathrm{G} c$ in psychometric theory. The various networks of concepts at this level are usually domain-specific in their meaning and in how they are represented, but they can be interconnected and translated to each other by the general processes specified by the theory.

An important aspect of domain specificity is representational specificity. Specifically, each SSS is symbolically biased to symbolic systems that are the most conducive to the representation of its own elements, properties, and relations (Demetriou 1988; Demetriou and Raftopoulos 1999). For example, quantitative thought is biased to mathematical notation, mental images are more appropriate than numbers or words to represent object characteristics and relations in space, and words are more appropriate than numbers or images to represent syntactical and propositional logical relations. Symbol systems can be translated into one another, but some information may be lost at the expense of other information when shifting from one system to the other.

\section{Functional loops of the mind}

From the point of view of education, which is the focus of this essay, it is important to stress that the architecture above is a dynamic system where all components are in constant interaction and interdependence. As indicated above, the power of this architecture with regard to problem solving and learning relies in the flow of effects from system to system rather than in the systems themselves. Several loops of processing may be discerned in this architecture. We will focus on two here, namely, the problem-solving and the self-awareness and control loops.

As shown in Fig. 1, the problem-solving loop is primarily activated by environmental stimuli and is therefore activated from within any of the domains. Once activated, it must first build a representation of the problem goal or the concept to be understood in the representational space (i.e., the SSS-STSS channel). An execution plan must then be planned which includes the necessary intervening steps or sub-goals to be made until attaining the final goal. These steps must be evaluated for their relevance to the goal, rejected or inhibited if not relevant, and ordered in an executable plan if relevant. Thus, planning for problem solving requires mental modeling of alternative or complementary paths to the final goal. Inference is needed at any moment in the planning process in order to judge the relevance or usefulness of sub-goals and the value of alternative sub-goal sequences. Duncan's (2010) conception of $g$ is relevant. According to Duncan, $g$ is equivalent to the ability to build cognitive enclosures. That is, sequences of small mental action plans are embedded into each other such that each one delivers its product to the next one in the sequence until a final goal is attained. The longer the sequence or the more integrated detours it involves, the more powerful $g$ is. This very process requires, one way or another, the construction of alternative mental models until a satisfactory representation or solution will be reached (i.e., the representational capacity-inference channel).

In the process of checking and selecting between representations and models, the second loop is needed. The self-awareness and control loop guides and protects the problemsolving loop through executive control (i.e., representational capacity-consciousness channel), it feeds it in with already available knowledge and experience by calling upon the mental maps available, and it provides evaluations that can guide decision making about 
the value of processing so that it may be carried on or interrupted any time. In short, this loop directs the application of reasoning and inference for the selection of the best problemsolving practices available under the circumstances (i.e., the problem-solving-domains channel). In this process, evaluations and comparisons between mental experiences and models may be reduced to other representations and principles that can be used in the future more efficiently and flexibly. This is the process of metarepresentation, which generates new representations and inferential possibilities to be called upon in the future.

\section{Dynamic developmental relations}

This architecture of mind implies that the various systems are dynamically and reciprocally related during development. The neo-Piagetians were the first to demonstrate empirically that increases in working memory capacity are systematically related to the development of thought (Pascual-Leone 1970; Case 1985, 1992; Demetriou et al. 1993, 2002, 2010a, b; Halford 1993; Halford et al. 1998; Mouyi 2008). This relation was ascribed to increasing processing efficiency as indicated by the speed of processing (Case 1985; Demetriou et al. 2002, 2008; Kail 1991, 1993) and control of attention (Demetriou et al. 2008; Posner and Rothbart 2006). Indeed, a large number of studies show that reaction times decrease with age in all domains and in all types of efficiency functions, reflecting the improvement in communication between the modules and levels of the mind (Case 1985; Case et al. 1996; Demetriou et al. 2002, 2008).

Mouyi (2008) (see also Demetriou et al. 2010a, b) demonstrated clearly these relations. She showed (see Fig. 3) that with increasing developmental level of inductive and deductive reasoning, reaction times to speed and control of processing tasks decreased and working memory capacity increased. In line with these findings, Barouillet and colleagues (Barrouillet et al. 2000, 2008; Markovits and Barrouillet 2002) showed that the development of deductive reasoning is a process of constructing mental models for real problems based on the content and knowledge available. The complexity of the models depends on working memory because more capacity allows for more models and more pointers from them to information in long-term memory. Awareness of this process and the ensuing executive control are important because they direct the final selection of models vis-à-vis the goal and their encoding into logical forms to be recalled later on.
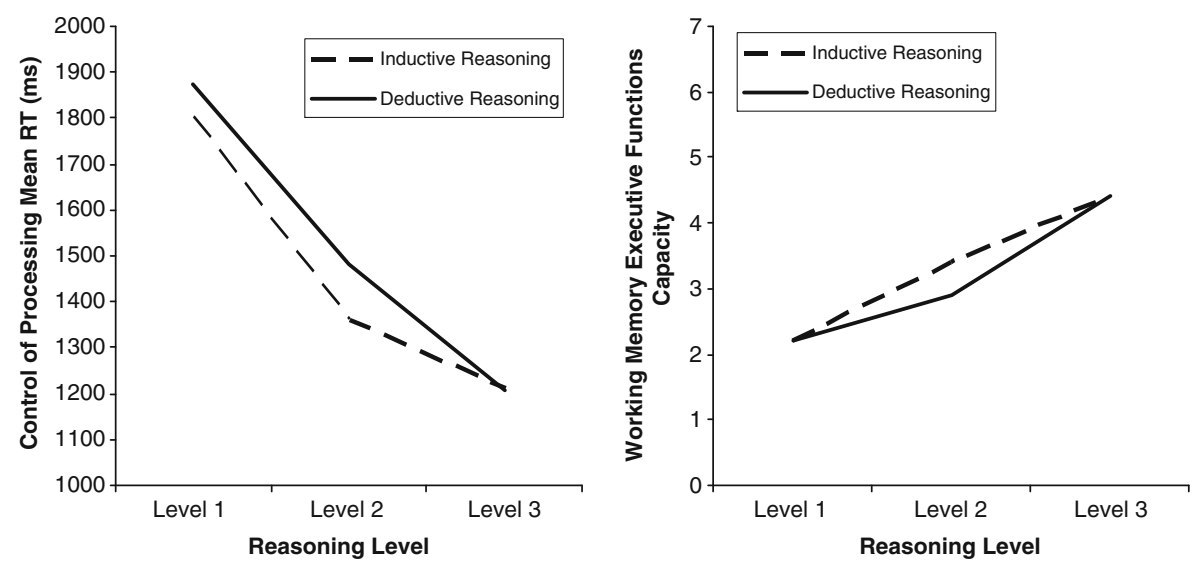

Fig. 3 Developmental levels of reasoning as a function of control of processing and working memory 
The architecture proposed here also predicts that acquisition of cognitive self-monitoring and self-regulation skills influences representational capacity and processing efficiency. In line with this prediction, Camos and Barrouillet (2011) showed that acquisition of rehearsal strategies between 7 and 9 years of age is related to an enhanced short-term storage capacity. Moreover, recent research suggests that increasing awareness of cognitive processes is related to a shift of reasoning from procedural (system 1) to algorithmic reasoning (system 2). Handley et al. (2004) found that the ability to decontextualize thinking from beliefs is associated with inhibitory control. Also, Klaczynski and Daniel (2005) showed that performance on modus ponens tasks is largely automatic and experientially based unless distractors are present, which must be processed and removed. However, consciously controlled analytic processing predominates on the uncertain forms (affirming the consequent and denying the antecedent) and on modus tollens, which require a suppositional attitude and systematic reflection on the meaning of the premises.

Also, there is clear empirical evidence about the interrelations of the processes in the problem-solving loop. English (1998) showed that deductive reasoning is important in the proper streaming of the sequence of mental models needed to represent the goal, assemble the steps needed to reach the goal, and choose actions. Albert and Steinberg (2011) showed that impulse control, which is part of executive inhibition, enables the thinker to design a full solution plan from the beginning, and working memory capacity is important for the representation of the plan, especially in problems requiring many steps to be solved. Interestingly, English (1998) showed that the relational complexity of the models needed is more important than their sheer number.

According to Halford et al. (1998), the relational complexity of concepts depends on the number of entities or the number of dimensions that are involved in the concept. For example, to understand any comparison between two entities (e.g., "larger than," "better than"), one must be able to represent two entities and one relation between them. To understand a transitive relation, one must be able to represent at least three entities (e.g., objects A, B, and C) and two relations (e.g., A is taller than B; C is shorter than B). Numerical analogies, or algebraic relations such as $7+x=9+y$, require four entities and two relations. Higher representational capacity allows models of higher relational complexity. In turn, this provides the possibility of more holistic representations to be conceived and longer or alternative solution sequences to be envisaged and evaluated against each other. As a result, problem solving can shift from isolated and thus frequently inefficient problem-solving strategies to more inclusive and thus more flexible strategies (Fireman 1996).

Our analysis about the role of consciousness in intellectual development is consistent with Zelazo's (2004) model of the levels of consciousness. According to this model, the depth of reflection associated with each successive level of consciousness (LOC), first, adds depth "to subjective experience because more details can be integrated into the experience before the contents of consciousness are replaced by new environmental stimulation. Second, each added degree of reflection (higher LOC) causes information to be processed at a deeper, less superficial level, which increases the likelihood of retrieval. Third, higher LOCs allow for the formulation and use of more complex knowledge structures" (p. 16). In conclusion, it is clear that increasing processing efficiency enables the individual to keep in focus more representations, work out their relations more exhaustively, and metarepresent new representations that may be created for possible future use. Self-awareness and ensuing control of reasoning processes improves efficiency in handling available representational resources and help the developing mind raise mental models and processes into logical argument forms. 
In line with these findings, dynamic systems modeling suggests that changes in higherlevel processes positively influence more fundamental processes (Case and Okamoto 1996; Demetriou et al. 2002). This is understandable from the point of view of modern dynamic systems theory. Higher-level structures, when attained, affect the operation of lower-level structures (Whitherington 2011). When attained, walking, as a complex coordination of the movements of the whole body, beneficially affects the movements of the feet, the hands, and the head. The mental number line, when consolidated, facilitates the specification of relations between different pairs of numbers (Dehaene 1997).

\section{Mechanisms of cognitive development}

Why does the mind improve over time? As noted above, the improvement of mind originates from the changes in any of its component processes. Specifically, novelty in the environment necessitates changes in the SSS. Novelty abounds in the environment. For one thing, the physical and social environment is rarely stable. By definition, changes in the environment beyond the control of the individual necessitate learning that would transform new information into knowledge available for future use. For another, education is the institution for cognitive change par excellence. As an institution of learning, school is a burden with the responsibility to tune individual cognitive development with past and current culture and civilization so that individuals acquire age-appropriate knowledge, understanding, and problem-solving strategies and skills.

According to the theory, all systems are interdependent. Dealing with new information or problems activates both the problem-solving and the self-awareness and control loops mentioned above. Thus, given the particularities of the new information or problems vis-àvis the related old ones, such as differences in the volume and kind of information that must be handled, novelty activates a chain of changes affecting the executive processes needed for efficient use of representational capacity, the inferential and the mental modeling processes needed to associate the old with the new and reach a conclusion, and the metarepresentational processes needed to lift successful intuitions and discoveries into knowledge and skills usable in the future.

Jensen (1998) argued that $g$ is learning. Provided that the two loops proposed here are complementary components of $g$, Jensen's position may be read both ways: Learning is $g$ as well. In other words, educating these loops can expand and refine both domain-specific mental operations and domain-general reasoning patterns that can bring to bear on the solution of new problems in the domains themselves.

How does the mind change? It is reminded that reflective consciousness is the mental tool for the activation and refreshing, comparison, variation, and mapping representations onto each other in order to deal with novelty and that metarepresentation is the mechanism that generates new representations out of these processes. This is a domain-general mechanism of cognitive development that feeds in a continuously expanding language of thought (LOT) (Fodor 1976). LOT includes a metalanguage of thought (i.e., general instructions about how to deal with new knowledge and new problems) and processes for the transfer of meaning from extant knowledge to new information (i.e., induction and analogy) and for the evaluation and selection of interpretations and decisions (i.e., deduction). Of course, this ever emergent process is always shaped under the constraints of the mental resources available and the motivation to think. The motivation to think requires schools that value and foster reflection and mental constructions. Below, we explicate this mechanism. 


\section{From inference and problem solving to the language of thought}

The core operators in the various domains are inferential systems that mediate between perception and particular organism-important patterns of information in the environment from very early in development. New mental operations and concepts develop through modification and differentiation of the core operators. Modification is possible when the patterns of information are close enough to the prototypical pattern to activate the operator but they also deviate from it so that a process of mapping is activated that will transfer meaning from the operator to the new information structure. The fundamental mechanism that permits mapping variations onto the core operators or onto each other is a three-step process: (1) abstraction, which extracts features from the input that can be fed into (2) a similarity search process and (3) induction that maps the abstracted feature onto the core prototype or another object and establishes a relation. Analogical reasoning is nothing more than an extra step in the inductive process that establishes a relation between two (or more) relations. According to Gentner (1989) and Gentner and Rattermann (1991), this extra step is a relational shift that enables children to shift processing from the similarity between objects based on an abstracted common feature to a similarity between relations (pairs of objects having the same relation). Similarity search and inductive decisions may be saturated by statistical regularities that may enable the infant to make predictions of the future state of events based on their present patterning (Téglás et al. 2011).

Some scholars (Braine 1990; Rosch 1975) do claim that there are pre-logical inferential schemas very early in development that are antecedent to deductive reasoning forms proper (such as joint iteration, which refers to repetitions of actions and is the basis for conjunction or permission rules or contingencies, e.g., "if you do this I will do that," which function as the basis for implication). However, these become deductive schemes only when integrated across occasions and contexts and used as such. Therefore, a universal LOT is gradually constructed when similar patterns of thought across domains are compared and reduced to inference schemes that are explicitly represented in or tagged with natural language elements (e.g., "and ... and" "or ... or", "if ... then") or other types of representations (e.g., mathematical notation) and are intentionally activated independently of context or domain.

A good sign of the state of this general LOT is logical necessity. When attained in development, it indicates that an inference scheme is lifted from a context-bound processing frame to an advanced rule-bound organizer of relations. Exceptions, when encountered, are considered as noise caused by errors in observation rather than as a fault of the inferential process. Under this condition, the general LOT becomes a powerful tool for checking the accuracy and precision of information and knowledge, and the consistency between alternative models or representations of it. Recent research shows that some grasp of logical necessity is present at the age of 7 years and is fully established by age 10 or 11, when children realize "that necessary truths are true everywhere, will never change, and cannot be imagined to be different [and] they refuse to draw a violation of a logical truth" (Miller et al. 2000).

\section{Metarepresentation}

The construction of new mental units is not tantamount to having them available for future use unless particular measures are taken for their preservation. New mental units are lost if they are not connected to symbols which will make them available for future use. Therefore, the endurance of new mental units depends, first, on metarepresentational awareness of the role and functioning of mental constructs. Second, it also depends on a 
process of symbolic individuation which pairs newly generated ideas with specific symbols with the aim of making them usable in the future (Demetriou and Raftopoulos 1999). These symbols, which may be idiosyncratic, such as mental images or personal scripts, or conventional, such as language or mathematical notation, fix and individuate a new representation so that it can be recalled, related to other representations, and mentally processed as needed.

Dual representation is the minimum requirement for using symbols to stand for objects or ideas. In addition, the thinker must be able to relate the referent with the symbol and mentally fix this relation so that the symbol always denotes the referent in the future, unless otherwise decided. Thus, the ability to metarepresent indicates an understanding of the asymmetric relation between the symbol and the referent (e.g., maps and scale models are much smaller than the depicted reality and may not include everything that exists in reality), and it is gradually differentiated according to several important parameters. The representational capacity available is crucial because it frames the complexity of realitysymbol relations that can be processed. The characteristics and demands of particular symbol systems, such as drawings, writing, and numbers, are also important, and they need to be learned as such if they are to be efficiently used as representations of reality (Yamagata 2007).

By the age of 4 years, children are adept in understanding the representational nature of different forms of symbols (Yamagata 2007). In the years following, children become increasingly flexible in adopting representations for their learning and understanding needs and for inventing their own representations. For example, research suggests that there are representational shifts during category learning such that, with learning, representations change from rules representing a single dimension to similarity-based exemplars integrating multiple dimensions (Johansen and Palmeri 2002).

Developing metarepresentational competence is increasingly intertwined with inferential capabilities and increasing mastery of dominant symbol systems, thereby enhancing the scope and power of the universal LOT. Natural language has a privileged relation with this emergent universal LOT because it is the main symbol system that can be used to express and manipulate LOT's components. One may imagine many examples of conversations in which the linguistic and the actual structure of events are in direct correspondence: "If you drop it, it will break into pieces, you see!" Natural language and the emergent LOT are gradually intertwined and used to guide and facilitate inference and processing within each of the domains. In line with this assumption, the permission schema theory (Cheng and Holyoak 1985 ) posits that these inductions occur in the context of permission rules which specify the conditions under which a given action can or must occur (Harris and Nunez 1996).

Also, Raffray and Pickering (2010) showed that thinkers first construct meaning-based representations based on thematic context and then abstract logical form when processing verbal information that is to be interpreted logically. For example, when processing sentences including quantifiers, such as "every" and "a," which require one to specify the number of actors, objects, and activities, thinkers abstract the universal and the existential quantifier from meaning-rich representations exemplifying the quantitative relations in the components of the sentence. Also, Fisher suggests that object naming functions in infancy as a pointer to similarity between objects, thereby guiding the induction of similarity relations between objects. Specifically, a common name for objects that do not appear completely identical directs 3- to 5-year-old infants to look for, represent, and tag similarities (Fisher 2010). Therefore, the symbolization process partakes in inferential processes by guiding the transfer of meaning across representations. 
A study by Gauffroy and Barrouillet (2011) lends support to the assumption that deductive reasoning development evolves from the handling of mental models implementing possibilities to the grasp of the logical relations of truth-falsity implied by the models. This study showed that basic logical relations are first grasped through the construction of mental models that translate a proposition (e.g., "if the box is red it contains cherries") into all possible compatible and incompatible. Specifically, conjunction, which requires only one model, is grasped at about 8 years of age (e.g., red box with cherries); the biconditional, which requires two models, is grasped at about 11 years (e.g., red box with cherries, green box with apples); the conditional, which requires at least three models, is grasped at about 15 years (e.g., red box with cherries, green box with apples, red box with apples). When these very same possibilities are expressed in terms of statements that are true or false, given the initial proposition, each of these relations is grasped 2-3 years later. Obviously, with experience and ensuing reflection, the set of mental models that are compatible with the various types of relations are condensed into a universal rule that can be used to fully generate or evaluate them, if needed. We will show below that this conception of development is important for education in reasoning and critical thinking.

\section{Developmental trends and individual differences}

It is stressed that the theory presented here is not a stage theory of development. In fact, the complexity of the dynamics between systems and processes in development are such that there are no hard or easily noticeable boundaries between developmental phases. There always are precursors before a particular milestone is reached, and its consolidation takes time. In terms of the dynamic systems theory (van Geert 1994), developmental milestones operate as pivotal points toward which precursors tend to stabilize and subsequent changes tend to be organized until the attainment of the next milestone.

Moreover, the general trends in development described above do not imply that the likelihood of attaining each of the developmental milestones is the same for all individuals or that development proceeds at the same rate across domains. On the one hand, there is strong evidence that the frequency of each next milestone decreases systematically in the general population. Specifically, the first three milestones are closely related with age and are attainable by most children. However, conditional and principled representations are not attained by the majority of persons and are very weekly related to age. Shayer and colleagues (Shayer et al. 1976; Shayer and Wylam 1978) showed that the higher levels of Piagetian formal operations are not very common in the general population, while Commons et al. (1982) showed that postformal levels of functioning are very sparse even among college students (see also Moshman 2011). On the other hand, however, if we translate our position that a LOT is gradually constructed that expands with development in psychometric terms, we would predict that $g$ would increase with age. Evidence shows that this is indeed the case. Pind et al. (2003) showed that scores on the Raven's Standard Progressive Matrices increase systematically from the first to the tenth school grade, suggesting that general cognitive competence increases with age.

However, it is noted that operations and concepts within each of the domains are only built as a result of experience and interaction with the domain concerned. Therefore, there may be extensive variations in the rate of development across domains and individuals, depending upon the person's engagement with the various domains (Demetriou et al. 1993, 2002, 2010a, b). In fact, Ackerman $(1996,2000)$ suggests that, with age, general cultural knowledge and more specialized knowledge related to an individual's social group and professional activity acquire prominence over general or fluid intelligence. In terms of the 
present theory, this would imply that the possibilities afforded to an individual by a particular profile of processing and inferential possibilities must be invested in readily available domain-specific, socially, and culturally relevant skills and knowledge. With age, this investment must be increasingly expressed through both a particular domain of professional activity and more general domains associated with culturally important roles, such as the role of the parent, the friend, etc.

\section{Towards a Theory of Instruction}

\section{Developmental constraints and educational ideals}

In this section, we outline the implications for education of the theory summarized here. The architecture of developing mind outlined here suggests that domain-specific systems always work together with general mechanisms and processes. All SSS and all general mechanisms interact variably with the various knowledge domains to be mastered at school. Therefore, the ideal of education would be to positively influence all of these processes depending upon (1) developmental time (i.e., the age and developmental condition of the students), (2) educational time (i.e., the grade and prior educational experience and knowledge already attained as specified in the curriculum), (3) the particularities of the subject matter or knowledge domain concerned, and (4) the structural and procedural aspects of education that are crucial for learning, such as the education of the teachers, teaching methods, technological support of learning, etc. The following issues will be discussed below:

1. Schooling-developing mind relations. It is important to specify how mental processes and capabilities are related to school performance and how schooling impacts mental processes and capabilities.

2. Tuning educational timing with developmental timing. Education should be guided by an overall roadmap that takes into account how the developing person relates to the world at different phases of development. Therefore, the developmental milestones outlined here must inform educational priorities for different phases of life. In addition, learning demands at successive school levels and grades must respect the representational and processing constrains and possibilities of the students' developmental level.

3. Mental modeling. Students should practice the ability to create and use mental models for the sake of understanding and problem solving. Mental model building and management must be an integral component of education for critical and creative thinking.

4. Domain-specific learning and conceptual change. It is clear that instruction must sharpen, refine, and muster subject-specific processing and problem-solving processes and skills. Instruction must generate controlled conceptual change so that students acquire new grade-appropriate knowledge in the various school subjects and rectify the various misconceptions they may have. Ideally, by the time they leave school, students must have a sound understanding of the fundamentals of knowledge about the world as represented by the sciences and disciplines of our time.

5. Inference, metarepresentation, and learning to learn. Students must be directed to generate, strengthen, and enhance general reasoning patterns and problem-solving skills out of handling and managing mental resources. Provided that reasoning emerges out of metarepresentational processes, metarepresentation must be a target of education in itself. 
6. Critical thinking and creativity. Students must be critical so that they can evaluate information and knowledge for its value relative to goals, either personal or social. Evaluation must be related to criteria of accuracy, sufficiency, validity, and usefulness. In a sense, building these criteria is the ultimate goal of education.

Relations between developing mind, school performance, and learning

The relation between cognition and education is bidirectional: Cognition shapes and affects learning in schools, and schooling shapes and affects cognition. In this section, we will summarize studies highlighting how this bidirectional relation evolves from preschool to early adulthood.

\section{Intelligence-schooling relations}

Many studies substantiate the relation between the various dimensions of the mind specified here and learning at school. Specifically, the relation between performance on intelligence tests and examinations reflecting school achievement are very high (approx. 0.8 for the SAT and the GCE). The relation between intelligence scores and school marks is lower but considerable (approx. 0.5).

Deary et al. (2007) showed that general intelligence at the age of 11 years strongly predicts school achievement at the age of 16 years all over 25 school subjects examined (the relation between the two latent factors was 0.81 ). The relation varied extensively across the various subjects. Specifically, the variance accounted for ranged from $58.6 \%$ in Mathematics and $48 \%$ in English to $18.1 \%$ in Art and Design. For those at the mean level of $g$ at age $11,58 \%$ obtained five GCE at the age of 16 years. A standard deviation increase or decrease in $g$ altered the values to $91 \%$ and $16 \%$, respectively. Rohde and Thomson (2007) showed that fluid intelligence as reflected in performance on the Raven Matrices is a very strong predictor of school achievement, as reflected in the SAT. However, they also found that different aspects of school achievement are differentially related to the various aspects of $g$. That is, general cognitive ability was a stronger predictor of SAT verbal than working memory, processing speed, and spatial ability. In contrast, spatial ability and processing speed predicted SAT math scores in addition to the contribution of general cognitive ability.

In a thorough study, Rindermann and Neubauer (2004) showed that processing speed influences both general intelligence and creativity and that these, in turn, influence school performance. Krumm et al. (2008) showed that reasoning is a good predictor of school achievement in science (mathematics, physics, biology, chemistry) and language. The executive and coordination processes of working memory additionally contribute to performance in science; verbal storage additionally contributes to achievement in language. Therefore, it seems that different subjects in school require a different combination of domain-specific and domain-general processes depending upon their requirements. It needs also to be noted that general intelligence is more important for individuals of low rather than of high intelligence (Detterman 2000).

A series of studies conducted in our laboratory explored these relations systematically from primary to high school in order to specify whether they vary with development (Demetriou 1998, 2000, 2010a, b). One of these studies (Demetriou et al. 2010a, b), which included 8- to 12-year-old students, found that a very large part of the variance of each of three school subjects is highly accounted for by speed of processing, working memory, and 
problem solving in three SSS (i.e., in total, $79 \%$ in Science, $72 \%$ in Mathematics, and $88 \%$ in Greek). Of the three dimensions, the strongest predictor was always the problem-solving factor underlying the three domains (i.e., $55 \%$ in Science, $67 \%$ in Mathematics, and $74 \%$ in Greek). The effect of processing speed, although considerably lower (i.e., 21\% in Science, $4 \%$ in Mathematics, and $10 \%$ in Greek), was always significant. The effect of working memory was very weak (lower than $4 \%$ in all cases).

A second study (Panaoura, Gagatsis, and Demetriou 2009) involved children and adolescents from 10 to 18 years of age. This study found that the relation between processing efficiency (speed and control of processing) and school performance was much stronger than in the previous study (i.e., it accounted for $50 \%$ of the variance in Science, $25 \%$ in Mathematics, and $16 \%$ in Greek). This may reflect the fact that the importance of general cognitive efficiency as such for learning becomes stronger with age until early adulthood (Grigorenko 2002). Problem-solving processes underlying performance on the five thought domains (which have a strong $\mathrm{G} f$ component) accounted for only $3 \%$ of performance in Science, 6\% in Mathematics, and 34\% in Greek. Crystallized intelligence accounted for $25 \%$ of the variance in Science, $25 \%$ in Mathematics, and $31 \%$ in Greek. Interestingly, processing efficiency and reasoning were important factors of school performance in all subjects throughout adolescence. The relation of school performance with crystallized intelligence became increasingly stronger. This is consistent with the developmental tendency noted earlier that from adolescence onwards, when basic knowledge extraction mechanisms are consolidated, knowledge acquisition and use become more important.

A third study (Demetriou and Panaoura 2006) aimed to assist learning in mathematics and specify the involvement of the various dimensions of mind, as they were presented above. This study, which involved 9- and 11-year-old students, found that children who were high in processing efficiency and working memory were equally able to profit from plain exposition to the teaching material or systematic instruction addressed to mathematical problem solving. However, those who were low in these two fundamental parameters of cognitive functioning were able to profit from systematic instruction, but not from plain exposition to the teaching materials. The message of this study for learning is clear: A well-structured learning environment enables the students who are weak in their processing and representational capabilities to learn despite their weaknesses. However, the students who are strong in processing and representational capacity can themselves compensate for the shortcomings in their learning environment because they learn fast and efficiently, thereby discovering and constructing by themselves the relations and concepts that float, so to speak, in the information provided. Also, Panaoura et al. (2009) showed that the more reflective and self-aware a person is, the more this person profits from instruction.

Hundreds of studies examined the effect of schooling on intelligence. The Abecedarian Study of Campbell and Burchinal (2008) was addressed to underprivileged children who were followed from early infancy to early adulthood. Treated participants consistently and significantly outperformed controls throughout the age phase studied, although their difference decreased systematically from about 10 IQ points in the age phase $2-5$ years to about 4.5 IQ points in the period from 6.5 to 21 years. Interestingly, the difference in IQ after the age of 12 years was due to the differences in verbal ability in the early preschool years. Overall, these studies suggest that there is an increase of something between 1 and 4 IQ points for each extra year of schooling (Ceci 1991; Winship and Korenman 1997). Gustafsson (2008) found that this effect came from changes in $\mathrm{G} f$ rather than in $g$ as such. Interestingly, this effect came mainly from academic rather than from vocational programs 
of study. Moreover, he found that programs oriented to science and technology exerted a positive effect on visuospatial ability and crystallized intelligence.

\section{Cognitive development-schooling relations}

Kyriakides and Luyten (2009) studied the relation between schooling and cognitive development from 12 to 18 years of age. They used a comprehensive test of cognitive development (Demetriou and Kyriakides 2006) that examines the student's level of reasoning in all of the domains of thought described here but social thought. To specify the effect of schooling, they compared students of the same age who differed by one school grade due to the fact that there is a conventional cutoff point in birth date which specifies when students enter primary school. They found that the effect of one extra year of schooling was significant and considerable (effect $=0.33$, Cohen's $d=0.61$ ) throughout the six secondary school grades. This effect suggests that more school experience accelerates progress along the hierarchy of cognitive developmental levels. The effect of schooling on mathematics (effect $=0.87$, Cohen's $d=0.68$ ) and language (effect $=0.87$, Cohen's $d=0.72$ ), expectedly, was larger. This is an interesting finding, showing that schooling, in addition to augmenting school-specific knowledge, also boosts the underlying mechanisms of cognitive development as such. The findings of Artman et al. (2006) are in line with this interpretation. They found that schooling enabled 12- to14-year-old adolescents to accept the verbal statements in an argument as premises calling for the specification of their logical relations rather than of their content.

The research of Shayer and Adey (2002) on the acceleration of cognitive development points to the same conclusion. These scholars showed that scaffolding cognitive development through controlled cognitive conflict, social support, and reflection produces immediate gains in the level of cognitive development, but also to subsequent gains in national public examinations taken 3 years later, in Science, Mathematics, and English language (Shayer and Adey 2002; Shayer and Adhami 2003).

Some aspects of culture which are tightly intertwined with education may be strongly associated with intellectual functioning. Research shows that this may indeed be the case with writing, which is major component of education. Logographic systems of writing, such as Chinese, are very different from alphabetic systems in their cognitive demands. That is, logographic systems are much more demanding than alphabetic systems in visuospatial processing and construction of associations between meaning and representations. Demetriou et al. (2005) maintained that learning the Chinese logographic system has a lasting effect on visuospatial processing that extends from basic information processing mechanisms related to speed and control of processing to visuospatial spatial working memory and spatial reasoning. Recent studies substantiate this claim. Cole and Pickering (2010) showed that learning Chinese makes children more flexible in using both visuospatial and phonological encoding strategies for storing and retrieving information from working memory as contrasted to learners of alphabetic orthography who use only phonological strategies. McBride-Chang et al. (2011) showed longitudinally that readers of logographic systems outperform readers of alphabetic systems on visual tasks and that learning to read Chinese has a general beneficial effect on visual-spatial reasoning. These findings may explain, at least in part, the fact that eastern nations (i.e., Chinese, Koreans, and Japanese), who use logographic systems of writing (average IQ in the range 105-108), outperform western nations (average IQ in the range 90-100) in measures of intelligence (Lynn and Vanhanen 2006).

In conclusion, there are well-documented reciprocal relations between the developing mind and schooling that are related to all aspects of the cognitive architecture depicted here. 
The discussion below builds on these relations in order to suggest how education can be more systematic and efficient in improving the students' minds and learning.

\section{Self-awareness, personality, motivation, and schooling}

The relation of self-awareness and self-representation with school performance is much more complicated and indirect rather than direct. Specifically, all of the studies summarized above showed that cognitive self-concept as such is very weakly, if at all, related to school performance, especially in primary school. However, accuracy in self-evaluation is related to school performance in adolescence. Specifically, we found (Demetriou and Kazi 2001) that adolescents who were not accurate in their evaluations of their own performance on cognitive tasks tended to obtain lower school grades than their classmates who attain the same cognitive performance and were accurate in their self-evaluations. Interestingly, high cognitive ability and self-evaluation accuracy go with a strong sense of self-control. Moreover, these individuals tend to engage in activities which require effort and originality. Overall, however, the additive contribution of personality factors to school performance is very low. That is, each of three personality factors, i.e., conscientiousness, openness to experience, and persistence to stay on goal, accounted for an extra $4 \%$ of the variance of school grades in the three school subjects above. It seems, therefore, that motivational and personality factors moderate the investment of cognitive factors into learning activities rather determine learning as such (Demetriou and Kazi 2001).

Tuning developmental and educational timing

Piaget was the first to note that children in different developmental stages live, in a way, in different worlds and that education must take this into account if it is to be successful. Therefore, learning tasks, to be successful, must be tailored to the child's phase of development. This section will discuss implications of the theory presented here for the developmental timing (Anderson 1985) of educational goals, concepts, and problem-solving skills across and within school grades or other educationally meaningful time units.

\section{Capitalizing on developmental milestones for learning (Table 4)}

The sequence of developmental milestones is an important guide for the formulation of major educational goals. So far, state education does not include programs for children younger than about 3-4 years of age. The time is ripe for a more systematic approach to education in infancy. The rich knowledge that we now have about the mental capabilities of infants provides a sound basis for the design of "educational environments" that would enable the infants to consolidate and expand these capabilities. Moreover, the increasing demands of primary education necessitate the required preparations in infancy.

Infancy and core operators Education in infancy should be directed to practicing the core operators in the SSS in order to enhance infants' (1) understanding of the nature, behavior, and relations of objects; (2) their own relations with objects and other persons and the influence of their own activity on objects and persons; and (3) the basics of number. Some examples are given below for each SSS.

Infancy is marked by limited representational capacity and executive control. Moreover, at this phase, the use of language as a medium of representation and instruction is limited. 
Table 4 Developmental milestones and educational priorities for the education of the developing mind

\begin{tabular}{|c|c|c|c|}
\hline $\begin{array}{l}\text { Age and } \\
\text { milestones }\end{array}$ & Educational priorities & Learning to learn & $\begin{array}{l}\text { Epistemological } \\
\text { awareness }\end{array}$ \\
\hline $\begin{array}{l}\text { Infancy: } 0-2 \\
\text { Elaboration of } \\
\text { core operations }\end{array}$ & $\begin{array}{l}\text { Educating directed discovery } \\
\text { and the SSS core processes. } \\
\text { Infants must construct (1) } \\
\text { a basic understanding of } \\
\text { the nature, behavior, and } \\
\text { relations of objects, (2) } \\
\text { their own relations with } \\
\text { objects and persons, the } \\
\text { influence of their own } \\
\text { activity on objects and } \\
\text { persons, and (3) the } \\
\text { basics of number. }\end{array}$ & $\begin{array}{l}\text { Educate infants to follow } \\
\text { instructions. Let them } \\
\text { do complementary actions } \\
\text { vis-à-vis a task of interest. } \\
\text { Let them have "controlled } \\
\text { failure" experiences. }\end{array}$ & $\begin{array}{l}\text { Differentiate one's } \\
\text { own knowledge } \\
\text { from others' } \\
\text { knowledge (e.g., } \\
\text { dad can do things } \\
\text { I cannot do and } \\
\text { so I can ask } \\
\text { for his help). }\end{array}$ \\
\hline $\begin{array}{l}\text { Toddlerhood: } \\
\text { 3-4 } \\
\text { Dual } \\
\text { representation }\end{array}$ & $\begin{array}{l}\text { Educating dual representation. } \\
\text { Explore alternative } \\
\text { appearances of objects, } \\
\text { perspectives of persons, } \\
\text { and representations of } \\
\text { objects and persons and } \\
\text { tag them with symbols. }\end{array}$ & $\begin{array}{l}\text { Explore their own actions } \\
\text { and talk about them. } \\
\text { Talk about each others' } \\
\text { representations and doings. } \\
\text { Differentiate between what } \\
\text { they can and what they } \\
\text { cannot do. Differentiate } \\
\text { between knowing what to } \\
\text { do and doing. Rehearse. }\end{array}$ & $\begin{array}{l}\text { Overcome } \\
\text { absolutism. }\end{array}$ \\
\hline $\begin{array}{l}\text { Primary school: } \\
\quad 7-8 \\
\text { Logical necessity }\end{array}$ & $\begin{array}{l}\text { Educating logical exploration } \\
\text { and coherence. Mapping } \\
\text { object characteristics onto } \\
\text { related mental operations, } \\
\text { representations, and concepts. } \\
\text { Explore relations between } \\
\text { operations and representations } \\
\text { and grasp how they constrain } \\
\text { each other in meaning and } \\
\text { conclusions. }\end{array}$ & $\begin{array}{l}\text { Differentiate between } \\
\text { mental functions (i.e., } \\
\text { attention, memory, } \\
\text { knowing, inference, } \\
\text { etc.) and relate them } \\
\text { with appropriate } \\
\text { activities. Formulate } \\
\text { plans of actions and } \\
\text { tell them to yourself. }\end{array}$ & $\begin{array}{l}\text { Understand the } \\
\text { multiplicity of } \\
\text { knowledge and } \\
\text { that the nature } \\
\text { and "quality" of } \\
\text { knowledge depends } \\
\text { upon the methods } \\
\text { or processes } \\
\text { generating it. }\end{array}$ \\
\hline $\begin{array}{l}\text { Adolescence: } \\
\text { 13-14 } \\
\text { Suppositional } \\
\text { thought }\end{array}$ & $\begin{array}{l}\text { Educating suppositional } \\
\text { thought. Educate the } \\
\text { "if ... then" stance. } \\
\text { Envisage alternative } \\
\text { worlds, test, validate, } \\
\text { choose, and argue. } \\
\text { Differentiate between } \\
\text { logic and inference. }\end{array}$ & $\begin{array}{l}\text { Differentiate between } \\
\text { mental operations in } \\
\text { different domains. } \\
\text { Associate them with } \\
\text { relevant representational, } \\
\text { inferential, and } \\
\text { logical systems. }\end{array}$ & $\begin{array}{l}\text { Grasp the } \\
\text { complementarity } \\
\text { of methods and } \\
\text { processes in } \\
\text { knowledge } \\
\text { production } \\
\text { and revision. }\end{array}$ \\
\hline $\begin{array}{l}\text { Young adulthood: } \\
20-22 \\
\text { Theoretical } \\
\text { thought }\end{array}$ & $\begin{array}{l}\text { Educating theory } \\
\text { building. Educate } \\
\text { on realism, relativity, } \\
\text { and theory building, } \\
\text { merging, and modeling. }\end{array}$ & $\begin{array}{l}\text { Associate mind operations } \\
\text { and products with culture } \\
\text { and history. Differentiate } \\
\text { knowledge construction } \\
\text { and control methods } \\
\text { according to historical era, } \\
\text { discipline, or social context. }\end{array}$ & $\begin{array}{l}\text { Understand the } \\
\text { differences between } \\
\text { traditions, schools } \\
\text { of knowledge, } \\
\text { epistemological } \\
\text { paradigms. }\end{array}$ \\
\hline
\end{tabular}

Therefore, education focusing on the core operations present before the age of 2 years must capitalize on the active discovery and exploration activities that dominate at this phase and control for the easily shifting attention and lack of language (Posner and Rothbart 2006). 
This can be attained by a careful organization of what is available to the infant to play with and discover the relations of interest. These must be limited in number so that the infant is not distracted by them.

For example, classification skills and induction of relations must be based on perceptual similarity that generates concepts in the categorical system. There may be special markers that can direct attention to particular features of the objects, such as shape or color, and facilitate the infant to ignore other features, such as texture. Moreover, there may be special effects that provide feedback about acceptable and not acceptable sorting actions, such as special sounds for successful and unsuccessful actions. These conditions may direct the infant to explore the form, size, shape, and relations between objects which may generate mental representations of the objects and their categorical and visuospatial relations. In the quantitative SSS, objects can be arranged variably within the subitization limit so that they can be counted, numbered, and tagged visually to generate representations about number. In the causal SSS, particular objects or components of objects may be associated with special effects, such as sounds or colors. The actions of the infant on these objects may enable him to build causal connections between his behavior, objects, and effects. Mapping variations of actions with corresponding variations of effects is conducive to the construction of a mental space of causality. Finally, in the social domain, pretend play may be used for recognizing emotional expressions, deciphering the emotional states of others in a social system, and understanding their effects on interpersonal interactions. It is interesting to note that the toy and the cartoon industry produces toys and cartoons that implement knowledge and ideas about the mental needs and capabilities of young infants. These products, if properly presented, may prove very conducive to the goals of infant education noted here.

At the edge between infancy and toddlerhood, with the emergence of language, education must enable the infant to connect core operators with representations and advance them into the respective mental operations of the specialized domains concerned. That is, the infant must be facilitated to recognize how different words, symbols, and the grammatical and syntactical structures of language are connected to realities related to each of the core operators mentioned above.

Education episodes in infancy must recycle with gradually shifting content and complexity to ensure that mastering of the target relations becomes consolidated and increasingly free of content and contextual restrictions. Education episodes in infancy must have a strong social component where empathy motivates the infant to engage in learning activity and imitation provides the frame for fast learning (Meltzoff et al. 2009). Moreover, individual differences in temperament and activity level must be taken into account for the formation of programs adjusted to different children (Keogh 2003). For example, some infants can focus and persist on an activity much more than other infants. Therefore, cycles of activity must be adapted to the focus span of the infant (Posner and Rothbart 2006).

Preschool and dual representations Education at the preschool years must provide conditions for the knowing and handling of dual representation. For instance, tagging photographs to the objects they represent and then varying the perceptual similarity between an object and its photograph until transforming the photograph into an abstract representation of the object is a method for inducing toddlers in the nature of representation in the categorical domain (DeLoache 1991). Tagging numbers onto sets of objects and tagging written words to expressions may have the same function in the quantitative domain and in the domain of language, respectively. Moreover, associating alternative 
representations with the same reality (e.g., number digits and number words) may be helpful in enabling the child to dissociate representation from thought as such.

Children must be systematically instructed to explore how the appearance of objects may change without affecting the identity of objects (e.g., changing the dressing of a doll, playing with transformers and other toys where variation of appearances is an integral part of their construction). They must be assisted (e.g., via role playing) to alternate between one's own point of view and another's point of view by systematically exchanging and comparing positions. Moreover, in these contexts, they must be induced to realize that different perspectives or different appearances may induce in different persons different representations and different beliefs about the realities concerned. Thus, tagging photographs of the different perspectives from which an object may be viewed and associating it with different persons, according to the perspective from which they view the object, is a good practice into perspective taking and theory of mind. Therefore, in this phase of life, education must enable preschool children to join their own overt actions with alternative representations that may be used to represent them.

Furthermore, toddlers must learn to observe their actions relative to a task, observe others doing the same task, and reflect (or talk) on both how they can themselves modify actions in order to become better tuned to a goal and on others' performance. Talking with others about an object or action helps in building a representational space where the same actions or objects are represented by different representations or different actions or objects may be represented by the same representation. In conclusion, bridging of self-modification experiences over different occasions must be encouraged as it strengthens self-regulation and executive control. Bridging actions and representations across persons helps differentiate how reality can be represented, how representations may be used to guide actions, and that alternative representations lead to alternative action plans.

Primary school, representational cohesion, and logical necessity Dual representation gradually evolves, in the primary school years, into coherent thought that can handle multiple representations. Therefore, education in the primary school years must focus on revealing the connections between concepts and operations and facilitate children to see their own overt or mental actions vis-à-vis the concepts and operations. For example, children must realize that sorting objects into different groups or stacks according to similarity results into category building. As a result, perceptual characteristics of objects and actions on them are reduced to mental representations and words standing for them. In turn, category building facilitates mental labor and learning because, for example, object characteristics may be logically derived from category properties and category names can generate the names of all objects included in each category. This will enable children to realize that series of representations are logically linked with each other so that particular series necessarily result into particular conclusions. This will help them understand that logic underlies inference and is governed by restrictions that need to be respected, if the outcomes of inference are to be valid (Barrouillet 1997; Daniel and Klaczynski 2006; Klauer et al. 2000; Overton et al. 1985).

Adolescence, suppositional, and theoretical thought The next milestone is the suppositional and theoretical stance of adolescence. Therefore, education in early adolescence should focus on developing the "if ... then" stance approach to problem solving and build epistemological awareness about the characteristics, possibilities, and limitations of different knowledge domains vis-à-vis their methods, functions, and priorities. That is, adolescents should be able, on the one hand, to handle logical inference efficiently. On the 
other hand, they must realize that very often, logical conclusions may vary depending on the premises involved and that premises may be derived from different theories or belief systems. Eventually, however, an acceptable truth may be reached through appropriate controls, even temporarily.

A useful framework for the strengthening of this stance is the systematic exploration of important phenomena from the point of view of different disciplines or different theories within a discipline. Motion is a good example. There are theories about motion in practically every science. In physics, it is described in reference to speed and space and is explained in reference to causal factors, such as energy, force, and work. In chemistry, it is described in reference to the structural and molecular characteristics of objects. In biology, it is described in reference to its function (e.g., survival), the structural enabling mechanisms (e.g., feed in walking animals, wings in flying animals), and the biological enabling mechanisms (e.g., eating, digestion, photosynthesis, metabolism). In psychology, it is described as an aspect of development (e.g., changes in the ability for movement in the first 3 years of life), or skill acquisition (e.g., learning to drive a car), as a means for social interaction (e.g., approach to another person), and as the result of underlying psychological causes (e.g., the expression of an intention or the implementation of a mental plan). Adolescents may be acquainted with different models for motion in each of the disciplines mentioned above, explore their similarities and differences in concern to the methods used to construct them, the data invoked to support them, the language or symbol systems used to represent them, and their functional role in each discipline as a system of knowledge. Moreover, they may run experiments especially designed to demonstrate specific models in different disciplines. For example, students may study the similarities and differences between Aristotle's, Newton's, and Einstein's models of motion in physics. Moreover, they may be acquainted with the use of concepts from one discipline to explain phenomena in another discipline (e.g., chemical reactions underlying the transformation of energy into work to explain metabolism enabling movement in animals) in order to grasp the general underlying mechanisms that cut across disciplines and use common models to represent them, such as the notion of function connecting variables of interest.

Adulthood, multiplicity of knowledge, rationality, and wisdom The goals of education for adolescence as stated above must culminate in the college level. The aim would be to refine conditional and theoretical thought and embed it into living science. Although a possibility of this phase of life, this stance is very rare even among college students despite the fact that universities take it for granted. Thus, in college, students must be given ad hoc education directed to the understanding of (1) science as a process of discovery and incessant change of knowledge and methods (2) and as an institution in interaction with other social and cultural institutions.

Courses on the nature and history of science would be conducive to the attainment of this aim. This knowledge would facilitate and consolidate the differentiation between knowledge and thought which is attained at this phase of life. Moreover, it would contribute to the understanding of the double nature of scientific knowledge. That, on the one hand, it is relative vis-à-vis other relevant theories of the past, present, and future, whereas, on the other hand, it is of certain heuristic value vis-à-vis relevant understanding and problem-solving needs. This would contribute to the refinement of critical thinking skills that are necessary to deal with complex problems more generally than the particular discipline of one's study.

Not all youth go to university. Programs of lifelong learning may compensate for this lack. These programs may focus on issues related to life choices and their possible impact 
on one's own and other persons' lives. Taking the different perspectives and ensuing choices of different persons involved in life episodes would enhance one's ability to alternate between choices and integrate accordingly. Rationality and wisdom may be facilitated.

\section{Tuning educational demands with cognitive possibilities}

According to the neo-Piagetians (Case 1992; Halford et al. 1998; Pascal-Leone 1988), to be grasped, concepts have a specific representational demand. Therefore, the concepts and activities to be taught must reside within the representational and processing possibilities of each child in the classroom. According to Halford et al. (1998), the mental demand of concepts is equal to the relational complexity of the mental units that they involve. Also, any sequence of concepts must be tuned to the needs of the developmental milestones of the phase concerned. This would, on the one hand, facilitate learning as such and, on the other hand, would consolidate the mental possibilities afforded by the developmental milestone of each developmental phase.

Moreover, concepts are usually defined on the basis of other concepts. For example, according to Dawson (2006), the concept of energy (as the ability to do work) requires the integration of three abstract concepts (e.g., kinetic energy, energy transfer, and gravity); these, in turn, are defined by simpler concepts (motion, pulling, pushing, etc.). Scholars (Case 1985; Demetriou et al. 2010a, b; Fischer 1980; Halford 1993; Pascal-Leone 1988) suggest that higher-level concepts can be grasped when the integration of the lower-level component concepts is representationally possible. Therefore, to properly teach the concept of energy, the educator should first establish the grasp of the lower-level component concepts at the right age.

Therefore, in preschool, teaching may focus on the activities of the infant, such as pushing or pulling and their results on objects. In primary school, students may reflect on the relations between the observations that give content to the component concepts, such as kinetic energy and energy transfer, with the aim of grasping the informational and representational cohesion that they entail. Subsequently, in early adolescence, students may reflect on the underlying principles that integrate kinetic energy and energy transfer and how they can be expressed into a single construct. At the end, the integrated concept of energy may be reflected from alternative points of view, such as from the point of view of physics, biology, ecosystems, etc. For example, teaching may elaborate on energy in diverse substances, such as oil and food, and the physical and biological mechanisms that can process it, such as engines and digestion and metabolic systems of animals. Obviously, the complexity of concepts and examples must remain within the representational capacity of each age level.

Also, it is to be noted that no individual functions continuously at his or her upper limit of capacity, especially at the initial phases of reaching this capacity or of implementing this capacity in the mastering of a concept or skill. Moreover, not all individuals in a classroom operate at the modal upper limit that is characteristic of the age of interest. In fact, research suggests that there may be systematic differences between the learning possibilities of children within the same classroom because of age differences at school entrance. These differences produce the so-called relative age effect in school performance. Cobley et al. (2009) found that the younger students in a classroom obtain significantly lower grades than their older classmates throughout the curriculum (i.e., science, maths, and physical education) across secondary school grades and gender. In terms of the theory presented here, this effect reflects possible initial differences in children's cognitive ability (also 
possible differences in skills for handling the learning environment) which cause a disadvantage on their part to understand and follow the pace of their older classmates.

Therefore, a general guiding principle for curriculum designers and teachers is as follows: The pacing of teaching (Anderson 1985) of any concept or skill must always start with examples having a cognitive demand that is lower than the optimum capacity of each student in the classroom. Even high-capacity children may operate at a level lower than their optimum when first facing a new concept or skill. Therefore, provided that there is variation across individuals for a given domain and within individuals across domains, the mastering of a concept or skill must be graded along a continuum of examples that range from the lowest necessary to the optimum for each individual student in each domain. Our study summarized above about the relations between learning mathematics and processing efficiency has clearly suggested that when processing efficiency and working memory are weak, guidance is necessary to compensate for the students' weakness to construct the necessary relations themselves. Concerning the relative age effect noted above, special provisions are needed that would enable the teachers to spot younger children in the classroom with possible understanding difficulties and provide them with special support to compensate for their difficulties. A good approach here is to start teaching a given target concept at level L by introducing the lower-level L-1, L-2, etc., component concepts of the target concept. Reviewing a large number of studies, cognitive load researchers have reached the same conclusion (Sweller 1994; Kirschner et al. 2006).

Therefore, each student must be given the opportunity to construct the concept or skill of interest gradually and steadily according to his or her own zone of proximal development and according to his or her own scaffolding needs. This kind of classroom management requires a flexible curriculum that allows individualization of learning in the same classroom so that treatment develops according to the aptitude of different students (Snow 1989). Below, we will focus on the education of the two main loops of understanding.

Educating the problem-solving loop

\section{Educating representational and processing efficiency}

An increasing number of studies tried to improve intelligence by training addressed directly to the various aspects of working memory, attention, and executive control (Buschkuehl and Jaeggi 2010; Jaeggi et al. 2008; Klingberg et al. 2002; Posner and Rothbart 2006; Thorell et al. 2009). This approach was based on the evidence showing that fluid intelligence is largely determined by these processes (Blair 2006; Kyllonen and Christal 1990). In all of these studies, training aimed to improve the ability to (1) monitor ongoing performance, (2) keep track of the flow of information and update it for as long as needed, (3) manage more than one task simultaneously (e.g., by alternating between blocks or types of information, if needed), (4) bind items according to type and time of presentation, and (5) inhibit irrelevant items. Clearly, these studies aimed to improve the quality of representation, management, and integration of information in working memory. Therefore, they directly addressed executive and episodic integration processes. In line with these findings, several studies found that these interventions resulted in improved performance on tests of fluid intelligence, such as the Raven Matrices. There is also evidence that training working memory has a long-lasting positive effect on the general intellectual and school performance of students diagnosed with ADHD (Westerberg 2004). 


\section{Educating mental modeling and conceptual change}

There is a vast literature on conceptual change and how it relates to education (e.g., Carey 1985; Vosniadou 2008). Education is a constant force of conceptual change because it imparts new scientific knowledge about the world that is often in conflict with knowledge coming from personal experience or important others. Therefore, teaching must rectify or displace the personal or lay knowledge available. This is not always easy because this knowledge is functional and supported by the phenomenal aspects of things. The heliocentric model of the world and the model presuming that the earth is flat are classical examples of this knowledge. These models persisted in human history for ages, and they still persist as spontaneous constructions of individual development (Vosniadou and Brewer 1992). Thus, teaching must lead the students to conceive of the new concepts and demonstrate their explanatory and problem-solving advantages relative to the old concepts.

Moreover, learning in schools is additive and takes place over many years. Thus, the very organization of teaching necessitates conceptual change because the concepts constructed at a given grade must be extended or connected with other related concepts that must be constructed at following grades. Also, knowledge changes as a result of new discoveries in science. Therefore, even knowledge presented by the school as proper at one time may be questioned by the school itself at some later time. Finally, knowledge about the same phenomena or realities may differ across different fields. Therefore, the school must develop a mindset for continuous conceptual change in students. This requires tools to represent and learn the new concepts presented in the classroom. Mental modeling is one of the main tools. Here, we will focus on the use of mental models in conceptual change. We will first elaborate on the construction of mental models for the use of the basic operations associated with the various operational domains. Then we will focus on the use of mental models for different knowledge domains and their role in conceptual change.

\section{Mental models for operational domains}

The various SSS involve different systems of operations. Students must acquire model templates for these systems to facilitate their use as knowledge extraction mechanisms. For example, it would be useful for the operation of the categorical system to have a template for classification and categorical relations between concepts, such as logical multiplication or tree diagrams. These models would help the student realize that the properties of objects intersect variably and that concepts are defined by these intersections. Thus, it would be useful to search for these intersections according to the template and fill it in according to the field in question, such as biology, physics, chemistry, etc. Moreover, they should understand that the template would be useful for reflection and elaboration on the relations between the objects and for subsequent recall and use. For example, in the phase of dual representations, preschoolers may be instructed to sort objects into piles according to various properties, such as shape or color, and tag them with names or other symbols. In primary school, they may be instructed to cross-classify according to two or more dimensions and elaborate on the logical relations implied by the classes constructed.

In a similar vein, it would be useful for the understanding of causal relations to have a template for their representation and manipulation. This template would involve the basic relations of causality (i.e., necessary and sufficient, necessary but not sufficient, neither necessary nor sufficient, and incompatible). Moreover, it would have to involve a demonstration of the basic tenet of causal modeling in science that covariation or correlation does not necessarily signify a causal relation. This is all the more important 
because correlation is taken as a sign of causality from very early in infancy (Keil 2011) and is part of everyday misconceptions of causal relations (Vosniadou 2008). A model of these relations would be helpful in directing the student how to manipulate the relations between factors in order to explore them and to interpret the results of experimentation. Moreover, the basic principles of the manipulation of causal relations, such as techniques and methods for the isolation of variables in different contexts and different knowledge domains, may be associated with the template. In primary school, children may be induced to single-factor experiments where one variable is varied along several levels to build a clear understanding of the relation between these variations and different effects. In adolescence, models for multifactor experiments may be taught where control requires matching between variables. Moreover, these models may be integrated with hypotheses and related deductive reasoning schemes.

In the quantitative domain, a model of the mental number line as early as preschool, a model of relations between different versions of mental number line in primary school, or models of different numerical operations would be useful for problem solving in mathematics. Also, models of different types of numbers, such as natural or rational numbers and the symbol systems used to express and operate on them, would be useful for learning mathematics. Finally, models of more complex notions, such as the notion of functions or algebraic relations, should be part of the teaching of mathematics at the end of primary school and in secondary school.

In the spatial domain, models of the three-dimensional space or episodic sequences in space may help represent the objects or relations concerned. It may be noted that training in visualization may be helpful. In clinical psychology, there is a vast literature in the use of mental imagery in cognitive behavior therapy. This literature highlights the techniques that may be used to educate students in constructing and using mental images for the sake of acquiring control of their behavior (Crits-Christoph and Singer 1981). Along this line, mental imagery is extensively used in the coaching of athletes. Visualizing the behavior under training beforehand facilitates performing the behavior as required (Jones and Stuth 1997). Also, the role of mental imagery in creativity and discovery is well known. Einstein's thought experiments about the appearance of objects and relations when we approach the speed of light, Kekule's model of the benzolium, and Watson and Crick's three-dimensional model of the DNA helix are some of the very famous examples of how mental imagery may be used to envisage and better explore the implications of relations between concepts and entities (Finke 1993; Reed 1993).

\section{Conceptual frames and conceptual change}

Students, when encountering new concepts or problems, must specify the broad field of knowledge the concepts or problem belong to (e.g., physics, biology, psychology); the particular domain within a field of knowledge (e.g., gravity or force within physics, evolution or heredity within biology); the type of procedures and operations required (e.g., interpretation, categorization, measurement or estimation, hypothesis testing or explanation); and the special algorithms required (e.g., recall from memory, special sorting actions or special mathematical operations required). They must also specify what they do not know about the concept or problem. They must then try to remove all unknowns by extrapolation from what they know. Extrapolation can initially occur by induction and analogy that generate mental models based on similarities between what is known and what needs to be specified. Constructing mental models about possible interpretations or solutions to problems is important in this process because mental models are the means to go from what is known to what is not 
known. In constructing new mental models, students should understand that they may have to map new knowledge onto extant knowledge by combining, interweaving, or fusing new with old knowledge. Alternatively, their new model may just be a differentiated or refined version of an old model (Demetriou and Raftopoulos 1999; Raftopoulos and Constantinou 2004). The mental models may be visual, verbal, mathematical, or anything else. Of the models generated by induction and analogy, not all are useful or relevant. Redundant, inappropriate, or irrelevant models may be eliminated by deductive reasoning which helps evaluate them on the basis of the constraints of the field or domain accepted as the basis of understanding and problem solving. That is, the models that fit the constraints are lifted to the level of solutions or new concepts and those that do not fit are eliminated.

In this process, metarepresentation comes into play to abstract reasoning patterns and makes them available for future use. Thus, metarepresentation operates on two levels: At a first level, it stabilizes the models selected and encodes them as solutions to be called upon in the future. At a higher level, it lifts the very evaluation process into increasingly more flexible inferential schemes, such as those leading from simple modus ponens reasoning to the flexible reasoning enabling one to deal with fallacies.

Therefore, students must understand that knowledge is generated in the context of social institutions that exist for this purpose. These institutions are to a large extent the products of their time, they may coexist, and they may often provide conflicting answers to the same questions. An example is religion and science. Religion is much older. Science came very late in the history of civilization and is primarily identified by the logic of systematic inquiry and control of knowledge rather than by knowledge as such or belief. However, even in science, disciplines differ in their methods of inquiry, the answers they generate, and the objectivity and precision of the controls they employ to validate knowledge. In Kagan's (2009) terms, humanities, social sciences, and natural sciences are the three cultures of knowledge. Engineering may be added as the realm of technical applications that can be derived from the various disciplines for the sake of particular social, cultural, or economical needs. The arts may be added as a special way of representing and interpreting reality, according to acceptable aesthetic criteria, in order to convey messages with special value for both the artist and society.

Students must understand that knowledge and concepts about the world are constrained by the particularities of the discipline that generated them. Therefore, students must develop mental models and templates appropriate for capturing how disciplines differ in using observation, controlled experiment, logical analysis, and argumentation for the construction of knowledge in their respective fields.

They must also understand how knowledge in each discipline is affected by the political, cultural, and historical contexts in which it was developed. Finally, they must develop a systemic approach that enables them to see each model from the point of view of others. For instance, although causal relations are everywhere the same, causation is expressed differently in physics, biology, human relations, and history. Specifically, in the various knowledge domains, cause-effect relations are expressed on different timescales (e.g., milliseconds in chemical reactions vs. thousands of years in evolution vs. billions of years in astronomy), take place on different levels of reality (e.g., observable reality vs. hidden reality that is not accessible to the senses), they may be masked by different kinds of confounding factors, and they thus require different manipulations to become obvious and established. Mental images have a different role in art (they may symbolize realities only remotely related to the image as such), geometry (analogical to the object of interest), natural science (closely related as representations of the realities of interest), and human interactions (laden with personal meaning and emotions). Quantitative thought is the mental 
background for mathematics, but it may not be equally applicable to express knowledge in physics, economics, psychology, and history. Thus, students must understand that operations in the various domains are expressed differently in different knowledge domains. As a result, their modeling is the same at one level of analysis (i.e., the fundamental causal relations are the same everywhere) but different at another level (i.e., content and form of interactions between factors). Moreover, educating students to translate between symbolic systems may be an excellent means for enabling them to explore the boundaries between domains, similarities and differences between mental operations within and across domains, and generate general inference patterns.

We suggest that the construction of new knowledge and skills and the epistemological awareness that is necessary may well be served if organized around the big ideas that were elaborated in different disciplines through the years. For example, ideas such as gravity, energy, or force in physics, evolution, heredity, or homeostasis in biology, or intelligence, motivation, or consciousness in psychology are good examples of ideas that can be developed in the curriculum. Each of these ideas may be presented from several perspectives. For example, they may be presented along a dimension that varies from their relevance to personal experience and everyday life to abstract models about underlying general laws that are remote from personal experience and everyday life. The historical perspective is also important. Explicating how an idea was conceived in different phases in the history of a discipline may enable students to realize that the same phenomenon may be differently understood over time as knowledge is tested and refined. Finally, the same idea may be discussed from the point of view of different disciplines. This would highlight both the differences between disciplines in their knowledge production mechanisms and also the multiplicity of representations that may exist for the same aspect of the world. The reader is reminded of the example of motion explicated above. Linn and Eylon's (2011) knowledge integration model for science teaching (i.e., building on personal knowledge and ideas, using evidence to distinguish between alternatives, reflecting on alternative accounts of scientific phenomena) is fully compatible with our theory. As Smith (2009) has noted, this approach brings back Piaget's epistemological orientation to knowledge construction as a guiding frame for educational science and practice.

The systemic approach advanced here requires a multidimensional representation of concepts that would enable the student to see how different elements or processes of the phenomenon concerned depend on and affect each other. For example, representing (1) the structure (e.g., what does it consists of, such as the wings of birds or airplanes); (2) the function (what is it for, such as for motion); and (3) the process (how does it operate, such as the flying movements of the birds or propulsion by the spinning of propellers or air emission of jet engines) of the phenomenon of interest enables students to grasp the relations both within and across concepts and disciplines and, when working on a problem, plan actions accordingly. Interestingly, several scholars proposed variants of these schemes as a means for guiding learning and problem solving in fields as different as engineering (Kalyuga et al. 2010) and biology (Hmelo-Silver and Pfeffer 2004). Kalyuga and Hanham (2011) have recently shown that a hierarchical exposition of how systems operate is more effective in producing learning and transfer. This is a general-to-detail instructional sequence where general ideas are presented first for each of the three aspects of the tripartite structure and are gradually differentiated into their specifics. However, it needs to be noted here that the effectiveness of the general-to-detail or the specific-to-general sequence may differ according to developmental level and expertise (Ericsson and Lehmann 1996). 


\section{Educating inference and reasoning}

We suggested above that development and learning within each of the domains does not automatically or necessarily generalize to the other domains. At the same time, the domains provide the background material for the activation and operation of metarepresentational processes that generate general reasoning patterns and problem-solving strategies that generalize beyond the domains. It is important for education to capitalize on these processes and direct the students to swing between the domain-specific and the domain-general operation as efficiently and profitably as possible. Below, we outline the framework that may be conducive to the attainment of this goal.

Education is directly or indirectly a process that gradually transforms automatic reasoning into controlled reasoning (Nisbett 2009; Olson 2003). However, this process can also be systematically educated. The theory and research discussed here suggest that the systematic education of reasoning should be directed to attain the following goals: (1) decontextualize inference; (2) differentiate between inferential processes and logical forms, such as inductive, analogical, and deductive reasoning; (3) make use of mental models for the sake of inference and reasoning; and (4) make use of metarepresentation to elevate reasoning from the handling of possibilities based on mental models to the mastering of the underlying logical relations and the implications of inference. This is an important educational goal because critical thinking would remain incomplete and impaired if the evaluation of information and arguments would be incomplete due to flaws in the analysis of their logical status and cohesion. Inductive and deductive reasoning may be the focus of teaching. Here, we will focus on deductive reasoning.

Deductive reasoning develops from a state where everything but content is implicit to a state where all crucial processes gradually become explicit (see above). Following the scheme outlined above, decontextualization of deductive reasoning would have to lead children to see the logical form of an argument beneath the content. An example is given below:

\begin{tabular}{lllll}
\hline & $\begin{array}{l}\text { Birds fly. } \\
\text { Sparrows are birds. }\end{array}$ & $\begin{array}{l}\text { Birds fly. } \\
\text { Ostriches are birds. }\end{array}$ & $\begin{array}{l}\text { Birds fly. } \\
\text { Elephants are birds. }\end{array}$ & $\begin{array}{l}\text { Bs do x. } \\
\text { As are Bs. }\end{array}$ \\
\cline { 2 - 4 } & Sparrows fly. & Ostriches fly. & Elephants fly. & As do x. \\
\hline
\end{tabular}

In this example, all four arguments are valid. However, in the first argument, both the premises and the conclusion are true. In the second argument, the premises are true but the conclusion is false. In the third argument, the second premise and the conclusion are false. Finally, the formal structure of the argument is shown.

At preschool, children may be led to realize that the information in the premises is connected by inference. Actual models of the organisms involved and visual representations of the line of inference going from the one to the other are obviously useful. At primary school, directed comparisons across the various arguments would enable children to differentiate form from content and understand that logic constrains inference. That is, when children understand that the conclusion "elephants fly" necessarily follows from the premises, given that we accept that "elephants are birds" and that "birds fly," they already know that logical structure underlies inference and that content is irrelevant for the conclusion. For this to be possible, children must focus on the logical form of each sentence as given in the argument and ignore any other previous knowledge or information related to the meaning of the words in the sentences. Also, they must understand that in order to grasp 
the logical relationships implied by a logical argument, they need to break down or analyze the argument into the premises involved and focus on their logical or formal relationships independent of content. The formal relationships implied by the premises in an argument are normally hinted at or suggested by particular words of natural language, such as class indicators "is," "are," "and," the conditionals "if ... then", the disjunctives "either ... or," etc.

In adolescence, the main aim of education would be to make metalogic explicit so that the adolescent understands that logic constrains the relations between statements and possible mental models and logical relations are specifiable through systematic search of an argument's space. Thus, instruction should explicate what mental models follow from different types of relations and how all models implementing the possibilities associated with a particular relation are expressed by the relevant logical principle. For example, the simple modus ponens argument "if $p$ then q," combined to other premises, implies the following possibilities and truth functions: "if $p$ then q" and "p," then the conclusion " $p$ and q" is compatible and true; "if $p$ then q" and "not $p$," then the conclusion "not p and not q" is compatible and true; "if $\mathrm{p}$ then q" and "not p," then the conclusion "not $\mathrm{p}$ and q" is incompatible and indeterminate; and "if $p$ then q" and " $p$," then the conclusion " $p$ and not q" is incompatible and false. In this way, controlled reasoning is gradually extracted and consolidated from automatic reasoning.

In our laboratory, Christoforides (2010) has shown that this approach is very successful in raising the reasoning capabilities of primary school children. Specifically, third and sixth grade children were systematically instructed to do the following: (1) interpret the premises analytically and differentiate them from the conclusion; (2) differentiate between necessary and likely conclusions; (3) spot contradictions between premises and conclusions and construct alternative models for premises and conclusions; and (4) recognize logical necessity and logical sufficiency. Although all children were able to profit from this program and become able to successfully deal with fallacies, children with higher working memory profited more. Moreover, children that were able to describe the logical similarities of arguments were also in advantage to gain from the program. Therefore, both processing efficiency and metacognitive awareness are conducive to educating logical reasoning.

Kuhn $(1991,2009)$ suggested that there are several skills that would be very important for sound reasoning in addition to decontextualization. Specifically, resisting certainty about conclusions, withholding judgment until examining all relations involved, and awareness that one's own personal biases may influence judgment are important because they enable the thinker to be exhaustive, objective, and systematic. Finally, it is important to note that reasoning is a means in the service of information exchange and evaluation in human communication (Mercier and Sperber 2011). Therefore, education for reasoning must be associated with education for argumentation from multiple perspectives (Kuhn 1991).

\section{Wrapping it up: education for problem solving}

The discussion above focused on the education of the various systems involved in the problem-solving loop. Here, we focus on the education of the loop as such. Problems may vary enormously in complexity, in required systems, and in aim. Moreover, the priorities and type of problems that are of concern to individuals vary extensively with development. For example, in infancy, tool use, such as eating tools, or building behavioral skills is important. In youth, life choices, such as choosing what to study, accepting a job offer, or getting married, are important. Later on, designing a new product, advancing theory in a particular discipline, or making a political decision that would lead a country out of a crisis 
may be important. In all phases, however, problem solving shares common elements that may be educated.

Specifically, problems require a clear conception of the final goal. Also, they require the formation of a solution plan that entails the specification of a sequence of steps until reaching the goal. Thus, education for problem solving must enable the individual to realize the value of withholding action until formulating an action plan. Tool use, such as using a spoon for eating, is useful for educating infants to understand how different actions (e.g., different ways of holding the spoon) may influence attainment of the final goal (food in the mouth). Constructions that require replicating a model, such as building a tower, are useful for showing the value of planning and the importance of sequencing steps in the proper order (Keen 2011). Later on, in primary school, problems requiring to transform one state into another, such as the Tower of Hanoi (Fireman 1996) or the Tower of London (Albert and Steinberg 2011), are good examples.

Planning may also profit from working on problems with multiple solutions or impossible problems. Specifically, working on problems which have multiple solutions enables children to shift between different ways of representing the final goal (the outcome space of the problem) and different methods for reaching the goal (the methods space). Tsamir et al. (2010) showed that even kindergarten children can be educated to conceive of multiple solutions in simple mathematical problems (e.g., imagining alternative ways of equally distributing a set of objects in two equal subsets). Stein and Burchartz (2009) presented a series of impossible geometrical puzzles of increasing complexity. These problems force students to consider alternative goals or alternative solution plans, evaluate them against each other, and establish logically the relations between alternative solutions or the impossibility of reaching a solution.

In secondary school, students must learn that problem solving in real life often involves hierarchies of problems that are embedded in each other so that a major or a final aim may be achieved (Jonassen 2000, 2003). For example, a strategic problem (e.g., reduce pollution in an area) may require solving a series of complex understanding problems (e.g., about air circulation, energy transfer, etc.), and each of these may require solving domain-specific reasoning problems (e.g., causality relations, mathematical estimations of relations, categorization of effects, etc.). Once solved, the problem may be transformed into a policy problem (e.g., how to change customs and behaviors in the society) and a story problem (e.g., how to convey the message about these changes). The students must be given the opportunity to think on and assemble complex hierarchical problems where hierarchies are embedded into each other. Working on problems of this kind may enable students to differentiate between the various cognitive systems and processes activated in problem solving (e.g., representing goal stacks, building relevant mental models, calling upon knowledge from memory or books, evaluating models and knowledge by reasoning, choosing between solutions, etc.).

Educating the self-awareness loop

Learning to learn requires awareness and control of the learning process so that it takes place at the right pace, it is geared on the demands of the task at hand, it can bypass possible processing and representational limitations by properly arranging the material to be learned, it judiciously uses relevant prior knowledge to enhance new learning, and it ensures that learning will endure. Therefore, at a basic level, learning to learn requires understanding of the role of the fundamental knowledge extraction and processing mechanisms. Namely, that control of attention is crucial for intake of relevant information, that rehearsal and association are crucial to establish the necessary connections and protect 
information from forgetting, and that self-testing is important to check if learning did occur. Learning to learn also requires an awareness of motivational and personality dispositions which are related to learning and relevant self-regulation skills that would maximize support and minimize hindrance to learning. Below, we will elaborate on interventions directed to improve knowing one's own mind and to the use of assessment for the sake of learning to learn.

\section{Learning to learn: knowing one's own mind and dispositions}

Learning to learn may be enhanced if students understand the organization and functioning of the mind. This would enable students to differentiate the handling of information coming from different systems. For example, mental images are more easily represented and preserved in working memory than abstract expressions in mathematics (Rasmussen and Bisanz 2005). Therefore, more rehearsal may be needed to process and remember mathematical representations as compared with mental images. Moreover, if students understand that all domains deliver their representations to a common limited representational space, they may become able to notice factors in the target concept, such as the organization or quantity of information, that cause difficulties in its representation and processing. For instance, realizing that working on too many relations at a time may jeopardize understanding might enable the student, if necessary, to reorganize and re-chunk information so that relations are gradually constructed within the range of one's own representational and processing capacity. Moreover, if students have an accurate selfrepresentation of their own strengths and weaknesses in concern to different domains, they may be able to differentiate their strategies for handling learning according to domain. For example, being strong or expert in a domain allows for faster processing of larger chunks of information than in domains where one is weak, which would require slower processing and more rehearsal (Gobet 1998).

Education for learning to learn should be adapted to the needs of different developmental phases. Infants are not explicitly aware of learning and mental processing. Therefore, educating learning to learn in infancy can only be indirect, aiming to make the infant realize that different approaches to solving a problem may lead to different information. For example, leading the infant to compare alternative ways of using a particular tool, such as a key, may show her that each way has a different implication, such as hindering or opening access to a different view or different objects. Imitation may be a powerful means for learning to learn at this phase. For instance, comparing one's own and an adult's way of using a tool and then imitating the adult may raise the infant's awareness of her own behavior and enhance self-monitoring and self-regulation as such.

Preschoolers have a limited representational capacity, a limited understanding of representation as a means for bypassing representational capacity limitations, and a limited command of representational aids, such as writing and note taking. This makes the learning of complex tasks at this phase of life very difficult. Some of the difficulties may be ameliorated if the children are aware that using representational aids may compensate for the other difficulties. For example, when working on a task with multiple solutions (e.g., Tsamir et al. 2010), preschoolers may be instructed to use scripts (e.g., specific signs on a paper) or real objects as tokens of the solutions generated up to a point. This approach, in addition to facilitating learning and problem solving as such, enables children to know the advantages and limitations of representation as a mental modeling function. Also, it brings to focus metarepresentation as the representation (e.g., the signs or token objects used) of representations (each solution) that can 
help one handle the difficulties of the problem-solving or the learning process. Obviously, this approach is useful for later phases as well.

In line with the approach above, Zelazo (2011) suggests that mindfulness training from preschool years enhances self-monitoring skills which in turn enhance executive control thereby improving learning. Mindfulness training at this age would involve raising awareness of self by systematically shifting attention to different sensory experiences, such as visual and auditory, and examining how they affect thought. For example, when a child looks at apples she thinks about apples and when she looks at pears she thinks about pears; however, when thinking about the mother while looking at apples, she may not "see" changes in the number of apples and thought may alternate between the mother and the apples. Flook et al. (2010) showed that training of this kind improves self-regulation and executive control significantly, especially in children who are not strong in this regard.

Primary school children still do not clearly differentiate between cognitive functions, nor do they understand the learning effects of different cognitive functions or activities. For instance, at this age, they may be deceived that what is in their eyes is also in their mind. Likewise, they may be deceived that what is in short-term-memory is also in long-term memory. That is, they think that they will remember something later on and be able to recall it simply because they understand it when it is in front of them or when they have just formulated a representation of it (Flavell et al. 1995, 1997). It is to be noted that these weaknesses coincide with the years of primary school that is a period of intensive formal learning of new concepts and skills, such as reading, writing, arithmetic, science, etc.

Therefore, at primary school, education must focus on building awareness of the differences between mental functions and of their differential impact on learning. Moreover, it must focus on bridging activities with different mental functions and aspects of learning. For instance, children must realize that recall of information from memory and its connection with what is in front of their eyes facilitates understanding of new information. In turn, they must realize through practice that rehearsal facilitates storage of new information in long-term memory for later use and that this may be tested by asking questions to themselves (Dehn 2008). Building associations and relating new with prior knowledge helps learning, but variation and differentiation helps originality in problem solving (Glassner and Schwarz 2007; Siegler 1996; Simonton 2000).

In adolescence, self-awareness gradually becomes process-driven and executive inhibition is intertwined with the suppositional stance associated with conditional representations. This allows problem solving to become planful and systematic. Moreover, the self-concept becomes dimensionalized and generally accurate. By middle adolescence, students start to differentiate between the cognitive processes involved in different kinds of knowledge and activities, such as mathematics vs. physics, they know where they are strong at and where they are weak at, and they can plan their problem-solving activities from the start so that they can seek information when and where it is needed and integrate it into their current problem-solving endeavors (Demetriou 2000; Demetriou and Kazi 2001, 2006).

Education for learning to learn at this phase should focus on awareness of the differences between cognitive domains in the mental processes they involve and in how they relate to their world domains. That is, the individual should be able to recognize and understand the formal relations between constructs, in the first case, and evaluate the consistency between a model and reality, in the second case. For example, they may be guided to grasp the differences between formal disciplines, such as mathematics, and empirical disciplines, such as physics, in knowledge construction. Therefore, planning requires different approaches in the two cases. In the first case, it requires exhaustive search of the logical relations between premises and presuppositions. In the second case, it requires a conception 
of the world as suggested by a model, the specification of the steps needed to produce crucial evidence, and the realization of these steps through the necessary actions.

Finally, students must understand that it is better for future performance and learning to metarepresent the processes activated or the solutions reached. On the one hand, science is a vast universe of representations about the world and metarepresentations specifying what the representations mean, why, how, and when they may be changed (van Fraassen 2010). On the other hand, classrooms are representational and metarepresentational laboratories. One of the aims of education is to gradually bring the representational and metarepresentational systems of the individual as close as possible to the representational and metarerepresentational systems of science. This is a double-faced process. On the one hand, inducing students to the representational and metarepresentational nature of science facilitates domain-specific learning. For example, Nesher and Sukenik (1991) showed that the learning of mathematical relations (i.e., ratios and proportions) is most enhanced when the learning experiences provided in the experiment were paired with relevant formal representations. These representations enabled the subjects to summarize and manipulate their learning experiences. On the other hand, it enhances the development and flexibility of general patterns of thought and the development of a general modeling ability that is associated with a general LOT because it enables students to work out the relations between different representational systems and metarepresent them (diSessa 2004; Yerushalmy 1997). In Carey's (2009) terms, newly acquired symbols function as placeholders which are gradually filled in with meaning through the mechanisms discussed above. To support metarepresentation and facilitate the emergence of general problem-solving strategies and reasoning patterns from domain-specific learning, teaching must continually raise awareness in students of what may be abstracted from any particular domain-specific learning. Moreover, students must be facilitated to map representations from different domains onto each other and tag new constructs with new representations that will enable them to mentally recall, manipulate, and relate the new representations with others already in existence (Dixon et al. 2010).

\section{Assessment for learning and learning to learn}

Assessment in education is crucial for learning because it informs the learner for possible divergences between learning goals and outcomes. It is beyond the aims of the present article to embark on the vast literature on assessment in education. It is to be noted, however, that theories of cognitive development are recognized as potentially useful frames for the development of assessment methods that would be valuable for learning and instruction. Unfortunately, however, very few attempts have been made to highlight how cognitive development theory and research can inform educational assessment (Ercikan 2006). The model of mind proposed here offers a full framework for assessment that would be very useful for learning in the school.

Here, we try to show how assessment in education can facilitate students to (1) enhance their knowledge of their own mind; (2) sharpen their self-monitoring, self-representation, and self-regulation skills; and (3) make them aware of their strengths and weakness in the various components of the mind and the different domains of knowledge. These provisions are in line with the aims of formative assessment or assessment for learning, which aims to make students owners of their own learning (Black and Wiliam 2009). In terms of the present theory, assessment must first of all enable the students to recognize the sources of difficulty in understanding a concept or solving a problem and assist them in developing strategies for overcoming them. The ultimate aim is to make assessment a powerful tool of metarepresentation. 
Difficulty may arise from any component of the architecture of mind proposed here. For example, students evaluate or tag problems or concepts as difficult if they cannot make sense of them in reference to prior relevant knowledge. Difficulty also arises from conflicts or inconsistencies between the concepts to be learned and those already possessed. Assessment here must highlight what is lacking and direct the student to search for necessary knowledge and use it for the sake of the problem at hand. Search must be both self-directed (Do I know something similar? Have I solved problems like this in the past?) and directed to external sources of knowledge (asking others, searching for similar problems in books or others sources, etc.). In the case of conflict or inconsistency between concepts, assessment must direct the student to notice the superiority of the new concepts to explicate the phenomena of interest. For example, why is the heliocentric model of our planetary system superior to the geocentric model.

Problems are also difficult for students if the amount or the presentation rate of information exceeds the available representational or processing resources. Assessment here must make the students sensitive to their representational and processing limitations. Exposing the students to a range of concepts or problems of varying complexity or presentation rate in order to make them sense the "personal point of command" can serve this purpose. This kind of assessment must be associated with instruction directed to build the necessary skills for bringing the problem back to the personal point of command. These skills are related to the building of the executive processes mentioned above (Brown 1987).

A third source of difficulty resides in the inferential processes themselves. That is, if the concept or problem to be dealt with involves relations that require inferential schemes that are not available, such as dealing with the fallacies, the crucial relations will not be worked out. Assessment here must highlight the inferential schemes missing and practice the student in their use.

Finally, difficulty and limited success in learning may come from inaccurate selfevaluation of performance. As shown above, self-evaluation of problem solving is moderated by a personal constant that is characteristic of the individual and is stable through the years. When inaccurate, self-evaluation may cause students to abandon a learning task because it is judged too difficult or terminate an attempt because it is unjustifiably judged to be successful. Inaccurate self-evaluations may even deceive the teachers themselves, thereby hindering them to provide to the student the assistance needed for a learning task. Therefore, assessment for learning to learn must help the students calibrate, so to speak, their personal constant to their actual ability and performance in a given domain. This calibration would require tasks where the students are asked to evaluate their performance and compare their evaluations with the evaluations of their teachers and other students (Harter 1999). The aim would be twofold in this regard. On the one hand, the students must acquire awareness of their overall self-evaluation trends: i.e., if they tend to be lenient, strict, or accurate. This awareness should include the cognitive (e.g., impulsivity and limited planning, limited or inappropriate mental modeling for solutions, lack of domain-specific criteria or standards for what is right and wrong, etc.) and motivational and emotional aspects of selfevaluation (e.g., fear of failure and criticism, anxiety, avoidance, etc.). On the other hand, students should acquire the self-monitoring and self-regulation skills that would improve the accuracy of their self-evaluations. The suggestions advanced above about educating the various aspects of problem solving and critical thinking are relevant here. Understanding the long-term value of self-evaluation for social standing and emotional stability must be part of education for accurate self-evaluation. 
Critical thinking, epistemological awareness, and creativity

Critical thinking has been a privileged topic of discussions in pedagogy and philosophy of education since a long time ago (Ennis 1962, 1996; Siegel 1988, 1989a, b). The main line of argument is that the development of critical thinking must be one of the main aims of education. Definitions vary, but there is consensus that critical thinking involves inference, recognition of assumptions, deduction, interpretation, and evaluation of arguments. Critical thinkers exhibit open-mindedness, tolerance of ambiguity, and a skeptical, questioning attitude (Bernard et al. 2008). Moreover, critical thinking includes the ability to (1) identify central issues and assumptions; (2) envisage alternative models; (3) associate each model with its own supportive evidence and logical substantiation; (4) embed each model into its own conceptual or belief system; (5) identify logical flaws in arguments, descriptions, or explications; and (6) adopt an informed preference based on evidence or argumentation (e.g., Ennis 1987; Furedy and Furedy 1985; Pascarella and Terenzin 2005; Watson and Glaser 1980).

From the point of view of the present theory, conceptual change, reasoning development, learning to learn, and critical thinking are complementary aspects of cognitive development and learning. Specifically, the very process of constructing and evaluating mental models for the sake of grasping target concepts and problem-solving skills may become a powerful field for the development of critical thinking. Envisaging, comparing, substantiating, debating, and choosing among alternative models, if properly directed, may enhance awareness of the role of evidence and logical and conceptual substantiation for alternative models. Siegel (1989a) suggests that for this to be possible, critical thinking must be embedded in a context of epistemological understanding. This is so because critical thinking presupposes particular answers to important epistemological questions (e.g., what is truth, what is evidence, what is reason or cause, what is more important, reason or evidence etc.). These questions are systematically answered in the context of different fields of knowledge, and thus the thinker can be critical if she is aware of the answers given to these questions so that she knows how and where to frame her analysis and arguments. Thus, epistemology is basic both to critical thinking and to its pedagogy. Understanding of the fundamental epistemological assumptions of the three main realms of human knowledge - that is, natural sciences, social sciences, and humanities-becomes a condition for critical thinking.

Educating for critical thinking must take into account the strengths and weakness of successive developmental phases. Thus, we propose that teaching for critical thinking must proceed by capitalizing on the worldview that is prevailing during each developmental milestone. The ultimate aim would be to enable the developing person to realize the knowledge, understanding, and decision-making limitations of each phase and gradually build up a comprehensive approach to knowledge acquisition and problem solving where information processing is a means to the end of understanding, reasoning is a tool for evaluation and analysis, and rationality is integrative judgment that bridges multiple frames and points of view (Jacobs and Klaczynski 2002).

In preschool, children must overcome the absolutist stance of this age phase that knowledge is either right or wrong. An example would be to make them realize that the knowledge of all three different children about an object (e.g., that it is red, and green, and blue) is right, depending on each child's perspective (i.e., because each of the three sides of the object is differently colored). In primary school, children must realize that the representations associated with each perspective are integrated by inference which gives them coherence and logicality, given the initial assumptions. Moreover, they must be 
gradually introduced to an epistemological approach to knowledge that would allow them to understand that the knowledge generated by different knowledge extraction mechanisms, such as observation and experiment, may differ in accuracy and validity, depending upon how well confounding factors are controlled by each. The adolescent and the college student must recognize that alternative approaches to knowledge, such as the three major realms of knowledge, or different epistemological traditions about knowledge, such as realism and relativism, may be equally acceptable depending upon the person's original stance to knowledge. For example, one is a realist if one believes, as scientists do, that there is truth about the world which can be approached through appropriate scientific methods. Distance from truth is only a matter of appropriateness and precision of methods and ingenuity of controls, which they improve with accretion of knowledge in time. One is a relativist if one believes that there is no single truth about a phenomenon and knowledge is a function of approach, perspective, or conviction. Adolescents must gradually become familiar with the fact that one's epistemological stance defines one's interpretation and even handling of knowledge (Chandler et al. 2002; Wildenger et al. 2010). Moreover, critical thinking includes the skills necessary for the students to know themselves so that they orient themselves to the directions that are most suitable not only to them but also for their group. Critical thinkers are the citizens who can make choices for their own benefit and the benefit of society. Obviously, nothing can compensate for actual experience, but studying cases and alternative scenarios might be helpful in increasing awareness about the value of logic, knowledge, experience, and learning for wise and useful decision making.

Creativity is a fast developing area of research and educational practice (Runco and Pritzker 1999; Sternberg 1999, 2005), which is not the focus of this essay. It needs to be briefly associated, however, with the present theory. From our point of view, creativity comes at the intersection of the problem-solving and the self-awareness and self-control loops and requires critical thought as a tool. Specifically, creativity is an approach to problem solving that systematically aims for solutions that are different from and/or better than earlier ones. This requires that problem-solving goals are contrastively specified in reference to earlier solutions so that a new solution integrates additive advantages or differences relative to earlier ones. In turn, this requires embedding problem solving in (1) a social and cultural context, where solutions are evaluated for their use and usefulness, and (2) a historical and epistemological context where advantages and disadvantages of solutions are specified relative to the historical, social, cognitive, and technical constrains related to their production.

Under this perspective, education for creativity is a long-term process that co-extends with the course of development described here. In infancy, education must enable the infant to see that alternative solutions to a problem may differ in their usefulness and completeness relative particular needs. In primary education, education may start focusing on the planning process of problem solving in order to enable the child to see that variations in the specification of the goal and the relative mental modeling required to plan solutions may lead to different solutions. That is, education for creativity must be an integral part of the education of problem solving as described above. In adolescence, in addition to refining problem-solving processes as above, education must familiarize the adolescent with how creativity may be practiced in different fields. That is, that in addition to the common processes that are required for creative accomplishments, different fields may have different standards or criteria for what is a creative solution or idea. In college, education should enable the students to relate their creative endeavors with the value and relevance of solutions vis-à-vis their historical, cultural, social, economic, technological, and disciplinary contexts. Finally, education for creativity must enable the person to value cooperation with 
other persons as conducive for creativity and aesthetic criteria as important for the quality and acceptance for the solutions to be produced.

\section{Conclusions}

We attempted to show that an educationally useful theory of the developing mind is possible. This theory integrates constructs from developmental, cognitive, and differential psychology. The main postulates of the theory can be summarized as follows:

There are general mechanisms of intelligence. These include general processing efficiency functions that enable humans to represent and process information, general inferential process underlying processing, and self-awareness, self-regulation, and reflection, directing and transforming processing. General mechanisms and possibilities coexist with, and are expressed through, a number of specialized domains of thought that capture different types of relations in the environment. Mental operations in the domains are knowledge extraction mechanisms whose products intermingle to generate knowledge domains, as we know them in the history of culture, science, and education.

These functions change with age, and their changes are reflected in changes in the quality of understanding and problem solving. In turn, these qualitative changes are expressed through particular world views that define a series of developmental milestones and are associated with an increasingly expanding language of thought. With age, there is a gradual shift of importance from knowledge representation and handling mechanisms to knowledge as such.

Individual differences in the state of the general efficiency factors and the condition of the domains cause differences in the rate of intellectual development both within and across individuals. Differences across individuals are reflected in psychometric measures of cognitive ability, such as the IQ tests. Moreover, these differences may come from differences in the predispositions or facility of different persons in the various domains. Differences in experience in different domains may be related to both intra- and inter-individual differences in performance and developmental rate.

Education can capitalize on this model. The main implications can be summarized as follows:

At any phase, education must lead the student to develop and refine the following cognitive skills: focus on relevant information; scan, compare, and choose according to goal; ignore irrelevant information; represent what is chosen and associate with extant knowledge; bind into models and rehearse if necessary; evaluate models in reference to evidence; reason by deduction to evaluate truth and validity of models and conclusions; prefer solutions that are better or nicer than extant solutions; estimate consistency with beliefs, extant theories, dominant views, etc; and encode, symbolize, and embed into the system. Being aware of epistemological issues concerning the similarities and differences between disciplines is an important part of education for critical thinking and creative thinking.

These general educational goals must be tuned to the developmental possibilities and constraints of successive developmental phases. The general rules that may govern this tuning are as follows: (1) Educational priorities must capitalize on developmental milestones to make education feel relevant, appropriate, and useful for each phase of life. (2) Organization and presentation rate of material to be learned must take representational capacity and processing efficiency into account in order to make learning possible and powerful at every phase. (3) Education must practice, consolidate, and build models for core and mental operators in each SSS because they function as knowledge extraction 
mechanisms; their efficiency influences the quality of information that is generated and fed into the system. With age, emphasis should shift from educating mental operations to knowledge as such. Students must be induced into theme- or concept-appropriate models of the fields of interest, such as gravity, inheritance, motion, etc. Teaching must lead the students to understand where and why these models are better than their own respective concepts or models. (4) In the process, special attention should be given to the lifting of inference from automatic (system 1) to analytic (system 2) functioning. Decontextualization of inference from content and context is important in this process. (5) Problem solving involves all of the processes above, and it should be demonstrated and practiced as such. Students must be educated in foresight, anticipation, and formulation of alternative plans for problems. Moreover, with age, knowledge and context are increasingly important for successful, acceptable, and creative problem solving. (6) Finally, students must know themselves: the organization and functioning of their own mind, their own strengths and weakness, and how to adjust their actions and learning accordingly.

One might object that our approach to education devolves into a readiness notion where nothing is taught on a subject until the mind is "ready" and that nothing is done to facilitate or accelerate development. In Piaget's (1980) words, this is "the American question." For one thing, in developmental terms, consolidating the constructions of each phase facilitates the earlier transition to the next phase. In psychometric terms, this approach augments $g$. Therefore, it makes learning self-expansive by definition. For another, our approach is person-centered in the sense that it supports the weaker students to build the capacities they are weak on and opens the way for the stronger students to capitalize on their strengths and move faster in the construction of new knowledge and skills.

It may be noted here that the gap in academic achievement that is observed in many countries between privileged and underprivileged children, such as the Black-White gap in the USA (Sackett et al. 2001), can be associated with lack of school readiness upon entry to school. Moreover, relative age effects are ubiquitous. They exist in every classroom and every grade. These influence the rate of learning in future grades, causing the gap to become increasingly bigger (Hunt 2011). Therefore, education designed on the basis of the principles proposed here may protect children, especially those at risk, from the problems they face later on when learning becomes more demanding. As it builds up, it frees students from their weakness because it strengthens intelligence as much as knowledge and learning.

The so-called Flynn effect is the systematic increase in intelligence test scores over the last century. Flynn (2009) ascribed this increase to two main factors. The increasing pressure for abstract thought that is required by our increasingly symbolic technological environment and the increasing expansion of education. This is fully compatible with the present theory: These changes in human culture affect, unsystematically, the two main loops of intellectual functioning described here which underlie performance on intelligence tests. At the same time, we predict that systematizing education according to the theory presented here will further accelerate the Flynn effect.

Concerning general issues about educational policies and orientations, the model suggests that plain constructivism, which dominated in discussions about educational priorities since the $1980 \mathrm{~s}$, is not enough for efficient education. In addition to self-directed activity and discovery, guided abstraction, representation, and meterepresentation are very important for stable learning and learning transfer. Epistemological awareness and understanding of social and historical relevance of knowledge and knowledge production mechanisms are very important for the proper and constructive functioning of the student as a citizen. Therefore, education must induce the student into the origins, nuances, and possible effects of the historical, cultural, social, and disciplinary frames of knowledge. 
Teachers operate in a vast field of intra- and inter-individual differences. Therefore, curriculum, instruction methods, and moment-to-moment teaching must adapt to different students and to different subject matters. It is reminded that students who are weak in processing efficiency need more help and support to learn. The implications of this suggest the development and use of appropriate diagnostic tools and the continuous and effective education of the teachers. After all, democratic education must lead each student as close as possible to his or her potential across the board at successive developmental phases.

It is obvious that the realization of the educational implications of the theory discussed here requires extensive changes in a number of domains that are relevant but distinct from education as such. First, it requires the development of new curricula and teaching content in different school subjects that would match the priorities and goals discussed here, from preschool to senior high school and college. Obviously, this requires the support of policymaking officials, including governments, academic bodies, and educational administrators. Second, the education of the teachers themselves is very important. Teachers must understand the processes and dynamics of mental processing, development, learning, and intra- and inter-individual differences in all of these aspects of the mind in the same way that medical doctors understand the processes and the dynamics of human body, its chemistry and genetics, and its change over time. Therefore, programs of study at the university must be organized so that the relevant knowledge and skills are available to the teacher upon graduation. Finally, the advantages of modern technology, including computer, virtual reality, and Internet technology, must be fully employed and incorporated in the learning procedure. For instance, modern computers and virtual reality systems may enable students to have access to and study the complex phenomena that go beyond direct experience, such as the structure of matter, the DNA, or the Universe, that go much beyond anything that the educational technology of the near past could support. This technology can also be used to practice practically every skill and ability discussed here. Learning scientists, computer scientists, teachers, subjects specialists, and industry should cooperate to transform these possibilities into special learning environments.

Obviously, we have a long way to go until the vision of education drawn here becomes a reality in all of its elements. We hope that this essay will open a constructive discussion that will lead us close.

Acknowledgments Special thanks are due to the following colleagues for reading and commenting upon the ideas advanced in an earlier version of this paper: Lorin Anderson, Erik De Corte, David Olson, Howard Gardner, Jarkko Hautamaki, Earl Hunt, Karin Bakracevic, Mary Koutselini, David Moshman, Willis Overton, Robert Ricco, Gabi Salomon, Michael Shayer, Leslie Smith, Timos Papadopoulos, Stella Vosniadou, and two anonymous reviewers.

Open Access This article is distributed under the terms of the Creative Commons Attribution Noncommercial License which permits any noncommercial use, distribution, and reproduction in any medium, provided the original author(s) and source are credited.

\section{References}

Ackerman, P. L. (1996). A theory of adult intellectual development: Personality, interests, and knowledge. Intelligence, 22, 227-257.

Ackerman, P. L. (2000). Domain-specific knowledge as the "dark matter" of adult intelligence: Gf/Gc, personality, and interests correlates. Journal of Gerontology: Psychological Sciences, 55B, 69-84. 
Albert, D., \& Steinberg, L. (2011). Age differences in strategic planning as indexed by the Tower of London. Child Development, $X X, 1-17$.

Anderson, L. W. (1985). Time and timing. In C. W. Fisher \& D. C. Berliner (Eds.), Perspectives on instructional time (pp. 157-168). London: Longman.

Anderson, L. W., Krathwohl, D. R., Airasian, P. W., Cruikshank, K. A., Mayer, R. E., Pintrich, P. R., et al. (2001). A taxonomy for learning, teaching, and assessing: A revision of Bloom's taxonomy of educational objectives. New York: Longman.

Artman, L., Cahan, S., \& Avni-Babad, D. (2006). Age, schooling and conditional reasoning. Cognitive Development, 21, 131-145.

Baars, B. J. (2002). The conscious access hypothesis: Origins and recent evidence. Trends in Cognitive Sciences, 6, 47-52.

Baars, B. J., \& Franklin, S. (2003). How conscious experience and working memory interact. Trends in Cognitive Sciences, 7, 166-172.

Baddeley, A. D. (1990). Human memory: Theory and practice. Hillsdale: Lawrence Erlbaum.

Baddeley, A. D. (2000). The episodic buffer: A new component of working memory? Trends in Cognitive Sciences, 4, 417-423.

Baltes, P. B., \& Staudinger, U. M. (2000). Wisdom: A metaheuristic (pragmatic) to orchestrate mind and virtue toward excellence. American Psychologist, 55, 122-137.

Barouillet, P., Portrat, S., \& Camos, V. (2011). On the law relating processing to storage in working memory. Psychological Review, 118, 175-192.

Barrouillet, P. (1997). Modifying the representation of if ... then sentences in adolescents by inducing a structure mapping strategy. Current Psychology of Cognition, 16, 609-637.

Barrouillet, P., Grosset, N., \& Lecas, J.-F. (2000). Conditional reasoning by mental models: Chronometric and developmental evidence. Cognition, 75, 237-266.

Barrouillet, P., Gauffroy, C., \& Lecas, J.-F. (2008). Mental models and the suppositional account of conditionals. Psychological Review, 115, 760-771.

Basseches, M. (1984). Dialectical thinking and adult development. New York: Ablex.

Bernard, R. M., Zhang, D., Abrami, P. C., Sicoly, F., Borokhovski, E., \& Surkes, M. A. (2008). Exploring the structure of the Watson-Glaser Critical Thinking Appraisal: One scale or many subscales? Thinking Skills and Creativity, 3, 15-22.

Black, P., \& Wiliam, D. (2009). Developing the theory of formative assessment. Educational Assessment, Evaluation and Accountability, 21, 5-13.

Blair, C. (2006). How similar are fluid cognition and general intelligence? A developmental neuroscience perspective on fluid cognition as an aspect of human cognitive ability. The Behavioral and Brain Sciences, 29, 109-160.

Blaser, E., \& Kaldy, Z. (2010). Infants get five starts on iconic memory: A partial-report test of 6-month-old infants' iconic memory capacity. Psychological Science, 21, 1643-1645.

Braine, M. D. S. (1990). The "natural logic" approach to reasoning. In W. F. Overton (Ed.), Reasoning, necessity, and logic: Developmental perspectives (pp. 133-157). Hillsdale: Lawrence Erlbaum.

Brown, R. (1968). The development of Wh questions in child speech. Journal of Verbal Learning and Verbal Behavior, 7, 279-290.

Brown, A. L. (1987). Metacognition, executive control, self-regulation, and other more mysterious mechanisms. In F. E. Weinert \& R. H. Kluwe (Eds.), Metacognition, motivation, and understanding (pp. 65-116). Hillsdale: Lawrence Erlbaum.

Buschkuehl, M., \& Jaeggi, S. M. (2010). Improving intelligence: A literature review. Swiss Medical Weekly, $140,266-272$.

Butterworth, G. (1998). Origins of joint visual attention in infancy: Commentary on Carpenter et al. Monographs of the Society for Research in Child Development, 63(4), 144-166.

Camos, V., \& Barrouillet, P. (2011). Developmental changes in working memory strategies: From passive maintenance to active refreshing. Developmental Psychology, 47, 898-904.

Campbell, F. A., \& Burchinal, M. R. (2008). Early childhood interventions: The Abecedarian Project. In P. C. Kyllonen, R. D. Roberts, \& L. Stankov (Eds.), Extending intelligence: Enhancement and new constructs (pp. 61-83). New York: Lawrence Erlbaum.

Carey, S. (1985). Conceptual change in childhood. Boston: The MIT Press.

Carey, S. (2009). The origins of concepts. Oxford: Oxford University Press.

Carroll, J. B. (1993). Human cognitive abilities: A survey of factor-analytic studies. New York: Cambridge University Press.

Case, R. (1985). Intellectual development: Birth to adulthood. New York: Academic.

Case, R. (1992). The mind's staircase: Exploring the conceptual underpinnings of children's thought and knowledge. Hillsdale: Lawrence Erlbaum. 
Case, R., \& Okamoto, Y. (Eds). (1996). The role of central conceptual structures in the development of children's thought. Monographs of the Society for Research in Child Development, 61 (Serial No. 246).

Case, R., Okamoto, Y., Griffin, S., McKeough, A., Bleiker, C., Henderson, B., \& Stephenson, K. M. (1996). The role of central conceptual structures in the development of children's thought. Monographs of the Society for Research in Child Development, 61 (17-2, Serial No. 246).

Case, R., Demetriou, A., Platsidou, M., \& Kazi, S. (2001). Integrating concepts and tests of intelligence from the differential and the developmental traditions. Intelligence, 29, 307-336.

Cattell, R. B. (1963). Theory of fluid and crystallized intelligence: A critical experiment. Journal of Educational Psychology, 54, 1-22.

Ceci, S. (1991). How much does schooling influence general intelligence and its cognitive components? Developmental Psychology, 27, 703-722.

Chandler, M. J., Hallett, D., \& Sokol, B. W. (2002). Competing claims about competing knowledge domains. In B. K. Hofer \& P. R. Pintrich (Eds.), Personal epistemology: The psychology of beliefs about knowledge and knowing (pp. 145-168). Mahwah: Lawrence Erlbaum.

Cheng, P. W., \& Holyoak, K. J. (1985). Pragmatic reasoning schemas. Cognitive Psychology, 17, 391-416.

Christoforides, M. (2010). The development of hypothetico-deductive thought in primary school children: Implications of an intervention program (Unpublished doctoral dissertation). University of Cyprus, Nicosia, Cyprus.

Cleeremans, A. (2008). Consciousness: The radical plasticity thesis. In R. Banerjee \& B. K. Chakrabarti (Eds.), Progress in brain research (Vol. 168, pp. 19-33). Amsterdam: Elsevier.

Cobley, S., McKenna, J., Baker, J., \& Wattie, N. (2009). How pervasive are relative age effects in secondary school education? Journal of Educational Psychology, 101, 520-528.

Cole, R. L., \& Pickering, S. J. (2010). Phonological and visual similarity effects in Chinese and English language users: Implications for the use of cognitive resources in short-term memory. Bilingualism: Language and Cognition, 13, 499-512.

Colom, R., Rebollo, I., Palacios, A., Juan-Espinosa, M., \& Kyllonen, P. (2004). Working memory is (almost) perfectly predicted by $g$. Intelligence, 32, 277-296.

Commons, M. L., Richards, F. A., \& Kuhn, D. (1982). Systematic and metasystematic reasoning: A case for a level of reasoning beyond Piaget's formal operations. Child Development, 53, 1058-1069.

Conway, A. R. A., Cowan, N., Bunting, M. F., Therriault, D. J., \& Minkoff, S. R. B. (2002). A latent variable analysis of working memory capacity, short term memory capacity, processing speed, and general fluid intelligence. Intelligence, 30, 163-183.

Cosmides, L., \& Tooby, J. (1994). Origins of domain-specificity: The evolution of functional organization. In L. Hirschfeld \& S. Gelman (Eds.), Mapping the mind: Domain-specificity in cognition and culture (pp. 85-119). New York: Cambridge University Press.

Cowan, N. (2010). The magical mystery four: How is working memory capacity limited and why? Current Directions in Psychological Science, 19, 51-57.

Crits-Christoph, P., \& Singer, J. L. (1981). Imagery in cognitive-behavior therapy: Research and application. Clinical Psychology Review, 1, 19-32.

Dalke, D. E. (1998). Charting the development of representational skills: When do children know that maps can lead and mislead? Cognitive Development, 13, 53-72.

Daniel, D. B., \& Klaczynski, P. A. (2006). Developmental and individual differences in conditional reasoning: Effects of logic instructions and alternative antecedents. Child Development, 77, 339354.

Davidson, M. C., Amso, D., Anderson, L. C., \& Diamond. (2006). Development of cognitive control and executive functions from 4 to 13 years: Evidence from manipulations of memory, inhibition, and task switching. Neuropsychologia, 44, 2037-2078.

Dawson, T. L. (2006). Stage-like patterns in the development of conceptions of energy. In X. Liu \& W. Boone (Eds.), Applications of Rasch measurement in science education (pp. 111-136). Maple Grove: JAM Press.

Deary, I. J. (2000). Looking down on human intelligence. Oxford: Oxford University Press.

Deary, I. J., Strand, S., Smith, P., \& Fernandes, C. (2007). Intelligence and educational achievement. Intelligence, 35, 13-21.

Dehaene, S. (1997). The number sense: How the mind creates mathematics. New York: Oxford University Press.

Dehn, M. J. (2008). Working memory and academic learning: Assessment and intervention. Hoboken: Wiley.

DeLoache, J. S. (1991). Symbolic functioning in very young children: Understanding of pictures and models. Child Development, 62, 736-752.

DeLoache, J. S. (1995). Early understanding of the use of symbols. Current Directions in Psychological Science, 4, 109-113. 
DeLoache, J. S. (2000). Dual representation and young children's use of scale models. Child Development, 71, 329-338.

DeLoache, J. S., \& Burns, N. M. (1994). Early understanding of the representational function of pictures. Cognition, 52, 83-110.

Demetriou, A. (Ed.). (1988). The neo-Piagetian theories of cognitive development: Toward an integration. Amsterdam: North-Holland.

Demetriou, A. (1998). Cognitive development. In A. Demetriou, W. Doise, \& K. F. M. van Lieshout (Eds.), Life-span developmental psychology (pp. 179-269). London: Wiley.

Demetriou, A. (2000). Organization and development of self-understanding and self-regulation: Toward a general theory. In M. Boekaerts, P. R. Pintrich, \& M. Zeidner (Eds.), Handbook of self-regulation (pp. 209-251). San Diego: Academic.

Demetriou, A. (2002). Tracing psychology's invisible giant and its visible guards. In R. J. Sternberg \& E. Grigorenko (Eds.), The general factor of intelligence: Fact or fiction? (pp. 3-19). Mahwah: Lawrence Erlbaum.

Demetriou, A. (2004). Mind, intelligence, and development: Ageneral cognitive, differential, and developmental theory of the mind. In A. Demetriou \& A. Raftopoulos (Eds.), Developmental change: Theories, models and measurement (pp. 21-73). Cambridge: Cambridge University Press.

Demetriou, A., \& Bakracevic, K. (2009). Cognitive development from adolescence to middle age: From environment-oriented reasoning to social understanding and self-awareness. Learning and Individual Differences, 19, 181-194.

Demetriou, A., \& Efklides, A. (1989). The person's conception of the structures of developing intellect: Early adolescence to middle age. Genetic, Social, and General Psychology Monographs, 115, 371-423.

Demetriou, A., \& Efklides, A. (1994). Structure, development, and dynamics of developing mind: A metaPiagetian theory. In A. Demetriou \& A. Efklides (Eds.), Intelligence, mind, and reasoning: Structure and development (pp. 75-110). Amsterdam: North-Holland.

Demetriou, A., \& Kazi, S. (2001). Unity and modularity in the mind and the self: Studies on the relationships between self-awareness, personality, and intellectual development from childhood to adolescence. London: Routledge.

Demetriou, A., \& Kazi, S. (2006). Self-awareness in $g$ (with processing efficiency and reasoning). Intelligence, 34, 297-317.

Demetriou, A., \& Kyriakides, L. (2006). A Rasch-measurement model analysis of cognitive developmental sequences: Validating a comprehensive theory of cognitive development. British Journal of Educational Psychology, 76, 209-242.

Demetriou, A., \& Panaoura, R. (2006). Mathematics in the mind: Its place, architecture, and development. In L. Verschaffel, F. Dochy, M. Boekaerts, \& S. Vosniadou (Eds.). Instructional psychology: Past, present and future trends. Fifteen essays in honor of Erik De Corte (Advances in Learning and Instruction Series) (pp. 19-38). Amsterdam: Pergamon.

Demetriou, A., \& Raftopoulos, A. (1999). Modeling the developing mind: From structure to change. Developmental Review, 19, 319-368.

Demetriou, A., Gustafsson, J.-E., Efklides, A., \& Platsidou, M. (1992). Structural systems in developing cognition, science, and education. In A. Demetriou, M. Shayer, \& A. Efklides (Eds.), Neo-Piagetian theories of cognitive development: Implications and applications for education (pp. 79-103). London: Routledge.

Demetriou, A., Efklides, A., Platsidou, M. (1993). The architecture and dynamics of developing mind: Experiential structuralism as a frame for unifying cognitive developmental theories. Monographs of the Society for Research in Child Development, 58, (Serial No. 234).

Demetriou, A., Christou, C., Spanoudis, G., Platsidou, M. (2002). The development of mental processing: Efficiency, working memory, and thinking. Monographs of the Society of Research in Child Development, 67, (Serial No. 268).

Demetriou, A., Kyriakides, L., \& Avraamidou, C. (2003). The missing link in the relations between intelligence and personality. Journal of Research in Personality, 37, 547-581.

Demetriou, A., Zhang, X. K., Spanoudis, G., Christou, C., Kyriakides, L., \& Platsidou, M. (2005). The architecture, dynamics and development of mental processing: Greek, Chinese or universal? Intelligence, 33, 109-141.

Demetriou, A., Mouyi, A., \& Spanoudis, G. (2008). Modeling the structure and development of $g$. Intelligence, 5, 437-454.

Demetriou, A., Mouyi, A., \& Spanoudis, G. (2010a). The development of mental processing. In W. F. Overton (Ed.), Biology, cognition and methods across the life-span. Vol. 1: Handbook of life-span development (pp. 306-343). Hoboken: Wiley (Editor-in-chief: R. M. Lerner).

Demetriou, A., Spanoudis, G., \& Mouyi, A. (2010b). A three-level model of the developing mind: Functional and neuronal substantiation. In M. Ferrari \& L. Vuletic (Eds.), The Developmental relations between mind, brain, and education: Essays in honor of Robbie Case (pp. 9-48). New York: Springer. 
Detterman, D. K. (2000). General intelligence and the definition of phenotypes. In G. R. Bock, J. A. Goode, \& K. Webb (Eds.), The nature of intelligence. Novartis Foundation Symposium 233 (pp. 136-148). Chichester: Wiley.

Dewar, K., \& Xu, F. (2010). Induction, overhypothesis, and the origin if abstract knowledge: Evidence from 9-month-old infants. Psychological Science, 21, 1871-1877.

diSessa, A. A. (2004). Metarepresentation: Native competence and targets for instruction. Cognition and Instruction, 22, 293-331.

Dixon, J. A., Stephen, D. G., Boncoddo, R. A., \& Anastas, J. (2010). The self-organization of cognitive structure. In B. Ross (Ed.), The psychology of learning \& motivation (Vol. 52, pp. 343-384). San Diego: Elsevier.

Duncan, J. (2010). How intelligence happens. New Haven: Yale University Press.

Efklides, A., Demetriou, A., \& Gustafsson, J.-E. (1992). Training, cognitive change and individual differences. In A. Demetriou, M. Shayer, \& A. Efklides (Eds.), Neo-piagetian theories of cognitive development: Implications and applications for education (pp. 122-143). London: Routledge.

Engel de Abreu, P. M. J., Conway, A. R. A., \& Gathercole, S. E. (2010). Working memory and fluid intelligence in young children. Intelligence, 38, 552-561.

English, L. D. (1998). Children's reasoning in solving relational problems of deduction. Thinking and Reasoning, 4, 249-281.

Ennis, R. H. (1962). A concept of critical thinking. Harvard Educational Review, 32, 81-111.

Ennis, R. H. (1987). A taxonomy of critical thinking dispositions and abilities. In J. Baron \& R. Sternberg (Eds.), Teaching thinking skills: Theory and practice (pp. 9-26). New York: W.H. Freeman.

Ennis, R. H. (1996). Critical thinking. Upper Saddle River: Prentice-Hall.

Ercikan, K. (2006). Developments in assessment of student learning. In P. A. Alexander \& P. H. Winne (Eds.), Handbook of educational psychology (pp. 929-952). Mahwah: Lawrence Erlbaum.

Ericsson, K. A., \& Kintsch, W. (1995). Long-term working memory. Psychological Review, 102, $211-245$.

Ericsson, K. A., \& Lehmann, A. C. (1996). Expert and exceptional performance: Evidence of maximal adaptation to task constraints. Annual Review of Psychology, 47, 273-305.

Finke, R. A. (1993). Mental imagery and creative discovery. In B. Roskos-Ewoldsen, M. J. Intons-Peterson, \& R. E. Anderson (Eds.), Imagery, creativity, and discovery: A cognitive perspective (pp. 255-286). Amsterdam: Elsevier.

Fireman, G. (1996). Developing a plan for solving a problem: A representational shift. Cognitive Development, 11, 107-122.

Fischer, K. W. (1980). A theory of cognitive development: The control and construction of hierarchies of skills. Psychological Review, 87, 477-531.

Fisher, A. V. (2010). Mechanisms of induction early in development. In M. Banich \& D. Caccamise (Eds.), Generalization of knowledge: Multidisciplinary perspectives (pp. 89-112). New York: Psychology Press.

Flavell, J. H., Green, F. L., Flavell, E. R. (1995). Young children's knowledge about thinking. Monographs of the Society for Research in Child Development, 60 (1, Serial No. 243).

Flavell, J. H., Green, F. L., Flavell, E. R., \& Grossman, J. B. (1997). The development of children's knowledge about inner speech. Child Development, 68, 39-47.

Flook, L., Smalley, S. L., Kitil, M. J., Galla, B. M., Kaiser-Greenland, S., Locke, et al. (2010). Effects of mindfulness awareness practices on executive functions in elementary school children. Journal of Applied School Psychology, 26, 70-95.

Flynn, J. R. (2009). What is intelligence: Beyond the Flynn effect. Cambridge: Cambridge University Press.

Fodor, J. A. (1976). The language of thought. Hassocks: Harvester Press.

Furedy, C., \& Furedy, J. (1985). Critical thinking: Towards research and dialogue. In Donald \& Sullivan (Eds.), Using research to improve teaching (New Directions for Teaching and Learning No. 23). San Francisco: Jossey-Bass.

Gardner, H. (1983). Frames of mind. The theory of multiple intelligences. New York: Basic Books.

Gauffroy, C., \& Barrouillet, P. (2011). The primacy of thinking about possibilities in the development of reasoning. Developmental Psychology, 47, 1000-1011.

Gelman, S. A. (2003). The essential child. Oxford: Oxford University Press.

Gelman, R., \& Brenneman, K. (1994). First principles can support both universal and culture-specific learning about number and music. In L. Hirschfeld \& S. Gelman (Eds.), Mapping the mind: Domains, culture and cognition (pp. 369-390). Cambridge: Cambridge University Press.

Gelman, S. A., \& Coley, J. D. (1990). The importance of knowing a dodo is a bird: Categories and inferences in 2-year-old children. Developmental Psychology, 26, 796-804.

Gentner, D. (1989). The mechanisms of analogical learning. In S. Vosniadou \& A. Ortony (Eds.), Similarity and analogical reasoning (pp. 199-241). Cambridge: Cambridge University Press. 
Gentner, D., \& Rattermann, M. J. (1991). Language and the career of similarity. In S. A. Gelman \& J. P. Byrnes (Eds.), Perspectives on language and thought: Interrelations in development (pp. 225-277). Cambridge: Cambridge University Press.

Gibson, E. J., \& Pick, A. D. (2003). An ecological approach to perceptual learning and development. Oxford: Oxford University Press.

Glassner, A., \& Schwarz, B. B. (2007). What stands and develops between creative and critical thinking? Argumentation? Thinking Skills and Creativity, 2, 10-18.

Gobet, F. (1998). Expert memory: A comparison of four theories. Cognition, 66, 115-152.

Grigorenko, E. L. (2002). Other than $g$. The value of persistence. In R. J. Sternberg \& E. L. Grigorenko (Eds.), The general factor of intelligence: How general is it? (pp. 299-327). Mahwah: Lawrence Erlbaum.

Gustafsson, J.-E. (1984). A unifying model for the structure of intellectual abilities. Intelligence, 8, 179-203.

Gustafsson, J.-E. (2008). Schooling and intelligence: Effects of track of study on level and profile of cognitive abilities. In P. C. Kyllonen, R. D. Roberts, \& L. Stankov (Eds.), Extending intelligence: Enhancement and new constructs (pp. 37-59). New York: Lawrence Erlbaum.

Gustafsson, J. E., \& Undheim, J. O. (1996). Individual differences in cognitive functions. In D. C. Berliner \& R. C. Calfee (Eds.), Handbook of educational psychology (pp. 186-242). New York: Macmillan.

Halford, G. S. (1993). Children's understanding: The development of mental models. Hillsdale: Lawrence Erlbaum.

Halford, G. S., Wilson, W. H., \& Phillips, S. (1998). Processing capacity defined by relational complexity: Implications for comparative, developmental, and cognitive psychology. The Behavioral and Brain Sciences, 21, 803-864.

Handley, S. J., Capon, A., Beveridge, M., Dennis, I., Evans, J. St. B. T. (2004). Working memory, inhibitory control and the development of children's reasoning. Thinking and Reasoning, 10, 175-195.

Harris, P., \& Nunez, M. (1996). Understanding of permission rules by preschool children. Child Development, 67, 1572-1591.

Harter, S. (1999). The construction of the self: A developmental perspective. New York: The Guilford Press.

Haun, D. B. M., Jordan, F. M., Vallortigara, G., \& Clayton, N. S. (2010). Origins of spatial, temporal and numerical cognition: Insights from comparative psychology. Trends in Cognitive Sciences, 14, 552-560.

Heit, E., \& Rotello, C. M. (2010). Relations between inductive reasoning and deductive reasoning. Journal of Experimental Psychology. Learning, Memory, and Cognition, 36, 805-812.

Hirschfeld, L. A., \& Gelman, S. A. (Eds.). (1994). Mapping the mind: Domain specificity in cognition and culture. New York: Cambridge University Press.

Hmelo-Silver, C. E., \& Pfeffer, M. G. (2004). Comparing expert and novice understanding of a complex system from the perspective of structures, behaviors, and functions. Cognitive Science, 28, 127-138.

Holland, J., Holyoak, K., Nisbett, R., \& Thagard, P. (1986). Induction: Processes of inference, learning, and discovery. Cambridge: MIT Press.

Hornung, C., Brunner, M., Reuter, R. A. P., \& Martin, R. (2011). Children's working memory: Its structure and relationship to fluid intelligence. Intelligence, 39, 210-221.

Hunt, E. B. (2002). Thoughts on thought. Mahwah: Lawrence Erlbaum.

Hunt, E. B. (2011). Human intelligence. New York: Cambridge University Press.

Huttenlocher, J., Vasilyeva, M., Newcombe, N., \& Duffy, S. (2008). Developing symbolic capacity one step at a time. Cognition, 106, 1-12.

Jacobs, J. E., \& Klaczynski, P. A. (2002). The development of judgment and decision making during childhood and adolescence. Current Directions in Psychological Science, 11, 145-149.

Jaeggi, S. M., Buschkuehl, M., Jonides, J., \& Perrig, W. J. (2008). Improving fluid intelligence with training on working memory. Proceedings of the National Academy of Sciences, 105, 6829-6833.

Jensen, A. R. (1998). The g factor: The science of mental ability. Westport: Praeger.

Johansen, M. K., \& Palmeri, T. J. (2002). Are there representational shifts during category learning? Cognitive Psychology, 45, 482-553.

Johnson, W., te Nijenhuis, J., \& Bouchard, T. J. (2008). Still just 1 g: Consistent results from five test batteries. Intelligence, 36, 81-95.

Johnson-Laird, P. N. (2001). Mental models and deduction. Trends in Cognitive Sciences, 5, 434-442.

Jonassen, D. H. (2000). Toward a design theory of problem solving. Educational Technology Research and Development, 48, 63-85.

Jonassen, D. H. (2003). Learning to solve problems: An instructional design guide. New York: Pfeifer.

Jones, L., \& Stuth, G. (1997). The uses of mental imagery in athletics: An overview. Applied and Preventive Psychology, 6, 101-115.

Kagan, J. (2009). The three cultures: Natural sciences, social sciences, and the humanities in the 21st century. Cambridge: Cambridge University Press.

Kail, R. (1991). Developmental change in speed of processing during childhood and adolescence. Psychological Bulletin, 109, 490-501. 
Kail, R. (1993). Processing time decreases globally at an exponential rate during childhood and adolescence. Journal of Experimental Child Psychology, 56, 254-265.

Kalyuga, S., \& Hanham, J. (2011). Instructing in generalized knowledge structures to develop flexible problem solving skills. Computers in Human Behavior, 27, 63-68.

Kalyuga, S., Renkl, A., \& Paas, F. (2010). Facilitating flexible problem solving: A cognitive load perspective. Educational Psychology Review, 22, 175-186.

Kargopoulos, P., \& Demetriou, A. (1998). Logical and psychological partitioning of mind: Depicting the same picture? New Ideas in Psychology, 16, 61-88.

Karmiloff-Smith, A. (1992). Beyond modularity: A developmental perspective on cognitive science. Cambridge: MIT Press.

Keen, R. (2011). The development of problem solving in young children: A critical cognitive skill. Annual Review of Psychology, 62, 1-21.

Keil, F. C. (2011). Science starts early. Science, 331, 1022-1023.

Keogh, B. K. (2003). Temperament in the classroom: Understanding individual differences. Baltimore: Brookes Publishing.

King, P. M., \& Kitchener, K. S. (1994). Developing reflective judgment. New York. Jossey-Bass.

Kirschner, P. A., Sweller, J., \& Clark, R. E. (2006). Why minimal guidance instruction does not work: An analysis of the failure of constructivist, discovery, problem-based, experiential, and inquiry-based teaching. Educational Psychologist, 41, 75-86.

Klaczynski, P. A., \& Daniel, D. B. (2005). Individual differences in conditional reasoning: A dual-process account. Thinking and Reasoning, 11, 305-325.

Klauer, K. C., Meiser, T., \& Naumer, B. (2000). Training propositional reasoning. The Quarterly Journal of Experimental Psychology, 53, 868-895.

Klingberg, T., Forssberg, H., \& Westerberg, H. (2002). Training of working memory in children with ADHD. Journal of Clinical and Experimental Neuropsycholy, 24(6), 781-791.

Kopp, C. B. (2011). Development in the early years: Socialization, motor development, and consciousness. Annual Review of Psychology, 62, 165-187.

Krumm, S., Ziegler, M., \& Buehner, M. (2008). Reasoning and working memory as predictors of school grades. Learning and Individual Differences, 18, 248-257.

Kuhn, D. (1991). The skills of argument. New York: Cambridge University Press.

Kuhn, D. (2009). Do students need to be taught how to reason? Educational Research Review, 4, $1-6$.

Kuhn, D., \& Pease, M. (2006). Do children and adults learn differently? Journal of Cognition and Development, 7, 279-293.

Kyllonen, P., \& Christal, R. E. (1990). Reasoning ability is (little more than) working-memory capacity? Intelligence, 14, 389-433.

Kyriakides, L., \& Luyten, H. (2009). The contribution of schooling to the cognitive development of secondary education students in Cyprus: An application of regression discontinuity with multiple cut-off points. School Effectiveness and School Improvement, 20, 167-186.

Labouvie-Vief, G. (2005). Self-with-other representations and the organization of the self. Journal of Research in Personality, 39, 185-205.

Leslie, A., Friedman, O., \& German, T. P. (2004). Core mechanisms in "theory of mind". Trends in Cognitive Sciences, 12, 528-533.

Linn, M. C., \& Eylon, B.-S. (2011). Science learning and instruction: Taking advantage of technology to promote knowledge integration. London: Routledge.

Lynn, R., \& Vanhanen, T. (2006). IQ and global inequality. Augusta: Washington Summit Publishers.

Mandler, J. M. (2004). The foundations of mind. Oxford: Oxford University Press.

Markovits, H., \& Barrouillet, P. (2002). The development of conditional reasoning: A mental model account. Developmental Review, 22, 5-36.

McBride-Chang, C., Zhou, Y., Cho, J.-R., Aram, D., Levin, I., \& Tolchinsky, L. (2011). Visual spatial skill: A consequence of learning to read? Journal of Experimental Child Psychology, 109, 256262.

McCune, L. (2008). How children learn to learn language. New York: Oxford University Press.

Meltzoff, A. N., Kuhl, P. K., Movellan, J., \& Sejnowski, T. J. (2009). Foundations for a new science of learning. Science, 325, 284-288.

Mercier, H., \& Sperber, D. (2011). Why do humans reason? Arguments for an argumentative theory. Behavioral and Brain Sciences (in press).

Miller, L. T., \& Vernon, P. A. (1992). The general factor in short-term memory, intelligence, and reaction time. Intelligence, 16, 5-29.

Miller, S. A., Custer, W. L., \& Nassau, G. (2000). Children's understanding of the necessity of logically necessary truths. Cognitive Development, 15, 383-403. 
Molenbergs, P., Cunnigton, R., \& Mattingley, J. B. (2009). Is the mirror system involved in imitation? A short review and meta-analysis. Neuroscience and Behavioral Reviews, 33, 975-980.

Moshman, D. (1990). The development of metalogical understanding. In W. F. Overton (Ed.), Reasoning, necessity, and logic: Developmental perspectives (pp. 205-225). Hillsdale: Lawrence Erlbaum.

Moshman, D. (1994). Reasoning, metareasoning and the promotion of rationality. In A. Demetriou \& A. Efklides (Eds.), Mind, intelligence, and reasoning: Structure and development (pp. 135-150). Amsterdam: Elsevier.

Moshman, D. (2011). Adolescent rationality and development: Cognition, morality, and identity (3rd ed.). New York: Psychology Press.

Mouyi, A. (2008). Developmental dynamics binding processing efficiency, working memory, and reasoning: A longitudinal study. Unpublished doctoral dissertation. Nicosia: University of Cyprus.

Nesher, P., \& Sukenik, M. (1991). The effect of formal representation on the learning of ratio concepts. Learning and Instruction, 1, 161-175.

Nisbett, R. E. (2009). Intelligence and how to get it: Why schools and cultures count. New York: Norton.

Olson, D. (2003). Psychological theory and educational reform: How school remakes mind and society. Cambridge: Cambridge University Press.

Overton, W. F. (2010). Life-span development: Concepts and issues. In W. F. Overton (Ed.), Biology, cognition and methods across the life-span. Vol. 1: Handbook of life-span development (pp. 1-29). Hoboken: Wiley (Editor-in-chief: Lerner RM).

Overton, W. F., Byrnes, J. P., \& O’ Brien, D. P. (1985). Developmental and individual differences in conditional reasoning: The role of contradiction training and cognitive style. Developmental Psychology, $21,692-701$.

Panaoura, A., Gagatsis, A., \& Demetriou, A. (2009). An intervention to the mathematical performance: Selfregulation in mathematics and mathematical modeling. Acta Didactica Universitatis Comenianae, 9, 63-79.

Pascal-Leone, J. (1988). Organismic processes for neo-Piagetian theories: A dialectical causal account of cognitive development. In A. Demetriou (Ed.), The neo-Piagetian theories of cognitive development: Toward an integration (pp. 25-64). Amsterdam: North-Holland.

Pascarella, E. T., \& Terenzin, P. T. (2005). How college affects students. San Francisco: Jossey-Bass.

Pascual-Leone, J. (1970). A mathematical model for the transition rule in Piaget's developmental stages. Acta Psychologica, 63, 301-345.

Piaget, J. (1970). Piaget's theory. In P. H. Mussen (Ed.), Carmichael's handbook of child development (pp. 703-732). New York: Wiley.

Piaget, J. (1980). Concerning creativity: Three methods. In J.-C. Bringuier (Ed.), Conversations with Jean Piaget (pp. 126-132). Chicago: University of Chicago Press (Original work published in 1977).

Piaget, J. (2001). Studies in reflecting abstraction. London: Psychology Press.

Piazza, M. (2010). Neurocognitive start-up tools for symbolic number representations. Trends in Cognitive Sciences, 14, 542-551.

Pind, J., Gunnarsdottir, E. K., \& Johannesson, H. S. (2003). Raven's standard progressive matrices: New school age norms and a study of the test's validity. Personality and Individual Differences, 34, 375-386.

Posner, M. I., \& Rothbart, M. K. (2006). Educating the human brain. New York: American Psychological Association.

Printz, W. (2003). Emerging selves: Representational foundations of subjectivity. Consciousness and Cognition, 12, 515-528.

Raffray, C. N., \& Pickering, M. J. (2010). How do people construct logical form during language comprehension? Psychological Science, 21(8), 1090-1097.

Raftopoulos, A., \& Constantinou, C. P. (2004). Types of cognitive change: A dynamical, connectionist account. In A. Demetriou \& A. Raftopoulos (Eds.), Developmental change: Theories, models and measurement (pp. 74-117). Cambridge: Cambridge University Press.

Rasmussen, C., \& Bisanz, J. (2005). Representation and working memory in early arithmetic. Journal of Experimental Child Psychology, 91, 137-157.

Reed, S. K. (1993). Imagery and discovery. In B. Roskos-Ewoldsen, M. J. Intons-Peterson, \& R. E. Anderson (Eds.), Imagery, creativity, and discovery: A cognitive perspective (pp. 287-328). Amsterdam: Elsevier.

Reynolds, C. A., Finkel, D., McArdle, J. J., Gatz, M., Berg, S., \& Pedersen, N. L. (2005). Quantitative genetic analysis of latent growth curve models of cognitive abilities in adulthood. Developmental Psychology, 41, 3-16.

Ricco, R. B. (2010). The development of deductive reasoning across the lifespan. In W. F. Overton (Ed.), Biology, cognition, and methods across the life-span. Vol.1: Handbook of life-span development (pp. 391-430). Hoboken: Wiley (Editor-in-chief: R. M. Lerner).

Ricco, R. B., \& Overton, W. F. (2011). Dual systems Competence - Procedural processing: A relational developmental systems approach to reasoning. Developmental Review doi:10.1016/j.dr.2011.07.005. 
Riegel, K. F. (1973). Dialectic operations: The final period of cognitive development. Human Development, $16,346-370$.

Rindermann, H., \& Neubauer, A. C. (2004). Processing speed, intelligence, creativity, and school performance: Testing of causal hypotheses using structural equation models. Intelligence, 32, 573-589.

Rips, L. J. (1994). The psychology of proof. Deductive reasoning in human thinking. Cambridge: MIT Press. Rizzolatti, G., \& Craighero, L. (2004). The mirror-neuron system. Annual Review of Neuroscience, 27, $169-192$.

Rohde, T. E., \& Thompson, L. A. (2007). Predicting academic achievement with cognitive ability. Intelligence, 35, 83-92.

Rosch, E. (1975). Cognitive representations of semantic categories. Journal of Experimental Psychology: General, 104, 192-322.

Runco, M. A., \& Pritzker, S. R. (Eds.). (1999). Encyclopedia of creativity. San Diego: Academic.

Sackett, P. R., Schmitt, N., Ellingson, J. E., \& Kabin, M. B. (2001). High-stakes testing in employment, credentialing, and higher education: Prospects in a post-affirmative-action world. American Psychologist, 56, 302-318.

Salthouse, T. A. (2000). Aging and measures of processing speed. Biological Psychology, 54, 35-54.

Schaie, K. W. (1996). Adulthood and old age. In T. Husen \& T. N. Postlewaithe (Eds.), International encyclopedia of education (pp. 163-168). Oxford: Pergamon.

Shayer, M., \& Adey, P. (2002). Learning intelligence: Cognitive acceleration across the curriculum from 5 to 15 years. Milton Keynes: Open University Press.

Shayer, M., \& Adhami, M. (2003). Realising the cognitive potential of children 5-7 with a mathematics focus. International Journal of Educational Research, 39, 743-775.

Shayer, M., \& Wylam, H. (1978). The distribution of Piagetian stages of thinking in British middle and secondary school children II: 14-16 year-olds and sex differentials. British Journal of Educational Psychology, 948, 62-70.

Shayer, M., Küchemann, D. E., \& Wylam, H. (1976). The distribution of Piagetian stages of thinking in British middle and secondary school children. British Journal of Educational Psychology, 46, 164-173.

Shayer, M., Demetriou, A., \& Pervez, M. (1988). The structure and scaling of concrete operational thought: Three studies in four countries. Genetic, Social, and General Psychology Monographs, 114, 307-376.

Sheppard, L. D., \& Vernon, P. A. (2008). Intelligence and speed of information-processing: A review of 50 years of research. Personality and Individual Differences, 44, 535-551.

Siegel, H. (1988). Educating reason: Rationality, critical thinking, and education. London: Routledge.

Siegel, H. (1989a). Epistemology, critical thinking, and critical thinking pedagogy. Argumentation, 3, $127-140$.

Siegel, H. (1989b). The rationality of science, critical thinking, and science education. Synthese, 80, 9-41.

Siegler, R. S. (1996). Emerging minds: The process of change in children's thinking. Oxford: Oxford University Press.

Simonton, D. K. (2000). Creative development as acquired expertise: Theoretical issues and an empirical test. Developmental Review, 20, 283-318.

Sloutsky, V. M., \& Fisher, A. V. (2011). The development of categorization. Psychology of Learning and Motivation, 54, 141-166.

Smith, L. (2009). Piaget's pedagogy. In U. Muller, J. I. M. Carpendale, \& L. Smith (Eds.), The Cambridge companion to Piaget (pp. 324-343). Cambridge: Cambridge University Press.

Snow, R. (1989). Aptitude-treatment interaction as a framework on individual differences in learning. In P. Ackermann, R. J. Sternberg, \& R. Glaser (Eds.), Learning and individual differences (pp. 13-59). New York: W.H. Freeman.

Spearman, C. (1904). "General intelligence" objectively determined and measured. The American Journal of Psychology, 15, 201-293.

Stanovich, K. E. (2009). What intelligence tests miss: The psychology of rational thought. New Haven: Yale University Press.

Stearns, P. N. (2006). Childhood in world history. London: Routledge.

Stein, M., \& Burchartz, B. (2009). The Invisible wall project: Reasoning and problem solving processes of primary and lower secondary students. Mathematical Thinking and Learning, 8, 65-90.

Sternberg, R. J. (Ed.). (1999). Handbook of creativity. New York: Cambridge University Press.

Sternberg, R. J. (2005). Creativity or creativities? International Journal of Human Computer Studies, 63, $370-382$.

Sweller, J. (1994). Cognitive load theory, learning difficulty, and instructional design. Learning and Instruction, 4, 295-312.

Téglás, E., Vul, E., Girotto, V., Gonzalez, M., Tenenbaum, J. B., \& Bonatti, L. (2011). Pure reasoning in 12month-old infants as probabilistic inference. Science, 332, 1054-1059.

Thorell, L. B., Lindqvist, S., Bergman Nutley, S., Bohlin, G., \& Klingberg, T. (2009). Training and transfer effects of executive functions in preschool children. Developmental Science, 12, 106-113. 
Tillman, C. M., Nyberg, L., \& Bohlin, G. (2008). Working memory components and intelligence in children. Intelligence, 36, 394-402.

Tsamir, P., Tirosh, D., Tabach, M., \& Levenson, E. (2010). Multiple solution methods and multiple outcomes-Is it a task for kindergarten children? Educational Studies in Mathematics, 73, 217-231.

Tyrrel, D. J., Stauffer, L. B., \& Snowman, L. G. (1991). Perception of abstract identity/difference relationships by infants. Infant Behavior \& Development, 14, 125-129.

Unsworth, N., \& Spillers, G. J. (2010). Working memory capacity: Attention control, secondary memory, or both? A direct test of the dual-component model. Journal of Memory and Language, 62, 392-406.

van der Maas, H. L. J., Dolan, C. V., Grasman, R. P. P. P., Wicherts, G. J. M., Huizenga, H. M., \& Raijmakers, M. E. J. (2006). A dynamical model of general intelligence: The positive manifold of intelligence by mutualism. Psychological Review, 113, 842-861.

van Fraassen, B. C. (2010). Scientific representation: Paradoxes of perspective. Oxford: Oxford University Press.

van Geert, P. (1994). Dynamic systems of development: Change between complexity and chaos. New York: Harvester Wheatsheaf.

Vosniadou, S. (Ed.). (2008). International handbook of research on conceptual change. London: Routledge.

Vosniadou, S., \& Brewer, W. F. (1992). Mental models of the earth: A study of conceptual change in childhood. Cognitive Psychology, 24, 535-585.

Wagner, S., Winner, E., Cicchetti, D., \& Gardner, H. (1981). "Metaphorical" mapping in human infants. Child Development, 52, 728-731.

Watson, G. B., \& Glaser, E. M. (1980). WGCTA Watson-Glaser Critical Thinking Appraisal Manual: Forms $A$ and B. San Antonio: The Psychological Corporation.

Wellman, H. M. (1990). The child's theory of mind. Cambridge: Bradford.

Westerberg, H. (2004). Working memory: Development, disorders, and training. Stockholm: Karolinska Institutet.

Whitherington, D. C. (2011). Taking emergence seriously: The centrality of circular causality for dynamic systems approaches to development. Human Development, 54, 66-92.

Wildenger, L. K., Hofer, B. K., \& Burr, J. E. (2010). Epistemological development in very young knowers. In L. Bendixen \& F. Haerle (Eds.), Personal epistemology in the classroom: Theory, research, and implications for practice (pp. 220-257). Cambridge: Cambridge University Press.

Williamson, R. A., Jaswal, V. K., \& Meltzoff, A. N. (2010). Learning the rules: Observation and imitation of a sorting strategy by 36-month-old children. Developmental Psychology, 46, 57-65.

Winship, C., \& Korenman, S. (1997). Does staying in school make you smarter? The effect of education on IQ in the Bell Curve. In B. Devlin, S. E. Fienberg, D. P. Resnick, \& K. Roeder (Eds.), Intelligence, genes, and success. Scientists respond to the Bell Curve (pp. 215-234). New York: Springer.

Wood, J. N. (2011). A core knowledge architecture of visual working memory. Journal of Experimental Psychology. Human Perception and Performance, 37, 357-381.

$\mathrm{Xu}, \mathrm{F}$., \& Garcia, V. (2008). Intuitive statistics by 8-month-old infants. Proceeding of the National Academy of Sciences, 105, 5012-5015.

Yamagata, K. (2007). Differential emergence of representational systems: Drawings, letters, and numerals. Cognitive Development, 22, 244-257.

Yerushalmy, M. (1997). Mathematizing verbal descriptions of situations: A language to support modeling. Cognition and Instruction, 15, 207-264.

Zelazo, P. D. (2004). The development of conscious control in childhood. Trends in Cognitive Sciences, 8 , $12-17$.

Zelazo, P. D. (2011). Mindfulness training in childhood. Human Development, 54, 61-65.

Zelazo, P. D., \& Frye, D. (1998). Cognitive complexity and control: The development of executive function. Current Directions in Psychological Science, 7, 121-126.

Zelazo, P. D., Müller, U., Frye, D., Marcovitch, S., Argitis, G., Boseovski, J., Chiang, J. K., Hongwanishkul, D., Schuster, B. V., Sutherland, S., Carlson, S. M. (2003). The development of executive function in early childhood. Monographs of the Society for Research in Child Development, 68, (Serial No. 3).

Zelazo, P. D., Qu, L., \& Müller, U. (2005). Hot and cool aspects of executive function: Relations with early development. In W. Schneider, R. Schumann, R. Hengsteler, \& B. Sodian (Eds.), Young children's cognitive development: Interrelationships among executive functioning, working memory, verbal ability, and theory of mind (pp. 71-93). Mahwah: Lawrence Erlbaum.

Zosh, J. M., Halberda, J., \& Feigenson, L. (2011). Memeory for multiple visual ensembles in infancy. Journal of Experimental Psychology. General, 140, 141-158. 